Elsevier

BRR 90048

\title{
Enduring Changes in Brain and Behavior Produced by Chronic Amphetamine Administration: A Review and Evaluation of Animal Models of Amphetamine Psychosis
}

\author{
TERRY E. ROBINSON and JILL B. BECKER
}

Department of Psychology and Neuroscience Laboratory Building, The University of Michigan, Ann Arbor, MI 48104-I687 (U.S.A.)

(Accepted December 31st, 1985)

Key words: amphetamine - sensitization - reverse tolerance — dopamine - catecholamine - schizophrenia amphetamine psychosis - animal model — striatum - stress - sex difference — conditioning neurotoxicity - stereotypy — autoreceptor

\section{CONTENTS}

1. Introduction 158

2. The effects of continuous amphetamine administration on brain and behavior (amphetamine neurotoxicity)

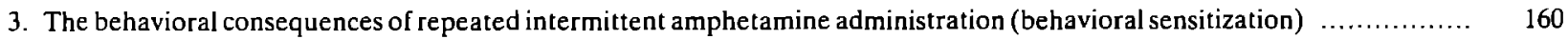

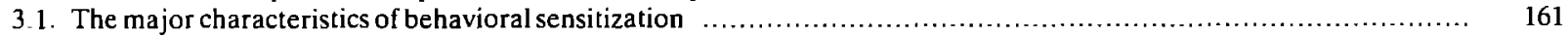

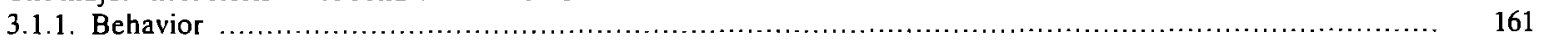

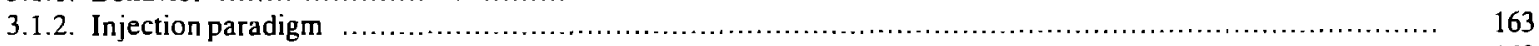

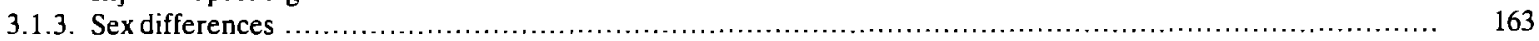

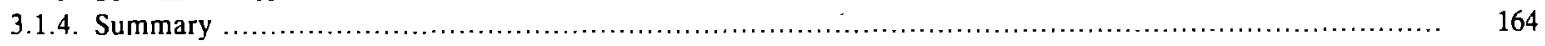

4. Behavioral sensitization and amphetamine neurotoxicity as animal models of amphetamine psychosis ....................... 164

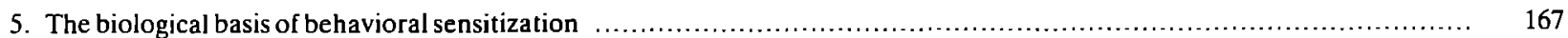

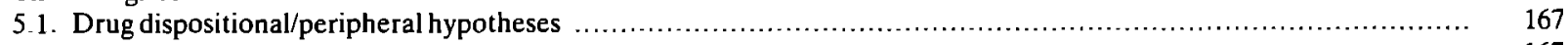

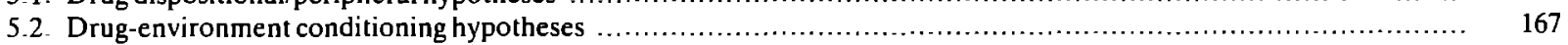

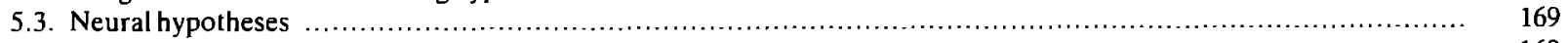

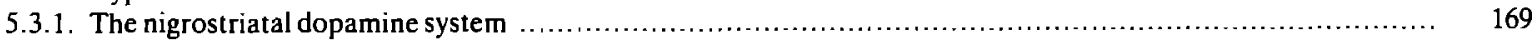

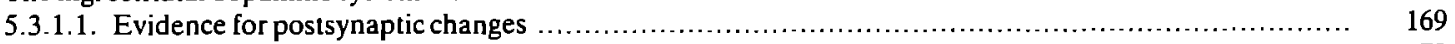

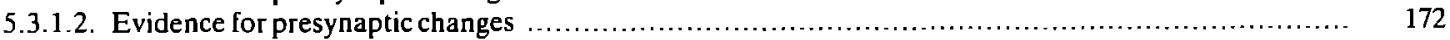

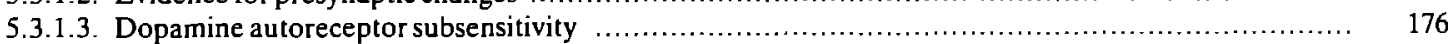

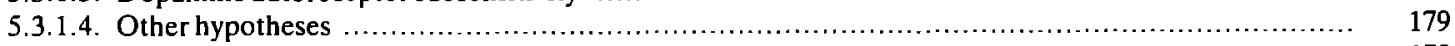

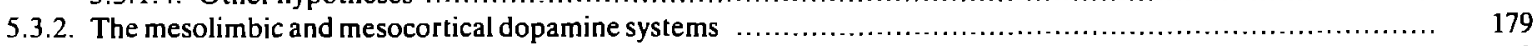

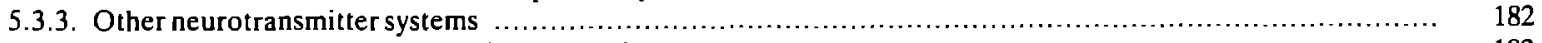

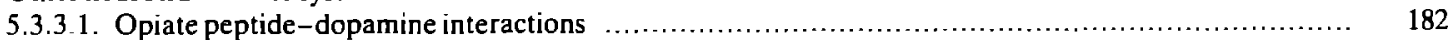

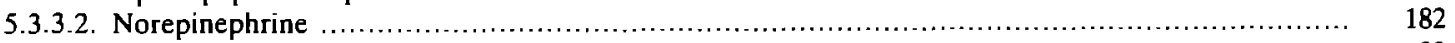

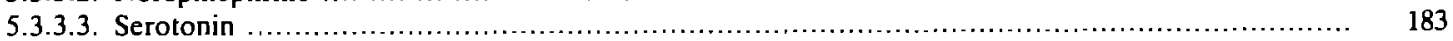

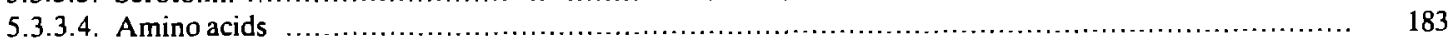

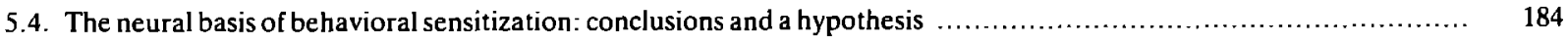

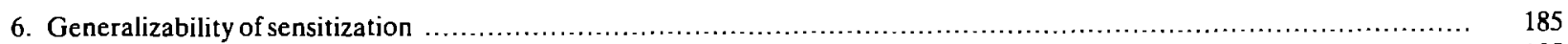

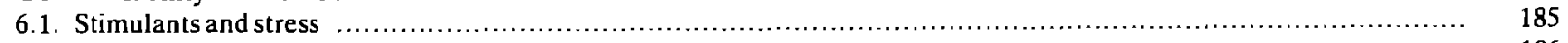

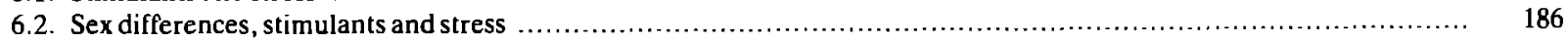

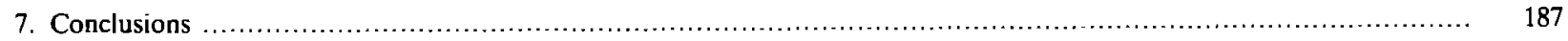

Correspondence: T.E. Robinson, The University of Michigan, Neuroscience Laboratory Building, 1103 E. Huron St., Ann Arbor, MI 48104-1687, U.S.A.

0165-0173/86/\$03.50 C 1986 Elsevier Science Publishers B.V. (Biomedical Division) 


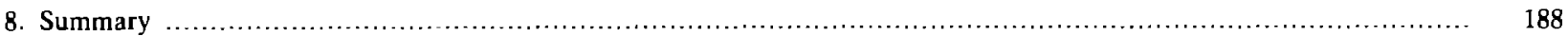

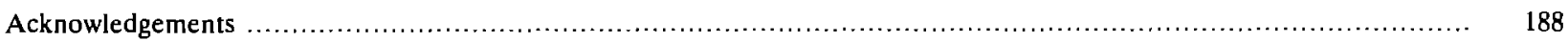

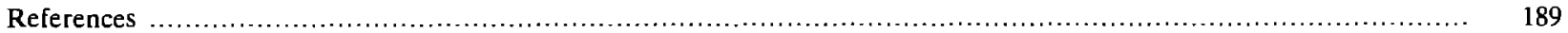

\section{INTRODUCTION}

The use of stimulant drugs to decrease fatigue and to heighten physical and mental abilities began when people first identified plants with these properties. For example, in ancient China herbal teas were brewed with plants containing ephedrine, and coco leaves, the source of cocaine, were chewed in South America by the ancestors of the Incas (see ref. 12 for an excellent historical review of central nervous system stimulants). Today, stimulant drugs such as the amphetamines remairi among the most widely used and abused of the many psychoactive compounds available. Although at one time amphetamine (AMPH) was prescribed in great numbers, for example as an anorexic in the treatment of obesity, its medical use has been greatly curtailed in recent years. AMPH is now usually prescribed only for the treatment of narcolepsy and childhood hyperkinesis. Nevertheless, illicit AMPH is still widely available and extensively used for its ability to decrease fatigue, elevate mood and produce euphoria ${ }^{96}$ (AMPH will be used to refer collectively to D-, L-, DL- and meth-amphetamine).

However, it is not fully appreciated that AMPH is also a potent psychotomimetic. In some schizophrenics it can rapidly intensify psychotic symptoms, and if a patient is in remission AMPH may precipitate a psychotic episode $\mathrm{e}^{265,275}$. In fact, an AMPH-induced exacerbation of symptoms in medicated schizophrenics is predictive of relapse following neuroleptic withdrawal $^{305}$. Perhaps the most dramatic effect of AMPH has been described in people who chronically use the drug. It has been well documented that nonpsychotic individuals who repeatedly use AMPH sometimes develop a psychosis that is very similar to paranoid schizophrenia ${ }^{48.320}$ (for reviews of AMPH psychosis see refs. $124,213,264,268,275)$. This AMPH-induced psychosis usually dissipates upon withdrawal from the drug, but former AMPH addicts are reported to remain hypersensitive to the psychotomimetic effects of AMPH even after years of absti- nence $^{248,302}$ (cf. ref. 99). There are also anecdotal reports that 'physical or psychological stress' can precipitate a psychotic episode in $20-25 \%$ of former AMPH addicts ${ }^{302,303}$. This suggests that chronic AMPH use produces a very long-lasting change in some neural system(s) involved in the psychotomimetic effects of AMPH.

These clinical observations generated considerable interest in the effects of chronic AMPH administration on brain and behavior in non-human animals, and in the development of animal models of AMPHinduced psychosis. There are now many studies showing that chronic AMPH administration has enduring consequences for behavior and brain function in non-human animals, and one purpose of this paper is to review this literature. However, even a cursory examination of the literature reveals that at least two different paradigms have been used to study the effects of chronic AMPH administration. With one paradigm, elevated brain concentrations of $\mathrm{AMPH}$ are maintained for a few days, either by the continuous administration of AMPH or by multiple repeated injections of high doses. The other paradigm involves the repeated intermittent administration of $\mathrm{AMPH}$, usually by discrete daily injections of relatively low doses. Since it will become obvious that these two paradigms produce different effects on brain and behavior, studies relevant to each will be reviewed separately.

Continuous AMPH administration produces a syndrome that will be called ' $A M P H$ neurotoxicity'. The literature on AMPH neurotoxicity has been reviewed recently (e.g. ref. 81), and therefore will be only briefly summarized to provide a comparison with the effects of repeated intermittent AMPH administration. The major portion of this paper will focus on a phenomenon that will be called 'behavioral sensitization', which is produced by repeated intermittent AMPH administration. In particular, an indepth and critical analysis of hypotheses concerning the biological basis of behavioral sensitization is presented. In addition, AMPH neurotoxicity and behav- 
ioral sensitization are evaluated as animal models of AMPH psychosis.

The review is confined almost exclusively to studies with AMPH, because much more is known about AMPH than about other psychomotor stimulants. The enduring effects of cocaine have been reviewed recently by R.M. Post ${ }^{213,216}$.

\section{THE EFFECTS OF CONTINUOUS AMPHETAMINE ADMINISTRATION ON BRAIN AND BEHAVIOR (AM- PHETAMINE NEUROTOXICITY)}

AMPH addicts often ingest increasing quantities of AMPH in 'runs' that can last 3-6 days, during which time their behavior becomes increasingly disorganized $^{165}$. Since blood levels of AMPH may remain elevated during these 'runs', some investigators have continuously administered AMPH to non-human animals in an attempt to mimic this pattern of drug use. In this context the phrase 'continuous AMPH administration' refers to the maintenance of elevated blood levels of AMPH for a prolonged period of time (usually 3-6 days). This can be achieved in one of 3 ways. The first is to implant a silastic pellet ${ }^{117}$ or osmotic pump that slowly and continuously releases AMPH ${ }^{198,229,285}$. The second is by frequent repeated systemic injections of high doses (e.g. refs. $270,308,309$ ), and the third by concomitant treatment with drugs, such as iprindole, that inhibit the metabolism of $\mathrm{AMPH}^{94,284}$. As will be described, all 3 methods can produce comparable effects on brain monoamine systems and behavior.

The behavioral changes associated with continuous AMPH administration have been reviewed recently by Ellison and Eison $^{81}$ (see also refs. 80, 83, $199,200,231)$. Briefly, in rats there is an initial short period of hyperactivity and then almost continuous intense stereotypy, followed by a period of inactivity. After 4-5 days, what has been described 'hallucinatory-like' behavior appears. The details of this hallucinatory-like behavior depend on the species, but it is similar to that seen after the administration of hallucinogenic drugs, such as $\operatorname{LSD}^{122.123}$. In the rat it is characterized by 'wet dog' shakes, limb flicks and excessive grooming and biting of the skin. This grooming and biting behavior is also pronounced in monkeys and may 'develop into episodes of parasitoticlike picking at the fur, during which the animal danc- es about as though stimulated on various parts of the skin $^{\text {'81 }}$ (p. 756). This behavior is similar to that reported to sometimes accompany tactile hallucinations in AMPH addicts (e.g. ref. 253).

There are now many studies showing that continuous AMPH treatment is neurotoxic, and that the appearance of hallucinatory-like behavior in non-human animals is accompanied by brain damage. It was originally thought that hallucinatory-like behavior was related to the inactivation of serotonin systems, but more recent evidence suggests it may be due to alterations in dopaminergic function ${ }^{85,297}$. The continuous infusion of relatively low doses of D-AMPH via pellet implants has a fairly selective effect on the nigrostriatal DA system, resulting in a depletion of striatal DA and its metabolites, a decrease in striatal tyrosine hydroxylase (TH) activity and a decline in the number of striatal DA receptors ${ }^{82,83,85,200,229}$ (for review see ref. 81 ). These effects are presumably due to degeneration of striatal DA terminals ${ }^{77,82,203,230}$. Similar damage to nigrostriatal DA neurons has been reported following a single injection of D-AMPH or meth-AMPH in rats pretreated with iprindole, a drug which inhibits the metabolism of $\mathrm{AMPH}^{94.207,284,285}$, or following repeated injections of extremely high doses of D-AMPH ${ }^{203,287,308}$.

There are a number of factors that determine how regionally and neurochemically specific the neurotoxic effects of continuous AMPH treatment are, including: (1) the dose of AMPH, (2) the duration of AMPH treatment, (3) the species, (4) the age of the organism, (5) the type of AMPH used (D-, L-, DL-, or meth-AMPH) and (6) prior drug history. For example, Steranka ${ }^{285}$ studied the effects of infusing $D$ AMPH for various periods of time on striatal DA. He gave rats a priming injection of $15 \mathrm{mg} / \mathrm{kg}$ of $\mathrm{AMPH}$ (i.p.), and then continuously infused $1.36 \mathrm{mg} / \mathrm{h}$ via an osmotic minipump. Six hours of infusion did not deplete striatal DA, $8 \mathrm{~h}$ produced a moderate depletion and $16 \mathrm{~h}$ produced a marked depletion (approx. $50 \%$ ). This depletion of striatal DA may be permanent because it had not recovered 6 months later. In a similar study, Ricaurte et al. ${ }^{229}$ found that the continuous infusion of meth-AMPH via an osmotic pump (with no 'priming' injection) at a rate of $4 \mathrm{mg} /$ day for 3 days produced toxic effects in the striatum. However, lower doses, for example, $1 \mathrm{mg} /$ day for 12 days, 2 $\mathrm{mg} /$ day for 6 days or $4 \mathrm{mg} /$ day for 1.5 day, were not 
sufficient to deplete striatal DA. Since the average rat in these studies weighed approximately $250 \mathrm{~g}$ it can be concluded that in the rat AMPH is neurotoxic only if approximately $48 \mathrm{mg} / \mathrm{kg}$ is continuously administered over 3 days $\left(16 \mathrm{mg} / \mathrm{kg} / \mathrm{day}^{229}\right)$, or if 102 $\mathrm{mg} / \mathrm{kg}$ is given over $16 \mathrm{~h}^{285}$. Schuster and Johanson ${ }^{258}$ report that if D-AMPH is given to rats by discrete multiple injections a minimum of $12.5 \mathrm{mg} / \mathrm{kg}$ (s.c.) twice a day for 4 days is required to deplete striatal DA.

Whether D-AMPH is toxic to other monoaminergic systems depends partly on how extreme the drug treatment regimen is. Ridley et al. ${ }^{231}$ reported that vervet monkeys given D-AMPH in increasing doses (from 4 to $12 \mathrm{mg} / \mathrm{kg} /$ day for 35 days) were depleted of norepinephrine (NE), serotonin and DA in the caudate and cortex. In addition, striatal tyrosine hydroxylase activity was reduced and the turnover of all the monoamines decreased. Interestingly, striatal choline acetyltransferase and glutamine decarboxylase activity were normal ${ }^{231}$. Cats seem to be especially sensitive to the neurotoxic effects of $\mathrm{AMPH}^{298}$. For example, Levine et al. ${ }^{179}$ found that caudate DA was 'depleted in cats for up to a year after only 3 injections of 1,2 and $4 \mathrm{mg} / \mathrm{kg}$ of D-AMPH, with each injection separated by 10 days. This is probably due at least in part to the much longer half-life of AMPH in cats $(6.5-8.5 \mathrm{~h})$ than in rats $(45-60 \mathrm{~min}$; see ref. 268 , p. 147 for references).

Most studies on the neurotoxic effects of AMPH have utilized its methylated form. Methamphetamine (meth-AMPH) appears to be more toxic than $\mathrm{D}-\mathrm{AMPH}$, and more non-selective. There are many reports of damage not only to striatal DA neurons following sustained treatment with methAMPH $^{77,113,181,228.270 .309}$, but also to serotonin and NE systems, especially in cats ${ }^{23,113,194,207,228,257,297.299}$. Nevertheless, there is still some selectivity. In adult animals the striatum, olfactory tubercle and cortex appear to be more sensitive to the toxic effects of meth-AMPH than the nucleus accumbens, hypothalamus or median eminence; and cholinergic and glutaminergic systems are not affected (e.g. refs. 23, 194, 218,228 ). In immature gerbils frontocortical neurons may be especially sensitive ${ }^{310}$. Prior drug history also influences the toxicity of meth-AMPH. For example, Schmidt et al. ${ }^{257}$ found that pre-exposure to increasing doses of meth-AMPH provides considerable pro- tection against the neurotoxic effects of high doses given later, an effect that may be partly due to changes in the disposition of meth-AMPH ${ }^{255}$.

The mechanism by which continuous AMPH produces its toxic effects is not well understood. One possibility is that 6-hydroxydopamine is formed from the massive quantities of DA released following high doses of meth-AMPH ${ }^{256,271}$. This idea is consistent with the observation that the integrity of the DA uptake carrier is required for meth-AMPH to have its toxic effects on striatal DA neurons ${ }^{254}$.

Although it has been argued here that the different treatment paradigms which continuously elevate brain levels of AMPH produce comparable effects on brain and behavior, it should be remembered that they are not identical. For example, the neural changes produced by the continuous infusion of low doses from a pellet implant are not exactly the same as those produced by multiple repeated injections of extremely high doses, and even the continuous infusion with pellets vs pumps may produce slightly different effects ${ }^{71}$. Therefore, there actually may be more than one 'AMPH neurotoxicity syndrome'. Nevertheless, there is no doubt that the prolonged and sustained exposure to AMPH produces progressive changes in behavior that are associated with brain damage.

The repeated intermittent administration of AMPH also produces progressive changes in brain and behavior, but these are quite distinct from those produced by continuous AMPH treatment, and are discussed next.

3. THE BEHAVIORAL CONSEQUENCES OF REPEATED INTERMITTENT AMPHETAMINE ADMINISTRATION (BEHAVIORAL SENSITIZATION)

Many of the initial studies on the effects of repeated AMPH administration were primarily concerned with its potent effects on the autonomic nervous system. It was found that with repeated administration, rapid tolerance developed to AMPH's autonomic effects, including those on body temperature, blood pressure, heart rate and respiration. Tolerance to AMPH's anorexic effects were also observed (e.g. for reviews see refs. 50, 164, 180). However, the first studies on the motor stimulant effects of AMPH were equivocal concerning the development of tolerance 
(e.g. refs. $68,262,321$; for review see ref. 164 ).

In the late 1960s, a re-examination of the effects of repeated AMPH treatment was prompted by descriptions of an evolving syndrome of progressively bizarre stereotyped behavior produced by repeated, increasing doses of $\mathrm{AMPH}^{73,75,76,79}$. It soon became apparent that there was not merely a lack of tolerance to the motor stimulant effects of $\mathrm{AMPH}$, but that the repeated intermittent administration of the same dose of AMPH produced a progressive enhancement in many behaviors. In addition, it was found that this enhanced sensitivity to AMPH persisted for very long periods of time following withdrawal from the drug. For example, Magos ${ }^{185}$ reported that in rats two injections of $6 \mathrm{mg} / \mathrm{kg}$ of D-AMPH given 2-5 weeks apart enhanced the behavioral stereotypy produced by a third injection given 4 weeks later. This treatment did not change the $\mathrm{LD}_{50}$ for AMPH. Similarly, Wallach and Gershon ${ }^{311}$ reported that the daily administration of AMPH to rats, cats or dogs enhanced the stereotypy produced by a subsequent injection of a lower dose.

It is now well established that repeated intermittent injections of AMPH sensitize animals to its stereotypy-producing effects ${ }^{152.153 .267}$. Since the early 1970s there have been many studies on the behavioral consequences of repeated intermittent AMPH administration (for reviews see refs. 17, 157, 158, 210, $216,264,268$ ), and these will be summarized here only for the purpose of outlining the most salient features of the behavioral phenomenon. The term behavioral sensitization will be used to refer to the progressive and enduring enhancement in many AMPHinduced behaviors produced by the repeated intermittent administration of AMPH. Other terms that have been used to refer to the same phenomenon include reverse tolerance, behavioral augmentation and behavioral facilitation.

\subsection{The major characteristics of behavioral sensiti- zation}

\subsubsection{Behavior}

The behavior produced by AMPH depends on a number of factors, including the species and sex of the subject, the dose administered and environmental surroundings. In rats, an acute injection of AMPH initially produces an increase in the incidence of forward locomotion, head movements, sniffing and rearing (i.e., the animal becomes generally hyperactive) and a concomitant decrease in the incidence of other behaviors, such as grooming ${ }^{219,251}$ (for reviews see refs. 51,120). If a low dose of AMPH is administered, this general hyperactivity persists for the duration of the drug's action. With higher doses the initial hyperactivity is soon followed by stereotyped behavior. During the stereotypy phase, locomotion and rearing cease, the animal assumes a crouched posture and engages in continuous or nearly continuous repetitive head movements, forelimb movements, sniffing, licking or biting. The intensity and duration of focused stereotyped behavior increases with increasing doses of AMPH.

When a constant dose of AMPH is repeatedly and intermittently administered many (but not all) of the behaviors described above are progressively enhanced or otherwise altered. For example, in animals that have been previously exposed to AMPH, subsequent AMPH treatment produces: (1) more intense stereotyped behavior; (2) a reduced time to the onset of stereotypy following injection of AMPH; and/or (3) the development of stereotyped behavior following administration of a lower dose of AMPH than would usually produce stereotypy (e.g. refs. 49, 112, $146,152,176,177,185,263,267,316)$. However, the stereotyped behavior produced by AMPH actually consists of a complex array of discrete behavioral elements, and not all of these show the same pattern of sensitization. For example, in rats, sniffing and repetitive head and limb movements show rapid sensitization, but oral behaviors (licking and biting) do not $^{69,224}$. We recently confirmed these findings and the results are shown in Fig. 1 to illustrate the typical pattern of sensitization to the stereotypy-producing effects of AMPH (see also ref. 191). The effects of repeated AMPH treatment on oral behaviors may be especially complex. Eichler et al. ${ }^{69}$ reported that daily AMPH injections resulted in the development of tolerance to AMPH-induced stereotyped licking behavior over the first 21 days of treatment, followed by the sensitization of licking behavior over the next 44 days of treatment.

The locomotion and rearing produced by low doses of AMPH are similarly enhanced with repeated intermittent AMPH administration, but this may also result in the emergence of focused stereotypy. After 
NOT ALL BEHAVIORAL ELEMENTS OF STEREOTYPY SHOW SENSITIZATION

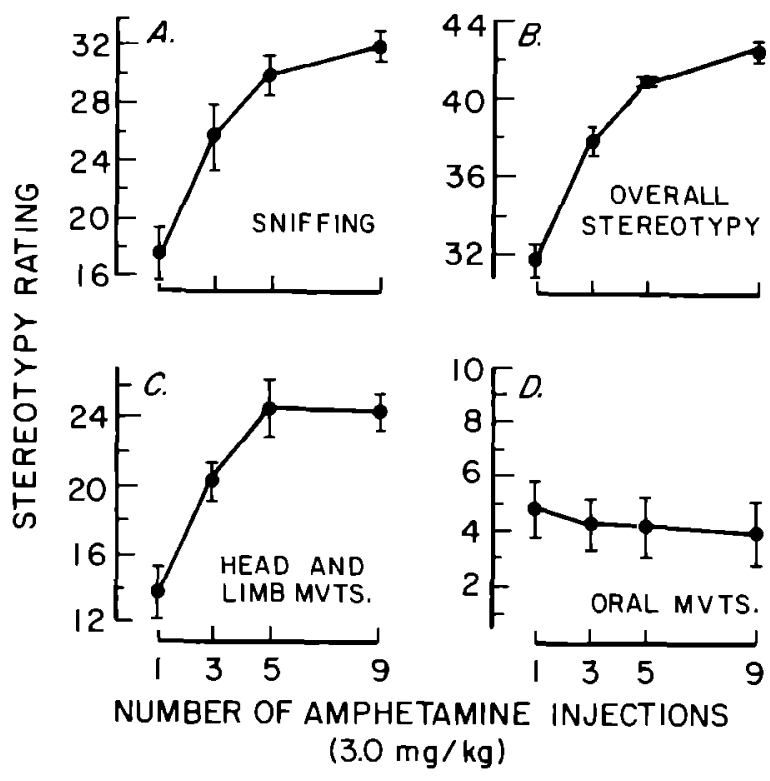

Fig. 1. The effects of repeated intermittent injections of amphetamine on stereotyped behavior. Adult female rats (Holtzman) received an i.p. injection of $3.0 \mathrm{mg} / \mathrm{kg}$ of D-amphetamine sulfate in their home cage once every 3-4 days for a total of 9 injections. Stereotyped behavior was rated at 10 and $30 \mathrm{~min}$ following the injection, and then every $30 \mathrm{~min}$ for a total of 150 min, following the first, $3 \mathrm{rd}$, 5th and 9 th in jection. Overall stereotypy was rated using the scale described by Dougherty and Ellinwood ${ }^{65}$, and the individual components of stereotyped behavior as described by Rebec and Segal ${ }^{224}$. Note the progressive increase in stereotyped sniffing, repetitive head and limb movements and overall stereotypy. In this experiment there was no significant change in oral movements (mvts.) over time.

the emergence of stereotypy the enhanced locomotion and rearing produced by repeated AMPH treatment are confined to the initial 'pre-phase' of hyperactivity, before the appearance of stereotypy, and the later 'after-phase' of hyperactivity, when the effects of AMPH are in decline $22,110.176 .177 .267 .273$. It should be noted that the pattern of locomotion produced by AMPH is not normal in all respects, but is itself abnormally stereotyped $d^{223,252,264}$.

Although there is general agreement that stereotyped behavior and locomotion are augmented by repeated intermittent AMPH treatment, not all researchers have reported exactly the same profile of changes. For example, Segal and his colleagues have typically found that the sensitization of stereotyped behavior is characterized by a decrease in the latency to the onset of stereotypy, and at some doses, more intense stereotypy; but not by any change in the duration of stereotypy (see Segal et al. ${ }^{264}$ for review). On the other hand, Eichler et al. ${ }^{69}$ reported that daily AMPH treatment produced a progressive increase in the duration (and intensity) of stereotyped sniffing. Leith and Kuczenski ${ }^{177}$ have shown that it is possible to dissociate different components of behavioral sensitization within the same animal. They found that the decreased latency to the onset of stereotypy and the enhancement of post-stereotypy locomotor activity seen with repeated AMPH developed at different rates and persisted for different periods of time. Furthermore, of 10 different strains of rats, all showed the decreased latency to the onset of stereotypy with repeated AMPH treatment, but only 5 showed an enhancement in post-stereotypy locomotion ${ }^{177}$. Some of these differences between studies are probably related to procedural differences, and especially to differences in how behavior is quantified. However, as pointed out previously ${ }^{69,177.264}$, many may be real and reflect a multiplicity of neural changes. Obviously, it will be important to consider these aspects of behavioral sensitization in trying to relate behavioral sensitization to enduring changes in specific neural systems.

Although in most studies of behavioral sensitization, stereotypy or locomotor activity were quantified, it should be noted that the repeated administration of AMPH sensitizes many other behaviors as well. These include: (1) rotational behavior, in either animals with unilateral damage to the nigrostriatal system or animals without lesions ${ }^{66,67,240,244}$; (2) drinking behavior ${ }^{17.247,294}$; (3) intracranial self-stimulation $^{217,236}$; (4) acoustic startle behavior ${ }^{156,159}$; (5) cage climbing behavior in mice ${ }^{186}$; (6) tail pinchinduced behavior ${ }^{15}$; and (7) performance in a $Y$ maze $e^{221}$. In addition, repeated AMPH administration has been reported to progressively disrupt measures of 'selective attention' and 'latent inhibition, 56,277 .

The sensitizing effects of AMPH do not seem to be species-specific. An enduring behavioral sensitization to the repeated intermittent administration of AMPH has been reported in every mammalian species studied to date, including: rats, cats, guinea pigs, mice, non-human primates and humans (rats ${ }^{49,112,145}$. 176.177, 185,224,240,263.267; cats $^{88.311}$; guinea pigs ${ }^{152,153}$; mice $22,67,186,273,274$; dogs ${ }^{311}$; non-human primates ${ }^{76}$, 95,231,232,303; and humans ${ }^{10,165,248,302}$ ). 


\subsubsection{Injection paradigm}

The paradigm used to administer AMPH is an extremely important variable to consider in evaluating studies on sensitization (cf. ref. 147). It will be documented below that many of the conflicting reports in the literature, particularly regarding the neural consequences of repeated AMPH administration, can be traced to the enormous variety of treatment paradigms that have been used.

One variable to be considered is the number of injections. In most studies of sensitization AMPH is administered (i.p. or s.c.) once or twice daily for 1-2 weeks. However, there is tremendous variation around this 'average'. For example, AMPH has been administered for up to 9 months, by injection, or in the food or water (e.g. ${ }^{109.125 .205 .231}$; see Table 3 in ref. 210). But it is not necessary to repeatedly administer AMPH for long periods of time to produce behavioral sensitization. In fact, one injection is sufficient. A single injection of AMPH has been reported to enhance the stereotypy ${ }^{40,83,268}$, drinking behavior ${ }^{17}$, and rotational behavior ${ }^{67,240,244}$ produced by a subsequent injection of AMPH given weeks later. Nevertheless, the repeated intermittent administration of AMPH does produce a progressive enhancement in behavior, over-and-above that produced by a single injection (e.g. ref. 240).

A second, and probably even more important variable, is the interval between AMPH treatments ${ }^{16,211}$. To produce robust behavioral sensitization AMPH must be given intermittently ${ }^{64,197,211}$. There is even evidence to suggest that injections given relatively far apart in time are more efficacious than those given more frequently ${ }^{16,211}$. For example, locomotion in mice is progressively enhanced to a greater extent if 10 injections of meth-AMPH are given 3-4 days or 7 days apart than if they are administered daily ${ }^{110}$. Similarly, male rats given $1.0 \mathrm{mg} / \mathrm{kg}$ of $\mathrm{D}$ AMPH once a week for 5 weeks show a greater elevation in rotational behavior than those given 5 injections once a day for 5 days ${ }^{240}$. In addition, Hitzemann et al. ${ }^{112}$ reported that after 3 weeks of twice daily AMPH injections it was necessary to withdraw the animals from the drug for more than one day to observe behavioral sensitization (i.e., animals withdrawn for one day did not show evidence of sensitization, whereas those withdrawn for 7,14 or 28 days did). Similarly, Kolta et al. ${ }^{161}$ reported greater be- havioral sensitization 15 or 30 days after withdrawal from repeated AMPH treatment than after only 3 days of withdrawal.

The importance of allowing time between treatments, presumably for some change in the nervous system to develop, has been discussed previously by Antelman and Chiodo ${ }^{16}$ and Post ${ }^{210,211}$ (although, for an incongruent report see ref. 87). These authors have suggested that the closer together in time injections are given, the more likely tolerance will develop, and the less likely sensitization will occur. Of course, giving injections too close together in time, especially when large doses are used, is functionally equivalent to continuous administration and will produce AMPH neurotoxicity. In order to evaluate reports of sensitization, it is critical to exclude studies in which toxic AMPH injection regimens were used (see below).

Behavioral sensitization has been reported following the repeated administration of both very low $\left(<1.0 \mathrm{mg} / \mathrm{kg}^{240}\right)$ and very high $\left(10 \mathrm{mg} / \mathrm{kg}^{273}\right)$ doses of AMPH, and therefore this does not seem to be a crucial variable ${ }^{210}$. More robust changes may be produced by higher doses, but extreme doses are not necessary and only increase the risk of producing neurotoxic effects.

\subsubsection{Sex differences}

Although most researchers use male animals, females show much greater rates of sensitization than do males. Robinson et al. ${ }^{244}$ first reported that gonadally intact female rats show a greater enhancement in rotational behavior following a single injection of AMPH than do gonadally intact males. This observation was verified and expanded in a later study using rats with unilateral 6-OHDA lesions of the substantia nigra ${ }^{240}$. Again, a greater enhancement in AMPH-induced rotational behavior was found in female than in male rats after either a single injection or repeated intermittent injections of AMPH. The sex difference in sensitization to AMPH is not unique to rotational behavior. Unpublished studies in this laboratory by D.M. Camp ${ }^{43}$ have revealed similar sex differences in the sensitization of stereotyped behavior and locomotion (see also ref. 213).

Sex differences in behavioral sensitization may be due to the influence of endogenous gonadal hormones on this form of neuroplasticity. Ovariecto- 
mized (OVX) and gonadally intact female rats sensitize at a comparable rate. However, castrated male rats show increased rates of sensitization relative to gonadally intact males, and are comparable to females in this respect ${ }^{43,240,244}$. The lower rate of sensitization in gonadally intact males may therefore be due to the suppression of sensitization by a testicular hormone. Of course, testicular hormones could influence sensitization indirectly, perhaps by their action on the pituitary. There is evidence that at least one pituitary hormone (vasopressin) can modulate the sensitization to cocaine ${ }^{214}$.

\subsubsection{Summary}

In summary, the most salient features of behavioral sensitization include the following: (1) Behavioral sensitization can be produced by a single injection of a relatively low dose of AMPH. (2) Behavioral sensitization is greater after multiple intermittent injections (as opposed to continuous treatment) than after a single injection. (3) Behavioral sensitization persists for months following withdrawal from AMPH. .(4) Behavioral sensitization is greater in females than in males, and greater in castrated males than intact males.

4. BEHAVIORAL SENSITIZATION AND AMPHETAMINE NEUROTOXICITY AS ANIMAL MODELS OF AMPHETAMINE PSYCHOSIS

Much of the interest in the effects of chronic AMPH treatment in non-human animals is because AMPH is commonly abused by humans, and because chronic AMPH use can produce a psychosis similar to paranoid schizophrenia ${ }^{48}$. It is therefore important to discuss the fact that two completely different syndromes, behavioral sensitization and AMPH neurotoxicity, have been proposed as animal models of AMPH psychosis (e.g. refs. 81, 264, 268). As described above, behavioral sensitization and AMPH neurotoxicity are produced by different treatment regimens and have different effects on behavior. They also have different long-term effects on the nervous system. (This latter point will be dealt with in detail in the next section of this review.) For example, continuous AMPH administration, which produces the AMPH neurotoxicity syndrome, destroys striatal DA terminals and depletes striatal DA (see above for references). The repeated intermittent administration of AMPH produces behavioral sensitization, does not deplete DA, but enhances DA release (see below). It is obvious that behavioral sensitization and AMPH neurotoxicity cannot both be 'animal models' of the same thing, i.e., AMPH psychosis. Unfortunately, there is no single piece of evidence that clearly establishes one or the other syndrome as the more valid animal model of AMPH psychosis. However, it is argued below that the weight of the evidence supports the idea that the phenomenon of behavioral sensitization provides a reasonably good model of AMPH psychosis, but that the AMPH neurotoxicity syndrome does not. Arguments against the AMPH neurotoxicity syndrome as a model of AMPH psychosis are given first.

(1) The main reason neurotoxic AMPH treatment regimens have been used to model AMPH psychosis is because it has been suggested this more closely mimics the conditions that result in AMPH psycho$\mathrm{sis}^{81}$. This idea comes mainly from the observation that many AMPH addicts, who present at hospital emergency wards with psychotic symptoms, have taken large quantities of AMPH, usually in 'runs' lasting a few days ${ }^{74,165}$. Although this is true, it does not follow that extremely large doses of AMPH are necessary to produce AMPH psychosis. It may be misleading to rely on doses used by hard-core 'speed freaks' to estimate the dose required to produce AMPH psychosis. People using smaller quantities of AMPH may also develop psychotic symptoms, but because they would be less likely to turn up in hospital emergency wards, their symptoms would probably go undiagnosed. Angrist and Gershon ${ }^{11}$ describe such a case (see also ref. 1). In fact, there is considerable evidence in the clinical literature which suggests that large doses of AMPH are not necessary to produce AMPH psychosis ${ }^{264,268}$.

A brief and selective review of studies in which psychotic symptoms were produced in non-schizophrenic subjects following the administration of relatively low known doses of AMPH follows (see also ref. 264). Griffith et al. ${ }^{100}$ administered $10 \mathrm{mg}$ of $\mathrm{D}$ AMPH i.v., and then 5-10 mg orally each hour until psychotic symptoms appeared. Six subjects developed an AMPH psychosis within 1-4 days following a total of 120-375 mg of AMPH. Two subjects developed symptoms within one day, two within 2.5-2.75 
days and two within 4 days. For the sake of estimating the dose relative to body weight, let us assume the subjects weighed around $65 \mathrm{~kg}$, on average. Using the $65 \mathrm{~kg}$ figure, it is estimated that the subjects in the Griffith et al. ${ }^{100}$ study showed psychotic symptoms after a total cumulative dose of $1.8-5.8 \mathrm{mg} / \mathrm{kg}$. If calculated on a mg/kg/day basis, on the order of 3.1-6.2 $\mathrm{mg} / \mathrm{kg} /$ day was required to produce psychotic symptoms. Bell ${ }^{32}$ obtained similar results. Bell ${ }^{32}$ infused meth-AMPH in divided doses over $60-75 \mathrm{~min}$. His subjects showed psychotic symptoms following a total of 50-640 mg. The $640 \mathrm{mg}$ dose was unusually high, as the subject requiring the next highest dose to produce psychosis showed symptoms after only 260 mg. Again, assuming an average weight of $65 \mathrm{~kg}$, psychotic symptoms were produced after only $0.8-4.0 \mathrm{mg} / \mathrm{kg}$ over $1 \mathrm{~h}$. Similarly, Sato et al. ${ }^{248} \mathrm{re}-$ cently reported that $30-90 \mathrm{mg}$ over $1-6$ days $(0.5-1.4 \mathrm{mg} / \mathrm{kg}$, assuming a $65 \mathrm{~kg} \mathrm{~b}$. wt.) was sufficient to produce AMPH psychosis. Segal ${ }^{264,268}$ has compiled a Table listing 13 different reports of AMPH psychosis following doses of less than $100 \mathrm{mg}$ of AMPH (see also ref. 99). It is clear from this Table that there are many cases in which the daily administration of only $0.3-1.2 \mathrm{mg} / \mathrm{kg}$ of AMPH produced AMPH psychosis (assuming an average weight of 65 $\mathrm{kg}$ ). In addition, it is supposedly common for narcoleptics being treated with low doses of AMPH to develop paranoid tendencies (S. Watson, personal communication and ref. 320).

Although there are clearly problems in making dose-response comparisons across species, and caution is required in doing so, the available evidence suggests the dose required to produce AMPH neurotoxicity is many times higher than that required to produce AMPH psychosis. Studies by Ricaurte et al. ${ }^{229}$ and Steranka ${ }^{285}$ in rats suggest that it is necessary to administer approximately $48 \mathrm{mg} / \mathrm{kg}$ of AMPH continuously over 3 days, or $102 \mathrm{mg} / \mathrm{kg}$ over $16 \mathrm{~h}$ to produce neurotoxic effects. Schuster and Johanson ${ }^{258}$ report that, if given twice daily, $25 \mathrm{mg} / \mathrm{kg} /$ day for 4 days is required to produce neurotoxicity. Furthermore, if animals are initially exposed to low doses of AMPH (as is usually the case with addicts), even much higher doses than this would be required to produce neurotoxicity, because of the protective effect of pre-exposure to low doses ${ }^{257}$. Therefore, on the order of at least $25-50 \mathrm{mg} / \mathrm{kg}$ of AMPH must be administered over 3-4 days to produce AMPH neurotoxicity in rats. In striking contrast, AMPH psychosis can be produced by as little as $0.5-2.0 \mathrm{mg} / \mathrm{kg} / \mathrm{day}$, that is, with doses at least $12.5-50$ times less than those that are toxic in rats.

(2) A prediction that follows from the idea that the AMPH neurotoxicity syndrome models the changes in brain and behavior associated with AMPH psychosis, is that people who have experienced AMPH psychosis should show signs of degenerative changes in brain DA systems. Unfortunately, we know of no evidence available on dopaminergic function in such people. It has been reported that AMPH psychosis is accompanied by increased cerebral blood flow, especially in the anterior frontal lobes ${ }^{33}$. However, it is not clear if this is consistent with damage in this region or not. To resolve the issue, PET studies or studies on DA metabolite levels in the CSF of former AMPH addicts would be extremely valuable (cf. ref. 218).

(3) The idea that a paranoid psychosis is due to decreased dopaminergic activity runs counter to nearly all the available evidence on the neurobiology of schizophrenia. There is considerable evidence that paranoid schizophrenia is not accompanied by DA depletion, and most current theories stress the idea that DA systems are hyperactive in schizophre$\mathrm{nia}^{58,306}$.

(4) One salient characteristic of AMPH psychosis is that it typically appears only during the time an individual is on the drug and dissipates following withdrawal from the drug. But the depletion of brain monoamines produced by toxic doses of AMPH appears to be permanent, and certainly is present following withdrawal from AMPH (see above for references). If the depletion of brain monoamines were causally related to AMPH psychosis it might be expected that the psychosis would also persist following withdrawal from the drug; but it does not. Of course, it might be argued that presynaptic compensatory processes mask the 'depletion-induced psychosis'.

(5) Lastly, it is well documented that former AMPH addicts show an enduring hypersensitivity to $\mathrm{AMPH}^{248,264,268}$, and the AMPH neurotoxicity syndrome does not account for this important feature of AMPH psychosis. Animals given toxic doses of AMPH, then withdrawn from AMPH and later challenged with an acute injection are not hypersensitive 
to AMPH (e.g. ref. 197). That is, the AMPH neurotoxicity syndrome is not accompanied by an enduring hypersensitivity to AMPH. This is not surprising, because the DA depletion produced by toxic doses of AMPH (around 30-70\%) is not sufficient to produce postsynaptic DA receptor supersensitivity. This usually requires a greater DA depletion, on the order of $85-90 \%$ (e.g. refs. $54,190,288$ ).

It is concluded, therefore, that the changes in brain and behavior produced by neurotoxic AMPH treatment regimens in non-human animals do not provide a good model of AMPH psychosis (see also refs. 204, $231,264)$. It is more likely that the neurotoxic effects of AMPH are related to the toxicity produced by structurally similar compounds, such as $p$-chloroamphetamine or MPTP (1-methyl-4-phenyl-1,2,3,6-tetrahydropyridine), and as such may represent a model of presymptomatic Parkinson's disease (e.g. ref. 93).

Next, how well behavioral sensitization models AMPH psychosis will be addressed. Schiorring ${ }^{253}$ (p. 115) has suggested that the basic requirements for a 'model' of schizophrenia or AMPH psychosis are: -(1) 'similarities in behavioral disorders'; (2) 'a sustained course of changes', i.e., progressive changes in brain and behavior; (3) 'liability to exacerbation', i.e., an enduring hypersensitivity to AMPH; and (4) the 'absence of gross morphological lesions in the brain'. The phenomenon of behavioral sensitization produced by the repeated intermittent administration of AMPH meets all of these requirements.

(1) 'Similarities in behavioral disorders'. Obviously, it is impossible to determine if non-human animals experience cognitive abnormalities comparable to those described in people repeatedly exposed to AMPH. However, it is possible to compare the effects of AMPH on motor behavior, and striking similarities have been found ${ }^{196,219,220,253}$. Indeed, the descriptions of AMPH-induced stereotyped activities shown by human and non-human animals are sometimes eerie in their remarkable similarity ${ }^{253}$. In humans AMPH-induced changes in behavior include: "(1) stereotyped, bizarre movements of arms, hands, legs; continuous chewing on the tongue or lips; licking on the lips; nail-biting; plus other kinds of aimless activities such as walking up and down the streets without any goal; walking in circles; standing immobile for several hours; 'pottering', 'punding' with var- ious objects, including own body; repetition of single words or phrases; stereotyped writing and/or drawing. (2) Social stereotypies: prolonged sexual intercourse without ejaculation. Collective monologues (talking without listening). (3) Social withdrawal ('autism', social isolation). (4) Paranoia. (5) Hallucinations and illusions; auditory, visual, tactile, olfactory. (6) Micro-hallucinations (worms, insects, etc., coming out of the skin) ${ }^{\prime 253}$ (p. 114). Segal ${ }^{264}$ has commented extensively on the similarities in the increasingly perseverative and restricted behavior patterns seen in both human and non-human animals repeatedly exposed to AMPH. Although more speculative, Solomon and his colleagues ${ }^{56,277}$ have also attempted to relate progressive alterations in attentional processes produced by repeated AMPH treatment in rats, to theoretically similar deficits in schizophrenics.

(2) 'A sustained course of changes'. The progressive development of increasingly stereotyped behavior with repeated intermittent injections of AMPH has been thoroughly documented, and was described in detail above. In a similar fashion, the probability of producing the cognitive abnormalities associated with AMPH psychosis in people is thought to increase with repeated exposure to the drug ${ }^{79}$. However, it should be noted that AMPH psychosis has been reported following the first exposure to $\mathrm{AMPH}^{99,219,265}$, just as an appropriate acute dose of AMPH can produce stereotypy in rats. Nevertheless, with the repeated intermittent administration of AMPH, and the development of sensitization, AMPH becomes progressively more potent in producing stereotyped behavior and psychosis.

(3) 'Liability to exacerbation'. The enduring nature of the changes in brain and behavior produced by repeated intermittent AMPH treatment is one of the most intriguing aspects of sensitization. Both human and non-human animals that have been previously exposed to AMPH remain hypersensitive to the drug for very long periods of time. Former AMPH addicts have been reported to be hypersensitive to the psychotomimetic effects of AMPH even after years of abstinence 248,302 , and animals sensitized to AMPH remain hypersensitive to the motor stimulant effects of AMPH for at least months, and perhaps much longer ${ }^{185,240}$.

(4) 'Absence of gross morphological lesions'. There is no doubt that robust behavioral sensitization 
can be produced by the repeated intermittent administration of AMPH in doses that do not produce brain damage, as will be documented in the following section. In fact, it will be argued below that if an AMPH treatment paradigm damages DA neurons this constitutes prima facie evidence for AMPH neurotoxicity, not behavioral sensitization.

\section{THE BIOLOGICAL BASIS OF BEHAVIORAL SENSI- TIZATION}

It is clear that the repeated intermittent administration of AMPH produces very long-lasting changes in behavior, and there has been a great deal of interest in how this occurs. An understanding of how stimulant drugs produce enduring behavioral changes may provide insight into how they produce their psychotomimetic effects, and thus into the neurobiology of psychosis. But regardless of whether behavioral sensitization is analogous to AMPH psychosis, it is important to determine how such a short-term alteration in neural function can produce such long-lasting consequences. A number of hypotheses have been entertained, and these can be divided into 3 categories: (1) drug dispositional or peripheral hypotheses; (2) drug-environment conditioning hypotheses; and (3) neural hypotheses. Each of these hypotheses will be evaluated in turn, taking into consideration the characteristics of behavioral sensitization summarized above.

\subsection{Drug dispositional/peripheral hypotheses}

It is possible that the increasing behavioral response produced by repeated AMPH administration is due to some change in the disposition of AMPH. For example, AMPH pretreatment may increase the amount of AMPH that reaches the brain due to changes in AMPH metabolism, or because AMPH accumulates in adipose tissue and is released lat$\mathrm{er}^{255.280}$. In support of a dispositional hypothesis, Kuhn and Schanberg ${ }^{170}$ reported that AMPH pretreatment increased the rate of AMPH uptake into the brain (at $10 \mathrm{~min}$ ), although it did not influence its rate of removal from the brain (at 1,4 and $12 \mathrm{~h}$ ). It should be noted, however, that Kuhn and Schanberg $^{170}$ administered AMPH daily, increasing the dose by $1 \mathrm{mg} / \mathrm{kg}$ each day from 10 to $32 \mathrm{mg} / \mathrm{kg}$. They mention in their paper that the changes in AMPH uptake they found could be due to the loss of body fat or decreased metabolism of AMPH resulting from liver damage associated with these extremely high doses of AMPH.

Further examination of the literature reveals little support for any simple dispositional/peripheral hypothesis, as noted in a number of recent papers $^{62,169,210,264}$. For example, it has been reported that chronic AMPH treatment with lower doses does not alter whole brain or regional brain (e.g. striatum, cortex, olfactory tubercle) levels of $\mathrm{AMPH}^{37,60}$. 127,312 . There is certainly no evidence that the behavioral sensitization produced by a single injection, or intermittent injections of relatively small doses of AMPH is accompanied by changes in the uptake of AMPH into the brain.

It has also been suggested that the formation and retention of the major metabolites of AMPH, $p$-hydroxyamphetamine ( $p \mathrm{OHA})$ and $p$-hydroxynorephedrine ( $p \mathrm{OHE}$ ), could contribute to either the tolerance or sensitization produced by repeated AMPH administration ${ }^{60}$. However, there is very little experimental support for this idea (see ref. 62 for review). For example, some authors have reported that AMPH pretreatment does not alter the formation of $p \mathrm{OHA}$ or $p \mathrm{OHE}^{170}$. More importantly, these metabolites are not formed after the administration of LAMPH or methylphenidate, but repeated injections of these drugs do produce behavioral sensitization $^{40,316}$. In addition, guinea pigs do not form $p \mathrm{OHE}$ from D-AMPH, but still show behavioral sensitization $^{272}$. Lastly, as noted by Lewander ${ }^{180}$, it is difficult to imagine how dispositional/peripheral factors could account for the development of tolerance to some of the effects of AMPH (e.g. autonomic effects) simultaneously with the sensitization of others (e.g. stereotyped head movements, rotational behavior).

In conclusion, there is a general consensus that dispositional/peripheral factors cannot account for the behavioral sensitization produced by repeated intermittent injections of low doses of AMPH ${ }^{62,169,210,264}$.

\subsection{Drug-environment conditioning hypotheses}

When the administration of a psychoactive drug is repeatedly paired with a unique test environment, the test environment can sometimes acquire the 
properties of a conditioned stimulus (CS). In this situation, behavior previously elicited only by the drug (the unconditioned stimulus) is eventually elicited by the environment (the CS) in the absence of the drug ${ }^{182.292}$. Psychomotor stimulant drugs, including AMPH, are subject to this kind of drug-environment conditioning. It has been suggested, therefore, that drug-environment conditioning may be at least partially responsible for the development of behavioral sensitization $^{72,110,209,215,226,250,293}$. The important question here is not whether the behavioral effects of AMPH can be conditioned, because there is no doubt they can, but whether drug-environment conditioning is necessary for behavioral sensitization. That is, can drug-environment conditioning alone account for the characteristics of behavioral sensitization? A review of the literature reveals that it cannot, as illustrated by the following points.

(1) Segal ${ }^{263}$ has previously argued that drug-environment conditioning cannot account for behavioral sensitization. For drug-environment conditioning to occur it is necessary to pair drug administration with a unique test environment ${ }^{250.293}$. However, in all their studies on sensitization, Segal and his colleagues minimized conditioning variables by housing animals continuously in the 'test' chambers. They found that under these conditions the repeated administration of AMPH still produces sensitization $^{40,263,264,267}$. Similar results have been obtained in this lab. For example, the data illustrated in Fig. 1 were obtained from rats that were always administered AMPH in their home (wire-hanging) cages, not in a unique test environment.

(2) Segal and his colleagues have also shown that it is not necessary to treat animals with AMPH in the test environment to produce sensitization ${ }^{40}$. Browne and Segal ${ }^{40}$ pretreated rats with $2.5 \mathrm{mg} / \mathrm{kg}$ of AMPH or saline daily for 4 days in one of 3 different environments: (a) the test chamber, (b) a plastic cage, singly housed, or (c) a plastic cage, group housed. On the 5 th day, all rats received $2.5 \mathrm{mg} / \mathrm{kg}$ of AMPH in the test chambers. All 3 groups pretreated with AMPH (regardless of environment) showed sensitization, as indicated by a more rapid onset of stereotypy relative to saline-pretreated control animals. Similar findings have been obtained in other studies where rotational behavior, stereotypy or locomotion were meas$\operatorname{ured}^{43,67,240}$. For example, Robinson ${ }^{240}$ compared
AMPH-induced rotational behavior in 3 different groups of rats, all of which had a unilateral 6-OHDA lesion of the substantia nigra. One group (sensitized) was given AMPH in the rotometers (the unique environment), and a second group saline in the rotometers weekly for 3 weeks. During the first 3 weekly test sessions, a third group (pseudoconditioned) received saline in the rotometers, and AMPH in their home cages following removal from the rotometer. On the 4th week, all rats received $3.0 \mathrm{mg} / \mathrm{kg}$ of AMPH in the rotometers and rotational behavior was recorded. Both of the AMPH pretreated groups showed greater AMPH-induced rotational behavior during the 4th test session than did saline pretreated rats. The saline pretreated rats made the same number of rotations as the sensitized animals the first time sensitized animals received AMPH in the rotometers. These studies establish that it is not necessary to pair AMPH administration with a unique test environment to produce sensitization ${ }^{40,240}$.

(3) The evidence discussed thus far does not support a drug-environment conditioning hypothesis, but it is still possible that some form of interoceptive conditioning is involved. However, this idea is not supported by studies showing that under appropriate experimental conditions, a saline injection fails to mimic the locomotor and stereotypy producing effects of AMPH in sensitized animals ${ }^{43,263.267}$, and weekly injections of AMPH do not produce conditioned rotational behavior ${ }^{240}$.

(4) A further argument against conditioning hypotheses has been raised by Segal ${ }^{263}$. He pointed out that when rats are repeatedly administered a low dose of AMPH, which initially produces only locomotion, that dose eventually comes to elicit stereotypy. That is, the pattern and character of the behavior elicited by the drug evolves from that associated with a low dose to that associated with a higher dose of the drug. This is not consistent with a conditioning hypothesis, because if locomotion were being conditioned to the test environment one would expect to observe conditioned locomotion; not the appearance of a new behavior ${ }^{263}$.

(5) Lastly, there have now been many reports that a single injection of AMPH can produce a very longlasting enhancement in a variety of AMPH-induced behaviors ${ }^{40,240,244,264}$. It is difficult to imagine that conditioning could account for these enduring effects 
of one exposure to AMPH, since most conditioning phenomena require repeated pairing of the $\mathrm{CS}$ and UCS. Furthermore, as pointed out by one of the anonymous reviewers of this paper, 'sensitized responses grow with the passage of time ... whereas conditioned responses should decline with time'16,17,161.

The conclusion to be drawn from the evidence just summarized is clear; drug-environment conditioning cannot fully account for behavioral sensitization. It needs to be emphasized, however, that even though drug-environment conditioning does not explain behavioral sensitization, it is probably a major factor influencing many studies of behavioral sensitization. If animals are repeatedly and frequently tested in a unique environment, it is very likely that drug-environment conditioning will occur ${ }^{110,215,250,293}$. It is therefore difficult to interpret and evaluate studies of behavioral sensitization that are confounded by conditioning variables because the extent to which changes in behavior can be attributed to sensitization vs conditioning is unclear. It is probable that some of the apparent discrepancies in the literature are due to differences in the extent to which conditioning variables predominate in any particular study (see below). Nevertheless, neither drug-dispositional nor conditioning hypotheses can fully explain behavioral sensitization, and so other hypotheses must be entertained.

\subsection{Neural hypotheses}

It has been suggested that the repeated intermittent administration of AMPH causes a long-lasting change in neural systems that mediate the motor stimulant effects of AMPH, and that this is responsible for the heightened behavioral response seen upon subsequent exposure to the drug ${ }^{152,186,267}$. The idea that a central change is involved is supported by the observation that rats given repeated systemic injections of AMPH are hypersensitive to the locomotorenhancing effects of a subsequent intraventricular injection of AMPH ${ }^{225}$. Research on the neural correlates of behavioral sensitization has addressed two basic questions: (1) what is the locus of the change(s), and (2) what is the nature of the change(s)? Because of the character of this research, the locus of change is largely defined in terms of spe- cific neurotransmitter systems. Most researchers have studied brain DA systems, and so evidence for changes in nigrostriatal, mesolimbic and mesocortical DA systems will be reviewed first. There is only limited evidence that behavioral sensitization is accompanied by changes in other neurotransmitter systems, and so this will be reviewed second. Since the literature is large and there are multiple hypotheses as to the nature of neural changes, studies proposing a primarily postsynaptic vs presynaptic basis to sensitization will be dealt with separately.

\subsubsection{The nigrostriatal dopamine system}

Most attempts to identify a neural correlate of behavioral sensitization have focused on the nigrostriatal DA system. This is to be expected because AMPH causes striatal DA release ${ }^{192}$, and many of the behaviors that are sensitized by AMPH (e.g. stereotypy, rotation) are thought to be caused by the release of DA from nigrostriatal neurons ${ }^{51.119 .192,193,300}$.

5.3.1.1. Evidence for postsynaptic changes. In one of the earliest papers on behavioral sensitization Klawans and Margolin ${ }^{152}$ proposed that the repeated administration of AMPH produces postsynaptic DA receptor supersensitivity. They based this idea on an experiment showing that guinea pigs sensitized to AMPH were also hypersensitive to apomorphine (APO), a direct-acting DA receptor agonist. In a later paper they provided neurochemical evidence for striatal DA receptor supersensitivity in AMPH-pretreated guinea pigs ${ }^{154}$.

Further studies to examine the hypothesis that postsynaptic DA receptors are supersensitive in AMPH-sensitized animals have largely utilized one of two approaches. (1) If AMPH-pretreated animals have supersensitive postsynaptic DA receptors they should be hypersensitive to the behavioral effects of direct-acting DA receptor agonists, as reported by Klawans and Margolin ${ }^{152}$. However, these data are equivocal. Table I shows that in the majority (12 out of 20) of studies of this type (albeit a small majority) it was found that AMPH-pretreated animals are not hypersensitive to APO.

(2) The second approach has been to study DA receptor binding. However, studies on DA receptor binding do not support the contention that striatal postsynaptic DA receptors are up-regulated in AMPH-sensitized animals; and in fact, most of these 
TABLE I

The effect of amphetamine sensitization on behavior induced by a subsequent injection of apomorphine

APO, apomorphine; M, male; F, female; D, D-AMPH; M, meth-AMPH; L, L-AMPH; mk, mg/kg; d, day; mo, month; inj, injections; wk, week; h, hours; $m$, minutes; $\rightarrow$, increasing doses

\begin{tabular}{|c|c|c|c|c|c|c|c|}
\hline Reference & Species & $\operatorname{Sex}$ & $A M P H$ & Injection schedule & $\begin{array}{l}\text { Withdrawal } \\
\text { period }\end{array}$ & Behavior & $\begin{array}{l}\text { APO } \\
\text { behavior } \\
\text { enhanced }\end{array}$ \\
\hline Antelman and Chiodo ${ }^{17}$ & Rats & $?$ & $\mathrm{D}$ & $4 \mathrm{mk} / \mathrm{d} \times 6 \mathrm{~d}$ & $11 \mathrm{~d}$ & locomotion & No \\
\hline Bailey and Jackson ${ }^{22}$ & Mice & $\mathbf{M}$ & $\mathrm{D}$ & $4 \mathrm{mk} / \mathrm{d} \times 20 \mathrm{~d}$ & $8 d$ & locomotion & $\mathrm{No}^{4}$ \\
\hline Conway and Uretsky ${ }^{49}$ & Rats & $\mathbf{M}$ & $?$ & $5 \mathrm{mk} 2 \times / \mathrm{d} \times 5 \mathrm{~d}$ & $3 d$ & stereotypy & No \\
\hline Hitzemann et al. ${ }^{112}$ & Rats & $\mathbf{M}$ & $\mathrm{D}$ & $3 \rightarrow 12 \mathrm{mk} 2 \times / \mathrm{d} \times 3 \mathrm{wk}$ & $1-30 d$ & stereotypy & No \\
\hline Hitzemann et al. ${ }^{.11}$ & Rats & F & $\mathrm{D}$ & $6 \mathrm{mk} 2 \times / \mathrm{d} \times 1-4 \mathrm{~d}$ & $16-20 \mathrm{~h}$ & stereotypy & $\mathrm{No} / \mathrm{Yes}^{5}$ \\
\hline Jackson et al. ${ }^{121}$ & Rats & M & $\mathrm{D}$ & $5 \mathrm{mk} / \mathrm{d} \times 25 \mathrm{~d}$ & $7 d$ & stereotypy & No \\
\hline Jenner et al. ${ }^{25}$ & Mice & $\mathbf{M}$ & $\mathrm{D}$ & $2.5 \rightarrow 20 \mathrm{mk} / \mathrm{d} \times 3 \mathrm{mo}$ & $1 \mathrm{wk}-3 \mathrm{mo}$ & rotation & $\mathrm{No}^{1}$ \\
\hline Kilbey and Ellinwood ${ }^{146}$ & Rats & $\mathrm{F}$ & $\mathrm{D}$ & $7 \mathrm{mk} / \mathrm{d} \times 14 \mathrm{~d}$ & $5 d$ & stereotypy & $\mathrm{No} / \mathrm{Yes}^{6}$ \\
\hline Rebec and Segal ${ }^{224}$ & Rats & $\mathbf{M}$ & $\mathrm{D}$ & $5 \mathrm{mk} / \mathrm{d} \times 4 \mathrm{~d}$ & $1 d$ & stereotypy & $\mathrm{No}^{3}$ \\
\hline Robinson ${ }^{240}$ & Rats & $\mathrm{F}$ & $\mathrm{D}$ & $3 \mathrm{mk} / 3-4 \mathrm{~d} \times 5 \mathrm{inj}$ & $7 \mathrm{~d}$ & rotation & No \\
\hline \multirow[t]{2}{*}{ Weston and Overstreet ${ }^{316}$} & Rats & $M$ & $\mathrm{D}$ & 2 or $8 \mathrm{mk} / \mathrm{d} \times 3-17 \mathrm{~d}$ & $1 \mathrm{~d}$ & $\begin{array}{l}\text { locomotion and } \\
\text { sniffing }\end{array}$ & No \\
\hline & & & $\mathrm{L}$ & 6 or $16 \mathrm{mk} / \mathrm{d} \times 3-17 \mathrm{~d}$ & $1 \mathrm{~d}$ & $\begin{array}{l}\text { locomotion and } \\
\text { sniffing }\end{array}$ & No \\
\hline Wilcox et al. ${ }^{319}$ & Mice & M & $\mathrm{D}$ & $4 \mathrm{mk} / \mathrm{d} \times 20 \mathrm{~d}$ & $4 d$ & cage climbing & $\mathrm{No}^{2}$ \\
\hline Bailey and Jackson 22 & Mice & $\mathbf{M}$ & $\mathrm{D}$ & $4 \mathrm{mk} / \mathrm{d} \times 20 \mathrm{~d}$ & $8 \mathrm{~d}$ & locomotion & $\mathrm{Yes}^{4}$ \\
\hline Echols $^{66}$ & Mice & $\mathbf{M}$ & $\mathrm{D}$ & $4 \mathrm{mk} / \mathrm{wk} \times 4 \mathrm{wk}$ & $1 \mathrm{wk}$ & rotation & Yes \\
\hline Klawans and Margolin ${ }^{152}$ & $\begin{array}{l}\text { Guinea } \\
\text { pigs }\end{array}$ & $\mathbf{M}$ & $\mathrm{D}$ & $4-5 \mathrm{mk} / \mathrm{d} \times 21 \mathrm{~d}$ & $3-10 \mathrm{~d}$ & stereotypy & Yes \\
\hline Martres et al. ${ }^{186}$ & Mice & M & $\mathrm{D}$ & $5 \mathrm{mk} / 90 \mathrm{~min} \times 4$ inj & $30 \mathrm{~h}$ & cage climbing & Yes \\
\hline .Nelson and Ellison ${ }^{197}$ & Rats & $\mathbf{M}$ & $\mathrm{D}$ & $3.2-3.7 \mathrm{mk} / \mathrm{d} \times 7-30 \mathrm{~d}$ & 1 or $30 \mathrm{~d}$ & stereotypy & Yes \\
\hline Nishikawa et al. ${ }^{20 I}$ & Rats & $\mathbf{M}$ & $\mathbf{M}$ & $6 \mathrm{mk} / \mathrm{d} \times 14 \mathrm{~d}$ & $14 \mathrm{~d}$ & stereotypy & Yes \\
\hline Weiner et al. ${ }^{312}$ & $\begin{array}{c}\text { Guinea } \\
\text { pigs }\end{array}$ & M & D & $5 \mathrm{mk} / \mathrm{d} \times 21 \mathrm{~d}$ & $10 \mathrm{~d}$ & stereotypy & Yes \\
\hline Wilcox et al. ${ }^{319}$ & Mice & $\mathbf{M}$ & D & $4 \mathrm{mk} / \mathrm{d} \times 20 \mathrm{~d}$ & 8 or $12 d$ & cage climbing & $\mathrm{Yes}^{2}$ \\
\hline
\end{tabular}

${ }^{1}$ Also added AMPH to drinking water; DA depleted and rotation depressed. ${ }^{2}$ No if $4 \mathrm{~d}$ withdrawal, yes if $8-12 \mathrm{~d}$ withdrawal. ${ }^{3} \mathrm{Re}-$ duction in oral stereotypy. ${ }^{4}$ No with 0.25 or $0.5 \mathrm{mg} / \mathrm{kg}$ and yes with $1-4 \mathrm{mg} / \mathrm{kg}$ APO. ${ }^{5}$ Yes with some treatments, but not others. ${ }^{6} \mathrm{No}$ with $1 \mathrm{mg} / \mathrm{kg}$ APO; small effect on onset of stereotypy with $3 \mathrm{mg} / \mathrm{kg}$ but no effect on intensity.

studies report that in AMPH-pretreated animals there is either a decrease in DA receptor binding, or no change (Table II). In only 4 of the 24 experiments summarized in Table II were AMPH-pretreated animals found to have increased DA receptor binding. These 4 reports differ somewhat from the rest in that in 3 of them $\left[{ }^{3} \mathrm{H}\right] \mathrm{DA}$ or $\left[{ }^{3} \mathrm{H}\right] \mathrm{ADTN}$ were used as the ligand. In contrast, $\left[{ }^{3} \mathrm{H}\right]$ spiroperidol was used in most studies reporting a decrease or no change in binding. Furthermore, the Klawans et al. ${ }^{154}$ study is unusual because they reported an increased affinity for $\left[{ }^{3} \mathrm{H}\right] \mathrm{DA}$ at 'high affinity' sites with no change in $\mathrm{B}_{\max }$, but an increase in the number of receptors at 'low affinity' sites (see also ref. 98). This is difficult to interpret. The only report of increased $\left[{ }^{3} \mathrm{H}\right]$ spiroperidol binding is an abstract by Robertson ${ }^{238}$, but in two subsequent papers Robertson ${ }^{237,239}$ reports a de- crease in striatal $\left[{ }^{3} \mathrm{H}\right]$ spiroperidol binding in AMPHpretreated rats. Attempts to identify changes in DAstimulated adenylate cyclase activity in sensitized animals have also been negative $e^{7,111,114,115}$.

In conclusion, the idea that behavioral sensitization is due to hypersensitive striatal postsynaptic DA receptors is not supported by most of the available evidence. In fact, much of the evidence suggests the opposite, that is, a small down-regulation of postsynaptic DA receptors in AMPH-pretreated animals. The idea that postsynaptic DA receptors are actually hyposensitive in AMPH-pretreated animals is further supported by a recent electrophysiological experiment by Kamata and Rebec ${ }^{136}$ (see also refs. 8 , 295), who found that the ability of iontophoretically applied DA to inhibit glutamate-induced striatal unit activity was reduced in AMPH-pretreated rats. 
TABLE II

The effect of amphetamine sensitization on striatal dopamine receptor binding

Abbreviations: as in Table I. NC, no change; ADTN, 2-amino-6,7-dihydroxy-1,2,3,4-tetrahydronaphthalene.

\begin{tabular}{|c|c|c|c|c|c|c|c|c|}
\hline Reference & Species & Sex & $A M P H$ & Injection schedule & $\begin{array}{l}\text { Withdrawal } \\
\text { period }\end{array}$ & Ligand & Competitor & $\begin{array}{l}\text { Bind- } \\
\text { ing }\end{array}$ \\
\hline Akiyama et al. ${ }^{6}$ & Rats & $M$ & $\mathbf{M}$ & $4 \mathrm{mk} / \mathrm{d} \times 14 \mathrm{~d}$ & $7 \mathrm{~d} \rightarrow 4 \mathrm{mk}^{2}$ & {$\left[{ }^{3} \mathrm{H}\right]$ spiperone } & spiperone & Down \\
\hline Akiyama et al. ${ }^{5}$ & Rats & $\mathbf{M}$ & $\mathbf{M}$ & $4 \mathrm{mk} / \mathrm{d} \times 14 \mathrm{~d}$ & $7 d$ & {$\left[{ }^{3} \mathrm{H}\right]$ spiperone } & butaclamol & Down \\
\hline Daiguji and Meltzer ${ }^{59}$ & Rats & M & D & $5 \rightarrow 15 \mathrm{mk} 2 / \mathrm{d} \times 20 \mathrm{~d}^{1}$ & $17-20 \mathrm{~h}$ & {$\left[{ }^{3} \mathrm{H}\right]$ spiroperidol } & ADTN & Down \\
\hline Hitzemann et al. ${ }^{111}$ & Rats & $\mathbf{F}$ & D & $6 \mathrm{mk} 2 \times / \mathrm{d} \times 1-4 \mathrm{~d}$ & $16-20 \mathrm{~h}$ & {$\left[{ }^{3} \mathrm{H}\right]$ spiroperidol } & $\begin{array}{l}\text { butaclamol or } \\
\text { sulperide }\end{array}$ & Down \\
\hline Howlett and Nahorski ${ }^{115}$ & Rats & $\mathbf{M}$ & $\mathrm{D}$ & $5 \rightarrow 15 \mathrm{mk} 2 \times / \mathrm{d} \times 20 \mathrm{~d}^{1}$ & $17-20 \mathrm{~h}$ & {$\left[{ }^{3} \mathrm{H}\right]$ spiroperidol } & $\begin{array}{l}\text { butaclamol or } \\
\text { dopamine }\end{array}$ & Down \\
\hline Howlett and Nahorski $i^{114}$ & Rats & $\mathbf{M}$ & $\mathrm{D}$ & $5 \rightarrow 15 \mathrm{mk} 2 \times / \mathrm{d} \times 20 \mathrm{~d}^{\mathrm{l}}$ & $17-20 h$ & {$\left[{ }^{3} \mathrm{H}\right]$ spiperone } & ? & Down \\
\hline Kaneno and Shimazono ${ }^{139}$ & Rats & $\mathbf{M}$ & M & $6 \mathrm{mk} / \mathrm{d} \times 14 \mathrm{~d}$ & $10 d$ & {$\left[{ }^{3} \mathrm{H}\right]$ spiroperidol } & in vivo ${ }^{3}$ & Down \\
\hline Muller and Seeman ${ }^{195}$ & Rats & $\mathbf{M}$ & $?$ & $10 \mathrm{mk} / \mathrm{d} \times 14 \mathrm{~d}$ (oral) & $1 \mathrm{~d}$ & {$\left[{ }^{3} \mathrm{H}\right]$ apomorphine } & apomorphine & Down \\
\hline Riffee et al. ${ }^{235}$ & Mice & M & $\mathrm{D}$ & $4 \mathrm{mk} / \mathrm{d} \times 14 \mathrm{~d}$ & $3 \mathrm{~d}$ & {$\left[{ }^{3} \mathrm{H}\right]$ spiroperidol } & $\begin{array}{l}\text { apomorphine } \\
\text { or butaclamol }\end{array}$ & Down \\
\hline Robertson ${ }^{237}$ & Rats & $\mathbf{M}$ & $\mathrm{D}$ & $5-10 \mathrm{mk} 2 \times / \mathrm{d} \times 21 \mathrm{~d}$ & $1 \mathrm{~d}$ & {$\left[{ }^{3} \mathrm{H}\right]$ spiroperidol } & domperidone & Down \\
\hline Robertson $^{239}$ & Rats & M & $\mathrm{D}$ & $10 \mathrm{mk} 2 \times / \mathrm{d} \times 21 \mathrm{~d}$ & $24-36 h$ & {$\left[{ }^{3} \mathrm{H}\right]$ spiroperidol } & domperidone & Down \\
\hline Akiyama et al. ${ }^{5}$ & Rats & $\mathbf{M}$ & $\mathbf{M}$ & $4 \mathrm{mk} / \mathrm{d} \times 14 \mathrm{~d}$ & $7 \mathrm{~d}$ & {$\left[{ }^{3} \mathrm{H}\right]$ spiperone } & ADTN & $\mathrm{NC}$ \\
\hline Algeri et al. ${ }^{7}$ & Rats & $\mathbf{M}$ & $\mathrm{D}$ & $10 \mathrm{mk} / \mathrm{d} \times 7 \mathrm{~d}$ & $1 \mathrm{~d}$ & {$\left[{ }^{3} \mathrm{H}\right]$ haloperidol } & haloperidol & NC \\
\hline Burt et al. ${ }^{41}$ & Rats & $?$ & $\mathrm{D}$ & $5 \mathrm{mk} / \mathrm{d} \times 3 \mathrm{wk}$ & $5-7 d$ & {$\left[{ }^{3} \mathrm{H}\right]$ haloperidol } & dopamine & $\mathrm{NC}$ \\
\hline Howlett and Nahorski ${ }^{115}$ & Rats & $\mathbf{M}$ & $\mathrm{D}$ & $5 \rightarrow 15 \mathrm{mk} 2 \times / \mathrm{d} \times 4 \mathrm{~d}^{1}$ & $17-20 \mathrm{~h}$ & {$\left[{ }^{3} \mathrm{H}\right]$ spiroperidol } & $\begin{array}{l}\text { butaclamol or } \\
\text { dopamine }\end{array}$ & NC \\
\hline Howlett and Nahorski ${ }^{114}$ & Rats & $\mathbf{M}$ & D & $5 \rightarrow 15 \mathrm{mk} 2 \times / \mathrm{d} \times 4 \mathrm{~d}^{\mathrm{l}}$ & $17-20 \mathrm{~h}$ & {$\left[{ }^{3} \mathrm{H}\right]$ spiperone } & $?$ & NC \\
\hline Jackson et al. ${ }^{121}$ & Rats & $\mathbf{M}$ & D & $5 \mathrm{mk} / \mathrm{d} \times 25 \mathrm{~d}$ & $7 d$ & {$\left[{ }^{3} \mathrm{H}\right]$ spiperone } & butaclamol & $\mathrm{NC}$ \\
\hline Muller and Seeman ${ }^{195}$ & Rats & $\mathbf{M}$ & $?$ & $10 \mathrm{mk} / \mathrm{d} \times 14 \mathrm{~d}$ (oral) & $1 d$ & {$\left[{ }^{3} \mathrm{H}\right]$ haloperidol } & pimozide & NC \\
\hline Owen et al. ${ }^{204}$ & Vervet & $\begin{array}{l}M \\
\text { and } F\end{array}$ & D & $4 \rightarrow 12 \mathrm{mk} / \mathrm{d} \times 35 \mathrm{~d}$ & $1 \mathrm{~d} ?$ & {$\left[{ }^{3} \mathrm{H}\right]$ spiperone } & butaclamol & $\mathrm{NC}$ \\
\hline Riffee et al. ${ }^{235}$ & Mice & $\mathrm{M}$ & $\mathrm{D}$ & $4 \mathrm{mk} / \mathrm{d} \times 14 \mathrm{~d}$ & 1 or $5 d$ & {$\left[{ }^{3} \mathrm{H}\right]$ spiroperidol } & $\begin{array}{l}\text { apomorphine } \\
\text { or butaclamol }\end{array}$ & $\mathrm{NC}$ \\
\hline Borison et al. ${ }^{35}$ & Rats & M & $\mathrm{D}$ & $3.75 \mathrm{mk} / \mathrm{d} \times 5 \mathrm{wk}$ & $5 \mathrm{~d}$ & {$\left[{ }^{3} \mathrm{H}\right]$ dopamine } & butaclamol & Up \\
\hline Klawans et al..$^{154}$ & $\begin{array}{l}\text { Guinea } \\
\text { pigs }\end{array}$ & M & $\mathrm{D}$ & $5 \mathrm{mk} / \mathrm{d} \times 4 \mathrm{wk}$ & $7 d$ & {$\left[{ }^{3} \mathrm{H}\right]$ dopamine } & $\begin{array}{l}\text { apomorphine } \\
\text { or butaclamol }\end{array}$ & Up \\
\hline Robertson ${ }^{239}$ & Rats & $\mathbf{M}$ & $\mathrm{D}$ & $10 \mathrm{mk} 2 \times / \mathrm{d} \times 21 \mathrm{~d}$ & $24-36 \mathrm{~h}$ & {$\left[{ }^{3} \mathrm{H}\right] \mathrm{ADTN}$} & dopamine & $\mathrm{Up}_{\mathrm{p}}$ \\
\hline Robertson ${ }^{238}$ & Rats & M & $\mathrm{D}$ & $5 \mathrm{mk} / \mathrm{d} \times 22 \mathrm{~d}$ & $2 \mathrm{~d}$ & {$\left[{ }^{3} \mathrm{H}\right]$ spiroperidol } & $?$ & $U_{p}$ \\
\hline
\end{tabular}

${ }^{1}$ Also added $25 \rightarrow 75 \mathrm{mg} / \mathrm{ml}$ to drinking water. ${ }^{2}$ Given $4 \mathrm{mg} / \mathrm{kg}$ of AMPH $1 \mathrm{~h}$ before kill. ${ }^{3}$ Cerebellum used to estimate non-specific binding.

Since the weight of the evidence is strongly against the DA postsynaptic receptor supersensitivity hypothesis, it is curious that there are so many studies in which 'cross-sensitization' to APO was found (Table 1). It is not clear what differentiates the studies in which cross-sensitization to APO was found from those in which it was not. The most obvious variables, such as treatment regimen or withdrawal period, do not account for the discrepancies. One hypothesis, that unfortunately is impossible to test posthoc, is that apparent cross-sensitization to APO is actually due to drug-environment conditioning effects. It is known that AMPH can act as an unconditioned stimulus, such that after the repeated pairing of
AMPH with a unique test environment even an injection of saline will produce many of the behaviors previously associated with only AMPH administration (see above for references). It is therefore possible that the enhanced behavioral response to APO that is sometimes observed in AMPH-pretreated animals is due to drug-environment conditioning, and not to an up-regulation of postsynaptic striatal DA receptors.

It should also be noted briefly that there have been no studies of striatal DA receptor binding in animals treated with a relatively conservative AMPH injection regimen (for example, every 4-7 days for a total of 5-10 injections), and then withdrawn for longer than 7 days. Therefore, despite the many studies on 
DA receptor binding shown in Table II, it is not known whether the behavioral sensitization produced by intermittent injections of AMPH is consistently accompanied by a small down-regulation, or any other change in DA binding.

5.3.1.2. Evidence for presynaptic changes. Upon cursory examination the evidence for presynaptic changes in the nigrostriatal DA system of sensitized animals appears to be contradictory and confusing. But much of this confusion is because different AMPH treatment regimens produce different effects on presynaptic indices of DA function. As discussed above, AMPH is neurotoxic if elevated brain concentrations are sustained for very long, either by continuous administration or frequent multiple injections of high doses. AMPH neurotoxicity is manifested by many presynaptic histopathological and neurochemical changes, including degeneration of nigrostriatal DA terminals and striatal DA depletion. However, it will be shown below that robust behavioral sensitization can be produced by a regimen of repeated intermittent AMPH injections that does not result in DA depletion secondary to degeneration of striatal DA Jerminals. Furthermore, behavioral sensitization persists for months following the withdrawal of $\mathrm{AMPH}$, in the absence of damage to nigrostriatal DA neurons. Therefore, to realistically evaluate whether behavioral sensitization is accompanied by changes in presynaptic striatal DA function it is imperative to exclude studies in which the AMPH treatment regimen may have been neurotoxic, and where measures were made without having withdrawn animals from the drug. Otherwise, the neurotoxic effects of AMPH, or the well known presynaptic compensatory responses that occur following partial damage to dopaminergic systems $s^{3.104 .288}$, could easily be mistaken for neural correlates of behavioral sensitization.

It is sometimes difficult to determine from a paper whether the AMPH treatment regimen used was neurotoxic. Some multiple injection regimens may produce a mix of toxic and sensitization effects. To avoid mistaking the neural correlates of behavioral sensitization with those associated with AMPH neurotoxicity, studies were excluded from the following analysis if: (1) AMPH was given more than two times per day; (2) animals were withdrawn from AMPH for less than one day; or (3) there was clear evidence of AMPH neurotoxicity (as indicated by the use of high doses of AMPH with accompanying DA depletion). Studies on the effects of chronic AMPH administration that were excluded on the basis of these criteria include refs.: $90,91,113,142,155,194,231$, 269 , and others discussed above in regard to AMPH neurotoxicity. There is considerably more consensus as to the nature of presynaptic changes accompanying behavioral sensitization when only those studies relevant to the phenomenon of behavioral sensitization are examined.

The following review includes experiments in which presynaptic DA function was estimated by either: (1) measures of DA concentrations; (2) measures of DA synthesis; and/or (3) measures of DA utilization or release. Each of these will be discussed in turn. These measures were obtained under either steady-state (resting) conditions, or following an additional 'challenge' injection of AMPH, and this is also noted.

(1) DA concentrations. Table III lists studies in which striatal DA concentrations were measured in animals sensitized to AMPH. It is clear from Table III that AMPH pretreatment can produce robust behavioral sensitization without causing a reduction in the steady-state concentrations of striatal DA (e.g. refs. 43, 167, 202 and unpublished studies by the authors). Following a challenge injection of AMPH, pretreated animals sometimes show a slightly greater decline in striatal DA concentrations than control animals ${ }^{202}$; but this is not always found ${ }^{167}$. Two studies in which whole brain concentrations of DA were measured are also included in Table III, because striatal DA would comprise the largest fraction of whole brain DA. Again, AMPH pretreatment had no effect on the whole brain concentrations of DA.

On the basis of the studies listed in Table III we would argue that a long-lasting depletion of DA in AMPH pretreated animals, over-and-above the transient changes that might occur following enhanced DA release (e.g. ref. 202), is prima facie evidence for AMPH neurotoxicity.

(2) DA synthesis. Table IV lists studies in which striatal (or whole brain) DA synthesis was estimated in AMPH-pretreated and control animals. The most consistent finding is that AMPH sensitization is not accompanied by changes in striatal DA synthesis under steady-state conditions, or following a subse- 
TABLE III

The effect of amphetamine sensitization on striatal dopamine concentrations'

Abbreviations: as in previous Tables.

\begin{tabular}{|c|c|c|c|}
\hline Reference & Injection schedule & Withdrawal period & Effect \\
\hline \multicolumn{4}{|l|}{ A. Steady-state (resting) conditions } \\
\hline Alloway and Rebec ${ }^{9}$ & $1 \mathrm{mk} 2 \times / \mathrm{d} \times 6 \mathrm{~d}$ & $1 \mathrm{~d}$ & NC \\
\hline Alloway and Rebec ${ }^{9}$ & $5 \mathrm{mk} 2 \times / \mathrm{d} \times 6 \mathrm{~d}$ & $1 \mathrm{~d}$ & Down \\
\hline Camp and Robinson ${ }^{43}$ & $2-3 \mathrm{mk} / 4 \mathrm{~d} \times 10 \mathrm{inj}$ & $8-13 d$ & $\mathrm{NC}$ \\
\hline Eichler et al. ${ }^{69}$ & $2-12 \mathrm{mk} / \mathrm{d} \times 65 \mathrm{~d}$ & $1 \mathrm{~d}$ & NC \\
\hline Jackson et al. ${ }^{121}$ & $5 \mathrm{mk} / \mathrm{d} \times 25 \mathrm{~d}$ & $7 \mathrm{~d}$ & NC \\
\hline Kuczenski and Leith ${ }^{167}$ & $3 \mathrm{mk} / \mathrm{d} \times 6 \mathrm{~d}$ & $2 \mathrm{~d}$ & NC \\
\hline Lynch et al. ${ }^{183}$ & $0.5 \rightarrow 2 \mathrm{mk} / \mathrm{d} \times 14 \mathrm{~d}$ & $36 \mathrm{~h}-7 \mathrm{~d}$ & NC \\
\hline Nishikawa et al. ${ }^{202}$ & $6 \mathrm{mk} / \mathrm{d} \times 14 \mathrm{~d}$ & $15 \mathrm{~d}$ & NC \\
\hline Pearl and Seiden ${ }^{205}$ (note 2) & $2.5 \mathrm{mk} / \mathrm{d} \times 60 \mathrm{~d}$ & $28 \mathrm{~h}$ & NC \\
\hline Pearl and Seiden ${ }^{206}$ (note 2) & $2.5 \mathrm{mk} / \mathrm{d} \times 60 \mathrm{~d}$ & $28 \mathrm{~h}$ & NC \\
\hline Riffee and Gerald ${ }^{233}$ (note 2) & $2.5 \mathrm{mk} / \mathrm{d} \times 7 \mathrm{~d}$ & $1-2 d$ & NC \\
\hline \multicolumn{4}{|l|}{ B. After challenge ${ }^{3}$} \\
\hline Kuczenski and Leith ${ }^{167}$ & $3 \mathrm{mk} / \mathrm{d} \times 6 \mathrm{~d}$ & $2 d$ & $\mathrm{NC}$ \\
\hline Nishikawa et al. ${ }^{202}$ & $6 \mathrm{mk} / \mathrm{d} \times 14 \mathrm{~d}$ & $15 \mathrm{~d}$ & Down \\
\hline
\end{tabular}

${ }^{1}$ Excludes studies in which: (a) AMPH was given more than two times per day; (b) animals were withdrawn for less than 1 day; (c) very high doses of AMPH were used (see text for rationale). ${ }^{2}$ Whole brain. ${ }^{3}$ After a subsequent challenge injection of AMPH.

quent challenge injection of $\mathrm{AMPH}^{34,167,202}$. None of the studies in which whole brain ${ }^{206.233 .273}$ or forebrain ${ }^{118}$ DA synthesis was estimated report any effect of prior AMPH treatment (Table IV). Besson et al. ${ }^{34}$ did report a small decline in the formation of $\left[{ }^{3} \mathrm{H}\right]$ DOPA in AMPH-pretreated rats, but the same paper reports no change in tyrosine hydroxylase ac- tivity. Although Algeri et al. ${ }^{7}$ and Taylor and $\mathrm{Ho}^{290}$ found a decline in tyrosine hydroxylase activity in AMPH-pretreated animals, it should be noted that they used a very large dose of AMPH $(10 \mathrm{mg} / \mathrm{kg})$ and withdrew animals for only one day. It is unlikely that this latter effect is related to behavioral sensitization, but may be due to AMPH neurotoxicity. The only re-

\section{TABLE IV}

The effect of amphetamine sensitization on striatal dopamine synthesis

Abbreviations: as in previous Tables.

\begin{tabular}{|c|c|c|c|c|}
\hline Reference & Injection schedule & $\begin{array}{l}\text { Withdrawal } \\
\text { period }\end{array}$ & Measure & Effect \\
\hline \multicolumn{5}{|l|}{ A. Steady state (resting) conditions } \\
\hline Algeri et al. ${ }^{7}$ & $10 \mathrm{mk} / \mathrm{d} \times 7 \mathrm{~d}$ & $1 d$ & Tyrosine hydroxylase & Down \\
\hline Besson et al. ${ }^{34}$ & $1 \mathrm{mk} / \mathrm{d} \times 8 \mathrm{~d}$ & $1 \mathrm{~d}$ & Tyrosine hydroxylase & $\mathrm{NC}$ \\
\hline Besson et al. ${ }^{34}$ & $1 \mathrm{mk} / \mathrm{d} \times 8 \mathrm{~d}$ & $1 \mathrm{~d}$ & {$\left[{ }^{3} \mathrm{H}\right]$ DOPA formation } & Down \\
\hline Hulme et al. ${ }^{118}$ (note 1 ) & $11.7 \mathrm{mk} / \mathrm{d} \times 3-7 \mathrm{~d}$ & $?$ & Tyrosine hydroxylase & $\mathrm{NC}$ \\
\hline Kuczenski and Leith ${ }^{167}$ & $3 \mathrm{mk} / \mathrm{d} \times 6 \mathrm{~d}$ & $2 d$ & {$\left[{ }^{3} \mathrm{H}\right]$ Tyrosine $\rightarrow\left[{ }^{3} \mathrm{H}\right] \mathrm{DA}$} & Up \\
\hline Nishikawa et al. ${ }^{202}$ & $6 \mathrm{mk} / \mathrm{d} \times 14 \mathrm{~d}$ & $15 d$ & Tyrosine hydroxylase & NC \\
\hline Pearl and Seiden ${ }^{206}$ (note 1) & $2.5 \mathrm{mk} / \mathrm{d} \times 60 \mathrm{~d}$ & $28 \mathrm{~h}$ & DOPA accumulation & NC \\
\hline Riffee and Gerald ${ }^{233}$ (note 1 ) & $2.5 \mathrm{mk} / \mathrm{d} \times 7 \mathrm{~d}$ & $2 \mathrm{~d}$ & {$\left[{ }^{3} \mathrm{H}\right]$ Tyrosine $\rightarrow\left[{ }^{3} \mathrm{H}\right] \mathrm{DA}$} & $\mathrm{NC}$ \\
\hline Taylor and $\mathbf{H o}^{290}$ & $10 \mathrm{mk} / \mathrm{d} \times 5 \mathrm{~d}$ & $1 \mathrm{~d}$ & Tyrosine hydroxylase & Down \\
\hline \multicolumn{5}{|l|}{ B. After challenge } \\
\hline Kuczenski and Leith ${ }^{167}$ & $1 \rightarrow 12 \mathrm{mk} 3 \times / \mathrm{d} \times 4 \mathrm{~d}$ & $2 \mathrm{~d}$ & {$\left[{ }^{3} \mathrm{H}\right]$ Tyrosine $\rightarrow\left[{ }^{3} \mathrm{H}\right] \mathrm{DA}$} & NC \\
\hline Nishikawa et al. ${ }^{202}$ & $6 \mathrm{mk} / \mathrm{d} \times 14 \mathrm{~d}$ & $15 \mathrm{~d}$ & Tyrosine hydroxylase & NC \\
\hline Short and Shuster ${ }^{273}$ (note 1) & $10 \mathrm{mk} 2 \times / \mathrm{d} \times 5 \mathrm{~d}$ & $3-25 d$ & Tyrosine hydroxylase & NC \\
\hline
\end{tabular}

\footnotetext{
${ }^{1}$ Whole brain or forebrain.
} 
port of an increase in striatal DA synthesis following AMPH-pretreatment is by Kuczenski and Leith ${ }^{167}$. They found a small (11-18\%) enhancement in the conversion of $\left[{ }^{3} \mathrm{H}\right]$ tyrosine to $\left[{ }^{3} \mathrm{H}\right]$ dopamine in AMPH-pretreated rats. However, they also point out that the effect is not strong because, 'a statistically significant increase is only observed when the number of animals is large' (p. 407). It would be informative to know if this effect persists for longer than the two-day withdrawal period used by Kuczenski and Leith $^{167}$. In contrast, Kuczenski and Leith ${ }^{167}$ did not find that AMPH-pretreatment enhanced DA synthesis following a subsequent challenge injection of AMPH (Table IV).

(3) DA utilization/release. Table $\mathrm{V}$ lists studies in which the concentration of DA metabolites and/or the metabolite to transmitter ratios were used to estimate DA utilization. Dihydroxyphenylacetic acid (DOPAC) concentrations are thought to provide a good estimate of DA utilization/release because it is mostly formed from DA after re-uptake into the presynaptic terminal ${ }^{162.174,187,246}$ (but see ref. 47). Table $\mathrm{V}$ also includes experiments in which the decline in DA concentrations following inhibition of tyrosine hydroxylase was used to estimate DA utilization ${ }^{38}$. It should be noted that both of these measures of DA 'turnover' are sensitive to changes in release.

It is clear from Table $V$ that there is little evidence for a change in striatal DA utilization in AMPH-sensitized animals when they are tested under steadystate conditions ${ }^{167,183,191,202,243}$. In addition, sensitization does not alter the basal rate of endogenous DA efflux from striatal tissue in vitro ${ }^{161,242,244}$, although the physiological significance of basal DA efflux in vitro is questionable because it is both temperatureand calcium-independent ${ }^{29}$. In contrast to these negative findings, Camp and Robinson ${ }^{43}$ recently found significantly higher striatal DOPAC to DA ratios in AMPH-pretreated than in control rats, suggesting enhanced DA release. However, this was only in $f e$ -

\section{TABLE V}

The effect of amphetamine sensitization on striatal dopamine utilization/release

Abbreviations: as in previous Tables. DOPAC, dihydroxyphenylacetic acid; HVA, homovanillic acid; MPT, alpha-methyl-p-tyrosine.

\begin{tabular}{|c|c|c|c|c|}
\hline Reference & Injection schedule & $\begin{array}{l}\text { Withdrawal } \\
\text { period }\end{array}$ & Measure & Effect \\
\hline \multicolumn{5}{|l|}{ A. Steady-state (resting) conditions } \\
\hline Camp and Robinson $(\mathrm{M})^{43}$ & $3 \mathrm{mk} / 4 \mathrm{~d} \times 10$ inj & $8-13 d$ & DOPAC/DA & $\mathrm{NC}$ \\
\hline Camp and Robinson $(F)^{43}$ & $2.6 \mathrm{mk} / 4 \mathrm{~d} \times 10 \mathrm{inj}$ & $8-13 d$ & DOPAC/DA & Up \\
\hline Jackson et al ${ }^{121}$ (note 1 ) & $5 \mathrm{mk} / \mathrm{d} \times 25 \mathrm{~d}$ & $7 d$ & Decline in DA after MPT & $\mathrm{NC}$ \\
\hline Kolta et al. ${ }^{161}$ & $5 \mathrm{mk} 2 \times / \mathrm{d} \times 5 \mathrm{~d}$ & $3-30 d$ & Endogenous DA release & $\mathrm{NC}$ \\
\hline Kuczenski and Leith ${ }^{167}$ & $3 \mathrm{mk} / \mathrm{d} \times 6 \mathrm{~d}$ & $2 d$ & DOPAC; HVA & $\mathrm{NC}$ \\
\hline Lynch et al. ${ }^{183}$ & $0.5 \rightarrow 2 \mathrm{mk} / \mathrm{d} \times 14 \mathrm{~d}$ & $7 \mathrm{~d}$ & DOPAC & $\mathrm{NC}$ \\
\hline Lynch et al. ${ }^{183}$ & $0.5 \rightarrow 2 \mathrm{mk} / \mathrm{d} \times 14 \mathrm{~d}$ & $12-48 \mathrm{~h}$ & DOPAC & Down \\
\hline Mittleman et al. ${ }^{191}$ & $3 \mathrm{mk} / 3 \mathrm{~d} \times 9 \mathrm{inj}$ & $1-2 \mathrm{mo}$ & DOPAC/DA & $\mathrm{NC}$ \\
\hline Nishikawa et al. ${ }^{202}$ & $6 \mathrm{mk} / \mathrm{d} \times 14 \mathrm{~d}$ & $15 \mathrm{~d}$ & DOPAC; HVA; DOPAC/DA & $\mathrm{NC}$ \\
\hline Robinson and Becker ${ }^{242}$ & $5 \mathrm{mk} 2 \times / \mathrm{d} \times 5 \mathrm{~d}$ & $10 \mathrm{~d}$ & Endogenous DA release & $\mathrm{NC}$ \\
\hline Robinson et al. ${ }^{244}$ & $1.25 \mathrm{mk}$ once & $3-5$ wk & Endogenous DA release & $\mathrm{NC}$ \\
\hline Robinson et al. ${ }^{243}$ & $3 \mathrm{mk} / \mathrm{d} \times 7 \mathrm{~d}$ & $8 \mathrm{~d}$ & Decline in DA after MPT & NC \\
\hline Robinson et al. ${ }^{243}$ & $3 \mathrm{mk} / 3-4 \mathrm{~d} \times 9 \mathrm{inj}$ & $10 \mathrm{~d}$ & Decline in DA after MPT & NC \\
\hline \multicolumn{5}{|l|}{ B. After challenge } \\
\hline Jori and Bernardi ${ }^{127}$ & $5 \mathrm{mk} / \mathrm{d} \times 4-10 \mathrm{~d}($ mice $)$ & $1 \mathrm{~d}$ & Elevation in HVA & NC \\
\hline \multirow[t]{2}{*}{ Jori and Bernardi ${ }^{127}$} & $5 \mathrm{mk} / \mathrm{d} \times 4 \mathrm{~d}$ (rats) & $1 \mathrm{~d}$ & Elevation in HVA & Down \\
\hline & $5 \mathrm{mk} / \mathrm{d} \times 10 \mathrm{~d}(\mathrm{rats})$ & $1 \mathrm{~d}$ & Elevation in HVA & NC \\
\hline Kolta et al. ${ }^{161}$ & $5 \mathrm{mk} 2 \times / \mathrm{d} \times 5 \mathrm{~d}$ & $3 \mathrm{~d}$ & Endogenous DA release & NC \\
\hline Kolta et al. ${ }^{161}$ & $5 \mathrm{mk} 2 \times / \mathrm{d} \times 5 \mathrm{~d}$ & $15-30 d$ & Endogenous DA release & Up \\
\hline Kuczenski and Leith ${ }^{167}$ & $3 \mathrm{mk} / \mathrm{d} \times 6 \mathrm{~d}$ & $2 \mathrm{~d}$ & Decline in DOPAC and HVA & Up \\
\hline Nishikawa et al. ${ }^{202}$ & $6 \mathrm{mk} / \mathrm{d} \times 14 \mathrm{~d}$ & $15 \mathrm{~d}$ & DOPAC/DA & Up \\
\hline Robinson and Becker ${ }^{242}$ & $5 \mathrm{mk} 2 \times / \mathrm{d} \times 5 \mathrm{~d}$ & $10 d$ & Endogenous DA release & $U_{p}$ \\
\hline Robinson et al.244 & $1.25 \mathrm{mk}$ once & $3-5$ wk & Endogenous DA release & $U_{p}$ \\
\hline Robinson and Becker (note 2) & $3 \mathrm{mk} / 3-4 \mathrm{~d} \times 10$ inj & $10 \mathrm{~d}$ & DOPAC; HVA & $\mathrm{Up}_{\mathrm{p}}$ \\
\hline
\end{tabular}

' Whole brain minus cerebellum; ${ }^{2}$ Unpublished observations - footshock stress challenge. 
male, but not male rats (Table V). Studies in which male rats were used report no effect of AMPH-pretreatment on steady-state (resting) DA utilization $^{167,191,202}$. This sex difference may be related to the sex difference in behavioral sensitization ${ }^{43,240,244}$. Perhaps because female rats show more robust behavioral sensitization than males, the neural correlates of behavioral sensitization will be more apparent in females. On the other hand, AMPH-pretreated female rats did not show a greater decline in striatal DA following tyrosine hydroxylase inhibition than control female rats ${ }^{243}$. It is not clear what accounts for the difference between the two methods for estimating DA utilization. Perhaps the effect is small and the former method is more sensitive to the neural consequences of repeated intermittent AMPH administration than the latter. Also, in the Robinson et al ${ }^{243}$ study only one point in time was sampled after tyrosine hydroxylase inhibition, and a more complete analysis of the rate of decline of DA is required to more accurately estimate DA utilization, especially given the low rate of striatal DA turnover.

In contrast with the paucity of evidence for changes in DA utilization/release under steady-state conditions, there are a number of reports of enhanced striatal DA utilization/release in AMPH-pretreated animals given a subsequent challenge injection of AMPH (Table V). Robinson and Becker ${ }^{242}$ first reported that repeated intermittent injections of AMPH in vivo produce an enduring enhancement (at least 10 days) in the AMPH-stimulated release of endogenous striatal DA in vitro, and more recent studies suggest this effect persists for at least 30 days following the last AMPH treatment ${ }^{161,244}$. In addition, Robinson et al..$^{244}$ found that even a single injection of $1.25 \mathrm{mg} / \mathrm{kg}$ of AMPH enhanced the AMPH-stimulated release of striatal DA measured in vitro 3-5 weeks later. An enhancement in AMPH-stimulated striatal DA release in sensitized rats has now been obtained in 5 different studies conducted in two different labs ${ }^{45,161,242,244}$, and therefore it would appear to be a robust phenomenon.

The effects of AMPH sensitization on DA release in vitro are consistent with a number of in vivo studies (Table V). Nishikawa et al. ${ }^{202}$ reported that the elevation of DOPAC to DA ratios produced by a challenge injection of meth-AMPH was enhanced following meth-AMPH pretreatment, suggesting that
AMPH stimulated more DA release in sensitized than in control animals. Furthermore, Kuczenski and Leith ${ }^{167}$ found that a challenge injection of AMPH was more effective in decreasing DA metabolite levels in AMPH-pretreated than in control rats; an effect that could be due to a leftward shift in the AMPH dose-response curve. In contrast, Jori and Bernar$\mathrm{di}^{127}$ found that AMPH pretreatment did not alter the effect of a challenge injection of AMPH on HVA concentrations. However, this could be because Jori and Bernardi ${ }^{127}$ withdrew animals from AMPH for only one day, and there is evidence to suggest that more robust behavioral sensitization results if animals are withdrawn for more than one day ${ }^{16,112,161}$. Considering the tendency of behavioral sensitization to 'grow' over time following the withdrawal of $\mathrm{AMPH}^{16,17,161}$, it is important to note that Kolta et al. ${ }^{161}$ found that AMPH-stimulated striatal DA release was not significantly enhanced 3 days after the last AMPH treatment, but was enhanced 15 and 30 days later. This latter finding underscores the importance of withdrawing animals from AMPH for a few days in studies concerned with the biological basis of behavioral sensitization.

In conclusion, there is strong evidence that the behavioral sensitization produced by the repeated intermittent administration of AMPH is accompanied by an enduring enhancement in the release of striatal DA produced by re-exposure to AMPH (Table V). (It should be noted that a neurotoxic regimen of meth-AMPH administration does not enhance DA release, but may actually decrease meth-AMPH stimulated DA release ${ }^{255}$.)

As an aside, there is an interesting difference between the reports of Kuczenski and Leith ${ }^{167}$ and $\mathrm{Ni}$ shikawa et al. ${ }^{202}$ which deserves comment. Kuczenski and Leith ${ }^{167}$ found that an acute injection of D-AMPH decreased striatal DA metabolite concentrations, but Nishikawa et al. ${ }^{202}$ reported that an acute injection of meth-AMPH increased DOPAC levels in AMPH-pretreated rats. The former effect would be expected if D-AMPH also blocked DA reuptake into presynaptic terminals, thus reducing DOPAC (and HVA) formation ${ }^{166}$. The latter effect would be expected as a consequence of enhanced DA release, but only if meth-AMPH did not prevent the re-uptake of DA into presynaptic terminals and its conversion into DOPAC. Perhaps meth-AMPH is 
not as potent a re-uptake blocker as D-AMPH, and therefore DOPAC formation is enhanced following meth-AMPH, but decreased by D-AMPH. Unfortunately, we know of no direct comparison between the re-uptake blocking vs release enhancing properties of meth-AMPH and D-AMPH (e.g. ref. 89 and R.M. Ferris and K.E. Moore, personal communication).

Because behavioral sensitization is accompanied by an enduring enhancement in the utilization/release of striatal DA produced by re-exposure to AMPH, it seems reasonable to hypothesize that presynaptic changes in striatal DA neurons are at least partially responsible for the behavioral phenomenon. Of course, this would not exclude changes in other neural systems as well. But before reviewing evidence for changes in other neural systems, ideas concerning the cellular basis of enhanced striatal DA release in sensitized animals will be discussed. In doing so, it should be kept in mind that hypotheses regarding the nature of the cellular change(s) responsible for enhanced DA release are constrained by evidence that it occurs in the absence of changes in striatal DA concentrations (at least under steadystate conditions; Tables III, IV).

5.3.1.3. Dopamine autoreceptor subsensitivity. One hypothesis is that the repeated exposure to abnormally high concentrations of DA produced by repeated AMPH administration causes DA autoreceptors to become subsensitive $e^{16,26,186,195,259}$. It is thought that autoreceptors on the presynaptic terminals, cell body and/or dendrites of DA neurons control DA synthesis, release and the discharge rate of the cell via negative feedback ${ }^{86,314}$. Subsensitivity of these autoreceptors would result in a reduction in this negative feedback and enhanced DA release. In support of this hypothesis, Muller and Seeman ${ }^{195}$ reported that repeated AMPH administration produced a decrease in $\left[{ }^{3} \mathrm{H}\right]$ apomorphine binding, but no change in $\left[{ }^{3} \mathrm{H}\right]$ haloperidol binding (Table II). They argued that the low concentrations of $\left[{ }^{3} \mathrm{H}\right]$ apomorphine used in their study reflected presynaptic DA receptor numbers. There is some question about this conclusion, however, for as White and Wang ${ }^{317}$ pointed out, $\left[{ }^{3} \mathrm{H}\right]$ apomorphine may not selectively label DA autoreceptors ${ }^{175,261}$. Nevertheless, the most consistent finding from striatal DA receptor binding studies is that repeated AMPH administration produces a small down-regulation (or no change) of DA recep- tors (Table II). It is possible this reflects a change in presynaptic DA receptors.

Much of the evidence for DA autoreceptor subsensitivity in sensitized animals comes from electrophysiological studies. These are summarized in Table VI. The firing rate of most mesencephalic DA neurons is decreased by the systemic application of either AMPH or APO, and this is thought to reflect negative feedback mediated by DA autoreceptors ${ }^{222}$. In animals previously exposed to repeated intermittent injections of AMPH, both AMPH and APO are less effective than normal in reducing the discharge rate of dopaminergic cells in the substantia nigra, zona compacta $\left(\mathrm{SNC}^{16,133,134}\right.$ ) and ventral tegmental area $\left(\right.$ VTA $\left.^{135,317}\right)$. In fact, the firing rate of some DA cells is actually enhanced by AMPH or APO in AMPHsensitized rats, an effect never seen in control animals ${ }^{16,133}$. Furthermore, the spontaneous firing rate of SNC and VTA units is increased ${ }^{134,317}$ (although see also refs. 133, 134, 135 and Table VI), and the ability of iontophoretically applied DA to inhibit VTA unit discharge decreased in AMPH-sensitized rats $^{317}$. These effects could be due to subsensitive DA autoreceptors. The experiment with iontophoretically applied $\mathrm{DA}^{317}$ suggests that DA autoreceptors located on the cell bodies and/or dendrites of VTA cells are hyposensitive in sensitized animals. In contrast, the sensitivity of nigral zona reticulata neurons to AMPH is increased following repeated AMPH administration ${ }^{137}$, as is the sensitivity of SNC neurons to APO following a neurotoxic regimen of AMPH administration ${ }^{78}$.

Although electrophysiological studies have supported the DA autoreceptor subsensitivity hypothesis, biochemical/pharmacological studies designed to test the same hypothesis have not (Table VI). One biochemical approach has been to study the ability of low doses of APO to reduce the formation of the DA metabolites, DOPAC and HVA, an effect thought to be due to the selective stimulation of DA autoreceptors ${ }^{49.168}$. However, the repeated intermittent administration of AMPH does not alter the ability of APO to reduce striatal DA metabolite levels, as would be expected if DA autoreceptors were subsensitive ${ }^{49.168}$. A second approach has been to measure the ability of APO to inhibit DA synthesis stimulated by gamma-butyrolactone, which is also thought to be due to the action of APO at DA autoreceptors. But 
this is not altered in sensitized animals either ${ }^{49}$. A third approach involves behavioral estimates of DA autoreceptor sensitivity. These have produced mixed support for the subsensitive autoreceptor hypothesis. At very low doses APO produces a decrease in locomotion, presumably because DA autoreceptors are selectively stimulated and this reduces DA release. If DA autoreceptors were subsensitive in AMPH-pretreated animals, low doses of APO should be less effective in reducing locomotion, as reported by Antelman and Chiodo ${ }^{17}$. However, using a very similar paradigm, Conway and Uretsky ${ }^{49}$ found no evidence for DA autoreceptor subsensitivity in AMPH-pretreated animals (Table VI). Furthermore, Riffee and
Wilcox ${ }^{234}$ reported that sensitization to AMPH does not alter the ability of APO to inhibit the locomotion produced by challenge injection of AMPH in mice (also R.E. Wilcox, personal communication).

It is not clear why the electrophysiological and biochemical estimates of DA autoreceptor sensitivity are so discrepant. Perhaps one should disregard the biochemical/pharmacological studies for the moment and ask how well the available electrophysiological evidence accounts for behavioral sensitization. The answer is, not that well; as illustrated in the following examples. One problem is raised by the studies of Kamata and Rebec ${ }^{133,134}$, who pretreated rats with either 1 or $5 \mathrm{mg} / \mathrm{kg}$ of D-AMPH two times a day for 6

\section{TABLE VI}

Evidence relevant to the dopamine autoreceptor subsensitivity hypothesis

Abbreviations: as in previous Tables. SNC, substantia nigra, zona compacta; VTA, ventral tegmental area; GBL, gamma-butyrolactone; Up, some cells showed an increase.

\begin{tabular}{|c|c|c|c|c|c|}
\hline Measure & $\begin{array}{l}\text { Challenge } \\
\text { drug }\end{array}$ & Injection schedule & $\begin{array}{l}\text { Wilhdrawal } \\
\text { period }\end{array}$ & Effect & Reference \\
\hline \multicolumn{6}{|l|}{ A. Electrophysiological evidence } \\
\hline \multirow{7}{*}{$\begin{array}{l}\text { 1. Ability of AMPH or APO to } \\
\text { inhibit SNC unit discharge }\end{array}$} & APO & $4 \mathrm{mk} / \mathrm{d} \times 6-15 \mathrm{~d}$ & $2-11 \mathrm{~d}$ & Down & Antelman and Chiodo ${ }^{16}$ \\
\hline & APO & $5 \mathrm{mk} 2 \times / \mathrm{d} \times 6 \mathrm{~d}$ & $1 \mathrm{~d}$ & Down & Kamata and Rebec ${ }^{134}$ \\
\hline & AMPH & $5 \mathrm{mk} 2 \times / \mathrm{d} \times 6 \mathrm{~d}$ & $1 \mathrm{~d}$ & Down & Kamata and Rebec ${ }^{133}$ \\
\hline & APO & $4 \mathrm{mk}$ once & $7-16 d$ & $\mathrm{NC}$ & Antelman and Chiodo ${ }^{16}$ \\
\hline & APO & $1 \mathrm{mk} 2 \times / \mathrm{d} \times 6 \mathrm{~d}$ & $1 \mathrm{~d}$ & $\mathrm{NC}$ & Kamata and Rebec ${ }^{134}$ \\
\hline & AMPH & $2.5-5 \mathrm{mk} 2 \times / \mathrm{d} \times 8-16 \mathrm{~d}$ & $1 \mathrm{~d}$ & $\mathrm{NC}$ & Staunton et al. ${ }^{283}$ \\
\hline & AMPH & $1 \mathrm{mk} 2 \times / \mathrm{d} \times 6 \mathrm{~d}$ & $1 \mathrm{~d}$ & Up & Kamata and Rebec ${ }^{133}$ \\
\hline \multirow{4}{*}{$\begin{array}{l}\text { 2. Change in spontaneous discharge } \\
\text { rate of SNC cells }\end{array}$} & - & $5 \mathrm{mk} 2 \times / \mathrm{d} \times 6 \mathrm{~d}$ & $1 \mathrm{~d}$ & Up & Kamata and Rebec ${ }^{134}$ \\
\hline & - & $1 \mathrm{mk} 2 \times / \mathrm{d} \times 6 \mathrm{~d}$ & $1 \mathrm{~d}$ & NC & Kamata and Rebec ${ }^{134}$ \\
\hline & - & $1-5 \mathrm{mk} 2 \times / \mathrm{d} \times 6 \mathrm{~d}$ & $1 \mathrm{~d}$ & NC & Kamata and Rebec ${ }^{133}$ \\
\hline & - & $1.5-5 \mathrm{mk} 2 \times / \mathrm{d} \times 8-16 \mathrm{~d}$ & $1 \mathrm{~d}$ & NC & Staunton et al. ${ }^{283}$ \\
\hline \multirow{5}{*}{$\begin{array}{l}\text { 3. Ability of AMPH or APO to } \\
\text { inhibit VTA unit discharge }\end{array}$} & $A M P H$ and $A P O$ & $1-5 \mathrm{mk} 2 \times / \mathrm{d} \times 6 \mathrm{~d}$ & $1 \mathrm{~d}$ & Down & Kamata and Rebec ${ }^{135}$ \\
\hline & AMPH and APO & $5 \mathrm{mk} 1$ or $2 \times / \mathrm{d} \times 7 \mathrm{~d}$ & $1 \mathrm{~d}$ & Down & White and Wang ${ }^{317}$ \\
\hline & $\mathrm{AMPH}$ and $\mathrm{APO}$ & $5 \mathrm{mk} 2 \times / \mathrm{d} \times 7 \mathrm{~d}$ & $8 \mathrm{~d}$ & Down & White and Wang ${ }^{317}$ \\
\hline & AMPH and APO & $5 \mathrm{mk} / \mathrm{d} \times 7 \mathrm{~d}$ & $8 d$ & $\mathrm{NC}$ & White and Wang ${ }^{317}$ \\
\hline & $A M P H$ and $A P O$ & $5 \mathrm{mk}$ once & $1 \mathrm{~d}$ & $\mathrm{NC}$ & White and Wang ${ }^{317}$ \\
\hline \multirow{2}{*}{$\begin{array}{l}\text { 4. Change in spontaneous discharge } \\
\text { rate of VTA cells }\end{array}$} & - & $5 \mathrm{mk} 2 \times / \mathrm{d} \times 7 \mathrm{~d}$ & $1 \mathrm{~d}$ & Up & White and Wang ${ }^{317}$ \\
\hline & - & $1-5 \mathrm{mk} 2 \times / \mathrm{d} \times 6 \mathrm{~d}$ & $1 \mathrm{~d}$ & $\mathrm{NC}$ & Kamata and Rebec ${ }^{135}$ \\
\hline $\begin{array}{l}\text { 5. Ability of iontophoretic DA to } \\
\text { inhibit VTA unit discharge }\end{array}$ & DA & $5 \mathrm{mk} 2 \times / \mathrm{d} \times 7 \mathrm{~d}$ & $1 \mathrm{~d}$ & Down & White and Wang ${ }^{317}$ \\
\hline \multicolumn{6}{|l|}{ B. Biochemical/pharmacological evidence } \\
\hline \multirow{4}{*}{$\begin{array}{l}\text { 1. Ability of APO to reduce striatal } \\
\text { metabolite levels } \\
\text { 2. Ability of APO to inhibit GBL- }\end{array}$} & APO & $5 \mathrm{mk} 2 \times / \mathrm{d} \times 5 \mathrm{~d}$ & $3 \mathrm{~d}$ & $\mathrm{NC}$ & Conway and Uretsky ${ }^{49}$ \\
\hline & APO & $3 \mathrm{mk} / \mathrm{d} \times 6 \mathrm{~d}$ & $2 d$ & NC & Kuczenski et al. ${ }^{168}$ \\
\hline & & & & & \\
\hline & APO & $5 \mathrm{mk} 2 \times / \mathrm{d} \times 5 \mathrm{~d}$ & $3 d$ & $\mathrm{NC}$ & Conway and Uretsky ${ }^{49}$ \\
\hline \multicolumn{6}{|l|}{$\begin{array}{l}\text { 3. Ability of a low dose of APO } \\
\text { to decrease: }\end{array}$} \\
\hline \multirow[t]{3}{*}{ - locomotion } & & $6 \mathrm{mk} / \mathrm{d} \times 6 \mathrm{~d}$ & $2-11 d$ & Down & Antelman and Chiodo ${ }^{17}$ \\
\hline & & $5 \mathrm{mk} 2 \times / \mathrm{d} \times 5 \mathrm{~d}$ & $3-10 d$ & NC & Conway and Uretsky ${ }^{49}$ \\
\hline & & $5 \mathrm{mk} 2 \times / \mathrm{d} \times 5 \mathrm{~d}$ & $3 d$ & $\mathrm{NC}$ & Riffee and Wilcox ${ }^{234}$ \\
\hline - rotation & & $3 \mathrm{mk} / \mathrm{d} \times 5 \mathrm{~d}$ & $7 d$ & $\mathrm{NC}$ & Robinson $^{240}$ \\
\hline
\end{tabular}


days, and then tested them after one day of withdrawal (Table VI). Pretreatment with either 1 or 5 $\mathrm{mg} / \mathrm{kg}$ of AMPH produces behavioral sensitization. However, when subsequently challenged with APO, only those animals pretreated with the $5 \mathrm{mg} / \mathrm{kg}$ dose of AMPH showed evidence of DA autoreceptor subsensitivity ${ }^{134}$. In animals pretreated with $1 \mathrm{mg} / \mathrm{kg}$ there was actually a significant increase in the ability of AMPH to inhibit SNC unit discharge ${ }^{133}$ (Table VI). This latter effect is opposite to that predicted by the DA autoreceptor subsensitivity hypothesis.

A second problem with the electrophysiological studies concerns their ability to account for the persistence of behavioral sensitization. Animals remain hypersensitive to the motor stimulant effects of AMPH for months after the cessation of treatment ${ }^{185.240}$. As mentioned above, there is even evidence to suggest that for some period of time following withdrawal from AMPH there is a progressive increase in sensitivity ${ }^{16,112.161 .211}$. The enhancement in AMPH-stimulated striatal DA release in AMPHsensitized animals is also very persistent, being evident weeks to months following withdrawal ${ }^{161,242,244}$. It is therefore unfortunate that in so many of the electrophysiological studies animals were withdrawn for only one day before testing (Table VI). This not only decreases the probability of observing changes related to behavioral sensitization, given that the behavioral effect and effect on AMPH-stimulated striatal DA release is larger with longer withdrawal periods $^{161}$, but does not allow an evaluation of the persistence of electrophysiological changes that are observed.

Antelman and Chiodo ${ }^{16}$ did report that the decrease in the ability of APO to inhibit SNC unit discharge seen in sensitized rats persisted for at least 11 days. However, White and Wang ${ }^{317}$ found that in the VTA this effect was greatly attenuated after only 8 days of withdrawal. White and Wang ${ }^{317}$ gave rats 5 $\mathrm{mg} / \mathrm{kg}$ of AMPH for 7 days, either daily or twice daily, and then withdrew them for one or 8 days before testing (Table VI). Both of these pretreatment regimens produce behavioral sensitization. In rats pretreated twice daily and withdrawn for 8 days, the decrease in the ability of AMPH or APO to inhibit VTA unit discharge was only $50 \%$ of that observed after one day of withdrawal. More importantly, in animals pretreated daily with AMPH there was no evidence of DA autoreceptor subsensitivity after 8 days of withdrawal. These results suggest that in the VTA the electrophysiological signs of autoreceptor subsensitivity do not persist sufficiently long to account for behavioral sensitization. More studies will be required to clearly establish whether the electrophysiological signs of autoreceptor subsensitivity in the SNC persist longer than in the VTA, as suggested by Antelman and Chiodo ${ }^{16}$.

There is a third feature of behavioral sensitization not accounted for by the electrophysiological evidence for DA autoreceptor subsensitivity. It is clear that enduring behavioral sensitization is produced by a single injection of $\mathrm{AMPH}^{17,40,240,268}$, as are enduring changes in striatal DA release ${ }^{244}$. However, both Antelman and Chiodo ${ }^{16}$ and White and Wang ${ }^{317}$ reported that a single injection of AMPH does not alter the ability of APO to inhibit SNC or VTA unit discharge (Table VI).

A final argument against the DA autoreceptor subsensitivity hypothesis is provided by studies on the role of DA terminal autoreceptors in the regulation of AMPH-stimulated striatal DA release. Autoreceptors on the presynaptic terminals of nigrostriatal DA cells are thought to regulate the depolarization-induced, calcium-dependent release of DA via negative feedback ${ }^{92.172}$. However, it has been reported that $A M P H$-stimulated striatal DA release, a process that is calcium-independent and may involve an exchange-diffusion process ${ }^{92}$, is not modulated by presynaptic DA autoreceptors ${ }^{132}$. It is difficult to imagine how the increase in striatal DA release in vitro produced by sensitization could be due to a change in presynaptic DA autoreceptors if these receptors do not normally modulate AMPH-stimulated DA release $\mathrm{e}^{173}$.

In summary, the DA autoreceptor subsensitivity hypothesis initially seems to provide an attractive explanation of behavioral sensitization and enhanced striatal DA release in animals given repeated intermittent injections of $\mathrm{AMPH}$, but it is not without problems. First, the electrophysiological evidence does not account for a number of critical features of behavioral sensitization. These include: (1) the behavioral and neurochemical effects persist for weeks to months and, at least in the VTA, the electrophysiological effects dissipate quickly ${ }^{317}$; (2) behavioral sensitization and enhanced striatal DA release are 
produced by a single injection of AMPH, but there is no evidence for DA autoreceptor subsensitivity after a single injection (Table VI); and (3) pretreatment with low doses of AMPH result in electrophysiological effects opposite those predicted by the DA autoreceptor subsensitivity hypothesis ${ }^{133}$. Second, the biochemical studies do not support the electrophysiological evidence for DA autoreceptor subsensitivity, and the pharmacological/behavioral studies are equivocal. Third, AMPH-stimulated DA release in vitro appears not to be modulated by presynaptic DA autoreceptors ${ }^{173}$. It is concluded that the available evidence does not provide strong support for the hypothesis that either behavioral sensitization or the enhanced striatal DA release produced by repeated intermittent AMPH treatment is caused solely by subsensitive DA autoreceptors. Of course, it is possible that there is a cascade of cellular changes that leads to the enduring behavioral and neurochemical signs of sensitization, and that changes in DA autoreceptors represent but one stage in this process.

5.3.1.4. Other hypotheses. If subsensitive DA autoreceptors are not directly responsible for the enduring effects of sensitization, there must be other ways that repeated intermittent AMPH treatment produces an enhancement in AMPH-stimulated striatal DA release ${ }^{242,244}$. These alternative hypotheses remain to be tested, but a couple deserve mention here for the sake of completion.

One possibility is that there is simply more DA available for release in AMPH-sensitized animals. This could occur, in the absence of changes in overall DA concentrations, if there was a shift in the distribution of DA between two hypothesized intracellular 'pools' of DA. It is thought that striatal DA is distributed in two functional pools within the presynaptic terminal - a newly synthesized, readily releasable pool with a rapid turnover rate, and a storage pool that turns over more slowly ${ }^{97,192}$. AMPH may stimulate DA release from the more readily releasable pool, because the behavioral response to AMPH is not depressed by depletion of vesicular DA stores with reserpine, but the motor stimulant (and euphoric) effects are depressed by synthesis inhibition with $\alpha$-methyl- $p$-tyrosine ${ }^{2,126,192,249,313}$. The fact that AMPH-induced DA release is calcium-independent supports this idea ${ }^{29,260,318}$. Therefore, if AMPH sensitization produced an increase in the size of the read- ily releasable pool, and a concomitant decline in the size of the storage pool, there might be an enhancement in AMPH-stimulated DA release without changes in overall DA concentrations.

Another possibility is that the primary effect of AMPH sensitization is on neurons afferent to striatal DA terminals, and these presynaptically facilitate DA release by hyperpolarizing DA terminals. This could also increase the rate of DA/AMPH transport, and thereby enhance AMPH-stimulated DA release ${ }^{92,140}$. To date there is no evidence for such an hypothesis. But it is an intriguing one, especially since the sensitization to electric shock in Aplysia described by Kandel and his colleagues is thought to be due to the facilitory effect of a hyperpolarizing presynaptic serotonergic input on subsequent transmitter release ${ }^{138}$. It would be very interesting if a similar mechanism was involved in the behavioral sensitization described here. There is only limited evidence for changes in serotonergic activity in AMPH-sensitized animals (e.g. ref. 281 and unpublished observations by the authors), and this requires further investigation. There is also very little known about the influence of serotonin on striatal DA release ${ }^{315}$, and we know of no studies on the effects of serotonin specifically on AMPH-stimulated striatal DA release.

In conclusion, there is good evidence for changes in the nigrostriatal DA system of sensitized animals, but considerably more work is required in even this most extensively studied system. Although it has been shown that striatal DA release/utilization is enhanced following an AMPH challenge in sensitized animals, the cellular basis of this effect is not known, and its relationship to behavioral sensitization needs to be further clarified. Furthermore, the nigrostriatal DA system is probably not the only brain DA system altered by the repeated intermittent administration of AMPH. Evidence for changes in other DA systems is discussed next.

\subsubsection{The mesolimbic and mesocortical dopamine systems}

There are a number of reasons for suspecting that AMPH sensitization might alter mesolimbic or mesocortical DA systems. First, according to the current Zeitgeist it would be expected that any treatment known to produce severe cognitive and affective disturbances in humans would also produce ab- 
normalities in one or many limbic and cortical structures. Second, there is indirect experimental evidence suggesting that mesolimbic or mesocortical DA systems are involved in behavioral sensitization. For example, Eichler and Antelman ${ }^{70}$ reported that electrical self-stimulation in mesolimbic or mesocortical pathways sensitized rats to a subsequent injection of AMPH. AMPH pretreatment also enhanced electrical self-stimulation at medial prefrontal cortex sites $^{236}$. Segal et al. ${ }^{266}$ found that 6-OHDA lesions of the nucleus accumbens attenuated the development of behavioral sensitization, further implicating the mesolimbic DA system in sensitization ${ }^{70}$. In spite of this indirect evidence, there is not much direct evidence for changes in either mesolimbic or mesocortical DA systems in animals repeatedly exposed to AMPH. This should not be taken to indicate that such changes do not exist, because it will become obvious in the following discussion that there have been very few attempts to identify neural changes in these structures using paradigms relevant to the phenomenon of behavioral sensitization.

Studies on mesolimbic DA receptor binding in ani.mals pretreated with AMPH are equivocal (Table VII). There are 4 reports of an increase, 3 of no change and 5 of a decrease in mesolimbic DA recep- tor binding (Table VII). It should be noted that in most of these studies extreme AMPH pretreatment regimens were used, and animals were withdrawn from AMPH for only one day $59,111,114,204,237,239$. As previously mentioned, it is doubtful that this paradigm provides information relevant to the neural basis of behavioral sensitization. As in the case of the striatum (Table II), it is concluded that there is no consistent evidence for changes in mesolimbic DA receptor binding in association with behavioral sensitization.

In the two studies on DA receptor binding in the frontal cortex that were found, a decline in in vivo $\left[{ }^{3} \mathrm{H}\right]$ spiroperidol binding was reported in one ${ }^{139}$, and no change in $\left[{ }^{3} \mathrm{H}\right]$ spiperone binding in the other ${ }^{6}$. It is difficult to compare these studies because in the latter one the animals were challenged with AMPH $1 \mathrm{~h}$ prior to being killed. Obviously, there is not sufficient evidence to draw any conclusions about changes in mesocortical DA receptors in sensitized animals. Nevertheless, the decrease in frontal cortex DA binding reported by Kaneno and Shimazono ${ }^{139}$ is interesting in relation to evidence that AMPH sensitization enhances frontal cortex DA utilization ${ }^{243}$ (see below). This may be similar to the situation in the striatum, where there appears to be a small

TABLE VII

The effect of ampheramine sensitization on mesolimbic (accumbens or accumbens plus tubercle) dopamine receptor binding

Abbreviations: as in previous Tables.

\begin{tabular}{|c|c|c|c|c|c|c|c|c|}
\hline Reference & Species & Sex & Drug & Injection schedule & $\begin{array}{l}\text { Withdrawal } \\
\text { period }\end{array}$ & Ligand & Competitor & $\begin{array}{l}\text { Bind- } \\
\text { ing }\end{array}$ \\
\hline Daiguji and Meltzer ${ }^{59}$ & Rat & $\mathbf{M}$ & $\mathrm{D}$ & $5 \rightarrow 15 \mathrm{mk} 2 \times / \mathrm{d} \times 20 \mathrm{~d}^{1}$ & $17-20 h$ & {$\left[{ }^{3} \mathrm{H}\right]$ spiroperidol } & ADTN & Down \\
\hline Hitzemann et al. ${ }^{\prime}$ & Rat & $\mathrm{F}$ & $\mathrm{D}$ & $6 \mathrm{mk} 2 \times / \mathrm{d} \times 1-4 \mathrm{~d}$ & $16-20 \mathrm{~h}$ & {$\left[{ }^{3} \mathrm{H}\right]$ spiroperidol } & $\begin{array}{l}\text { butaclamol or } \\
\text { sulperide }\end{array}$ & Down \\
\hline Kaneno and Shimazono ${ }^{139}$ & Rat & $\mathbf{M}$ & M & $6 \mathrm{mk} / \mathrm{d} \times 14 \mathrm{~d}$ & $10 \mathrm{~d}$ & {$\left[{ }^{3} \mathrm{H}\right]$ spiroperidol } & in vivo ${ }^{2}$ & Down \\
\hline Rober & Rat & $\mathbf{M}$ & $\mathrm{D}$ & $\times 21 \mathrm{~d}$ & $24-36 \mathrm{~h}$ & $\begin{array}{l}{\left[{ }^{3} \mathrm{H}\right] \text { spiroperidol }} \\
{\left[{ }^{3} \mathrm{H}\right] \text { ADTN }}\end{array}$ & $\begin{array}{l}\text { domperidone } \\
\text { dopamine }\end{array}$ & $\begin{array}{l}\text { Down } \\
\text { Down }\end{array}$ \\
\hline Akiyama et al..$^{5}$ & Rat & $\mathbf{M}$ & M & $4 \mathrm{mk} / \mathrm{d} \times 14 \mathrm{~d}$ & $7 \mathrm{~d}$ & {$\left[{ }^{3} \mathrm{H}\right]$ spiperone } & ADTN & $\mathrm{NC}$ \\
\hline Howlett and Nahorski ${ }^{114}$ & Rat & $\mathbf{M}$ & $\mathrm{D}$ & $5 \rightarrow 15 \mathrm{mk} 2 \times / \mathrm{d} \times 20 \mathrm{~d}^{1}$ & $17-20 \mathrm{~h}$ & {$\left[{ }^{3} \mathrm{H}\right]$ spiperone } & $?$ & $\mathrm{NC}$ \\
\hline Owen et al. ${ }^{204}$ & Vervet & $\begin{array}{l}\mathrm{M} \\
\text { and } \mathrm{F}\end{array}$ & $\mathrm{D}$ & $4 \rightarrow 12 \mathrm{mk} / \mathrm{d} \times 35 \mathrm{~d}$ & $1 \mathrm{~d} ?$ & {$\left[{ }^{3} \mathrm{H}\right]$ spiperone } & butaclamol & $\mathrm{NC}$ \\
\hline Akiyama et al..$^{5}$ & Rat & $\mathrm{M}$ & M & $4 \mathrm{mk} / \mathrm{d} \times 14 \mathrm{~d}$ & $7 d$ & {$\left[{ }^{3} \mathrm{H}\right]$ spiperone } & buta & Up \\
\hline Akiyama et al. ${ }^{6}$ & Rat & $\mathbf{M}$ & $\mathbf{M}$ & $4 \mathrm{mk} / \mathrm{d} \times 14 \mathrm{~d}$ & $\begin{array}{l}7 \rightarrow 4 \mathrm{mk} 1 \mathrm{~h} \\
\text { prior to kill }\end{array}$ & {$\left[{ }^{3} \mathrm{H}\right]$ spiperone } & spiperone & Up \\
\hline Howlett and Nahorski ${ }^{1 / 4}$ & Rat & $\mathbf{M}$ & $\mathrm{D}$ & $5 \rightarrow 15 \mathrm{mk} 2 \times / \mathrm{d} \times 4 \mathrm{~d}^{1}$ & $17-20 \mathrm{~h}$ & {$\left[{ }^{3} \mathrm{H}\right] \mathrm{spi}$} & $?$ & Up \\
\hline Robertson ${ }^{238}$ & Rat & M & $\mathrm{D}$ & $5 \mathrm{mk} / \mathrm{d} \times 22 \mathrm{~d}$ & $2 d$ & {$\left[{ }^{3} \mathrm{H}\right]$ spiroperidol } & $?$ & Up \\
\hline
\end{tabular}

${ }^{1}$ Also added $25 \rightarrow 75 \mathrm{mg} / \mathrm{ml}$ to drinking water. ${ }^{2}$ Cerebellum used to estimate non-specific activity. 
down-regulation of DA receptors in response to enhanced DA release in sensitized animals.

Evidence that behavioral sensitization is accompanied by presynaptic changes in mesolimbic DA structures is also quite limited (Table VIII). There is a consensus that the steady-state concentrations of mesolimbic DA are not altered by repeated intermittent injections of low doses of AMPH ${ }^{167,183,202}$ (and unpublished studies by the authors), although sensitized animals may show a greater decline in DA levels than control animals when subsequently challenged with meth-AMPH ${ }^{202}$. The only study to examine mesolimbic tyrosine hydroxylase activity reports no change in sensitized rats, suggesting mesolimbic DA synthesis is not altered ${ }^{202}$. AMPH sensitization also does not seem to influence mesolimbic DA utilization under steady-state conditions, as indicated by DA metabolite levels ${ }^{167,183,202}$, or the rate of the decline in DA after tyrosine hydroxylase inhibition ${ }^{243}$ (Table VIII). However, Camp and Robinson ${ }^{43}$ have obtained preliminary evidence for enhanced nucleus accumbens DA metabolite levels (utilization?) in sensitized female, but not male rats. When sensitized rats were subsequently challenged with methAMPH, Nishikawa et al. ${ }^{202}$ found that mesolimbic DA utilization was enhanced, but in a similar study Kuczenski and Leith ${ }^{167}$ found no difference between sensitized and control animals (Table VIII). There was a similar discrepancy between the reports of Kuczenski and Leith ${ }^{167}$, who used D-AMPH, and Nishikawa et al. ${ }^{202}$, who used meth-AMPH, in regards striatal DA utilization (Table V). In conclusion, more work is required to determine if AMPH sensitization produces changes in mesolimbic DA activity. They may very well occur, but are only apparent in female animals, or when sensitized animals are subsequently challenged with a stimulus that increases dopaminergic activity (e.g. see the discussion of opiate-DA interactions below)

We are aware of only one report that repeated intermittent injections of AMPH produce enduring effects on DA neurons projecting to the neocortex (Table VIII). In two independent experiments, Robinson et al. ${ }^{243}$ found an enduring enhancement in medial prefrontal cortex DA utilization in OVX female rats previously exposed to AMPH, as indicated by an increase in the rate of decline of DA following tyrosine hydroxylase inhibition. The significance of these enduring changes in mesocortical DA neurons to behavioral sensitization, and how they are related to similar changes in the striatum (Table V) will be explored in future studies. Nevertheless, it is encouraging that there is enhanced frontal cortex DA utilization in this animal model of AMPH psychosis, be-

\section{TABLE VIII}

The effect of amphetamine sensitization on presynaptic indices of mesolimbic and mesocortical dopamine activity

Abbreviations: S, steady-state (resting) conditions; $C$, after a challenge injection of AMPH.

\begin{tabular}{|c|c|c|c|c|c|c|}
\hline Reference & Structure & Injection schedule & $\begin{array}{l}\text { Withdrawal } \\
\text { period }\end{array}$ & Condition & Measure & Effect \\
\hline Alloway and Rebec ${ }^{9}$ & Accumbens & $1-5 \mathrm{mk} 2 \times / \mathrm{d} \times 6 \mathrm{~d}$ & $1 \mathrm{~d}$ & $S$ & DA concentrations & $\mathrm{NC}$ \\
\hline Eichler et al. ${ }^{69}$ & Accumbens & $2-12 \mathrm{mk} / \mathrm{d} \times 65 \mathrm{~d}$ & $1 \mathrm{~d}$ & $\mathbf{S}$ & DA concentrations & $\mathrm{NC}$ \\
\hline Kuczenski and Leith ${ }^{167}$ & Mesolimbic & $3 \mathrm{mk} / \mathrm{d} \times 6 \mathrm{~d}$ & $2 d$ & $S$ or $C$ & DA concentrations & $\mathrm{NC}$ \\
\hline Lynch et al. 183 & Amygdala & $0.5 \rightarrow 2 \mathrm{mg} / \mathrm{ml} / \mathrm{d} \times 14 \mathrm{~d}$ & $1-7 \mathrm{~d}$ & $S$ & DA concentrations & NC \\
\hline Nishikawa et al. ${ }^{202}$ & Mesolimbic & $6 \mathrm{mk} / \mathrm{d} \times 14 \mathrm{~d}$ & $15 \mathrm{~d}$ & $S$ & DA concentrations & $\mathrm{NC}$ \\
\hline Nishikawa et al. ${ }^{202}$ & Mesolimbic & $6 \mathrm{mk} / \mathrm{d} \times 14 \mathrm{~d}$ & $15 d$ & $\mathrm{C}$ & DA concentrations & Down \\
\hline Alloway and Rebec ${ }^{9}$ & Accumbens & $1-5 \mathrm{mk} 2 \times / \mathrm{d} \times 6 \mathrm{~d}$ & $1 \mathrm{~d}$ & $\mathbf{S}$ & DOPAC & $\mathrm{NC}$ \\
\hline Camp and Robinson $(F)^{43}$ & Accumbens & $2.6 \mathrm{mk} / 4 \mathrm{~d} \times 10 \mathrm{inj}$ & $8-13 d$ & $\mathrm{~S}$ & DOPAC; HVA & Up \\
\hline Kuczenski and Leith ${ }^{167}$ & Mesolimbic & $3 \mathrm{mk} / \mathrm{d} \times 6 \mathrm{~d}$ & $2 d$ & S or $\mathrm{C}$ & DOPAC; HVA & NC \\
\hline Lynch et al. ${ }^{183}$ & Amygdala & $0.5-2 \mathrm{mg} / \mathrm{ml} / \mathrm{d} \times 14 \mathrm{~d}$ & $1-7 d$ & $\mathrm{~S}$ & DOPAC & NC \\
\hline Nishikawa et al. ${ }^{202}$ & Mesolimbic & $6 \mathrm{mk} / \mathrm{d} \times 14 \mathrm{~d}$ & $15 \mathrm{~d}$ & S or $\mathrm{C}$ & Tyrosine hydroxylase & NC \\
\hline \multirow[t]{2}{*}{ Nishikawa et al. ${ }^{202}$} & Mesolimbic & $6 \mathrm{mk} / \mathrm{d} \times 14 \mathrm{~d}$ & $15 \mathrm{~d}$ & $\mathrm{~S}$ & DOPAC; HVA; DOPAC/DA & $\mathrm{NC}$ \\
\hline & & & & $\mathrm{C}$ & DOPAC; DOPAC/DA & Up \\
\hline Robinson et al. ${ }^{243}$ & Accumbens & $3 \mathrm{mk} / 1-4 \mathrm{~d} \times 7-9 \mathrm{inj}$ & $8-10 d$ & $\mathrm{~S}$ & Decline in DA after MPT & NC \\
\hline Robinson et al. ${ }^{243}$ & Frontal cortex & $3 \mathrm{mk} / 1-4 \mathrm{~d} \times 7-9 \mathrm{inj}$ & $8-10 d$ & $\mathbf{s}$ & Decline in DA after MPT & Up \\
\hline
\end{tabular}


cause dysfunction in the frontal lobe has been implicated in the manifestation of AMPH psychosis and schizophrenia $^{33,160,201,306}$.

\subsubsection{Other neurotransmitter systems}

5.3.3.1. Opiate peptide-dopamine interactions. Although the effects of repeated AMPH administration on brain opiate peptide systems have not received much attention there is accumulating evidence that some of the enduring changes in behavior produced by the repeated administration of opiates may be mediated via changes in dopaminergic activity. As with AMPH, tolerance develops to many of morphine's effects, but its motor stimulant effects are progressively enhanced upon repeated intermittent administration, either systemically ${ }^{20}$ or into the ventral tegmental area $\left(V_{T}{ }^{128,307}\right)$. The sensitizing effects of systemic morphine are also very persistent, lasting for months following withdrawal ${ }^{21,25}$. Morphine-induced sensitization of motor activity is probably due to morphine's action on an endogenous mesencephalic opiate system, because the daily administration of a peptidase-resistant enkephalin analog (DALA; D-Ala ${ }^{2}$-D-Met ${ }^{5}$-enkephalinamide) into the VTA also produces a progressive and enduring enhancement in the motor stimulant effects of a subsequent intra-VTA DALA challenge ${ }^{131}$. This DALAinduced behavioral sensitization is blocked by naloxone; and morphine or D-Ala ${ }^{2}$-D-Leu ${ }^{5}$-enkephalin, but not dynorphin, partially substitute for DALA ${ }^{131}$. On the basis of this evidence Kalivas et al. ${ }^{131}$ have suggested that delta or mu, but not kappa opiate receptors are probably involved in DALA-induced sensitization.

Behavioral, electrophysiological and neurochemical studies suggest that some of the motor stimulant effects of opiates are due to opiate-DA interactions, and therefore the sensitizing effects of opiates could also be due to opiate-DA interactions (see refs. 129, 131 for references). In support of this, Kalivas ${ }^{129}$ has shown that in animals sensitized by daily intra-VTA DALA injections a subsequent challenge injection of intra-VTA DALA produces a greater enhancement in nucleus accumbens DOPAC and HVA concentrations than in non-sensitized controls, and that this effect persists for at least 7 days. Interestingly, the steady-state concentrations of nucleus accumbens DA, DOPAC and HVA are not influenced by sensi- tization to DALA, which is similar to the situation following AMPH sensitization (Tables III, V). Furthermore, animals sensitized by intra-VTA DALA are hypersensitive to the motor stimulant effects of systemically administered AMPH or intra-VTA neurotensin, effects thought to be mediated by mesotelencephalic DA neurons. They are not hypersensitive to the motor stimulant effects of caffeine, which are thought to be non-dopaminergic ${ }^{129}$. Kalivas ${ }^{129}$ also presented evidence that neither changes in opioid nor postsynaptic DA receptors underlie intraVTA DALA-induced sensitization. It is concluded that both AMPH and opiate peptides may produce some of their enduring effects on behavior by altering the presynaptic activity of mesotelencephalic DA neurons.

5.3.3.2. Norepinephrine. The effects of repeated intermittent injections of AMPH on indices of brain norepinephrine (NE) activity are summarized in Table IX. Some researchers have reported a small decline in brain NE concentrations after repeated AMPH administration ${ }^{9.183,205,273}$, but in all instances animals were treated at least twice a day, for very long periods of time, and/or with relatively high doses of AMPH. Certainly AMPH treatment regimens that are toxic to DA neurons may also deplete $\mathrm{NE}^{113.228 .299}$. When a less extreme treatment regimen is used, or when animals are withdrawn for a longer period of time, repeated AMPH administration does not alter brain NE concentrations ${ }^{9,69,109,121,233}$ (and unpublished studies by the authors). There is also little evidence for changes in NE synthesis or release in AMPH sensitized rats ${ }^{121,281}$; although admittedly there has been insufficient effort to identify such changes. One exception comes from studies on the noradrenergic input to cerebellar Purkinje cells. Sorenson et al. ${ }^{279}$ reported that 50 days following withdrawal from repeated AMPH treatment the discharge rate of Purkinje cells was abnormally low, and disruption of the NE input to these cells from the locus coeruleus partially reversed this effect ${ }^{278}$. Furthermore, cerebellar cortex 3-methoxy-4-hydroxyphenyl glycol (MHPG) concentrations were elevated 10 days after withdrawal from AMPH, perhaps indicating enhanced NE release. MHPG levels had returned to control levels by 30 days of withdrawal ${ }^{278}$. The authors concluded that sensitization to AMPH enhances NE neurotransmission in the cerebellum. 
However, this cannot completely account for the effect on Purkinje cells because removal of the NE input only partially reversed the effect ${ }^{278}$.

The evidence for enduring changes in NE receptors is largely negative (Table IX). For example, Banerjee et al. ${ }^{24}$ reported an increase in $\left[{ }^{3} \mathrm{H}\right] \mathrm{DHA}$ binding after 1-2 days of withdrawal, but normal levels of [ $\left.{ }^{3} \mathrm{H}\right]$ DHA binding by 4 days of withdrawal.

5.3.3.3. Serotonin. Serotonin-containing neurons modulate both brain DA activity and the behavioral effects of stimulant drugs, and therefore could be involved in the development of behavioral sensitization. However, there is very little direct evidence for changes in serotonergic systems in AMPH-sensitized animals. Again, this may be due to insufficient effort to identify such changes. Although steady-state brain 5-hydroxytryptophan activity and serotonin concentrations are not influenced by the repeated intermittent administration of non-toxic doses of $\mathrm{AMPH}^{109,118,290}$ (and unpublished studies in this labo- ratory), there is one intriguing report of altered serotonergic activity in AMPH-sensitized rats. Sparber and Tilson ${ }^{281}$ reported that AMPH-stimulated $\left[{ }^{3} \mathrm{H}\right]$ serotonin release into the lateral ventricle was significantly enhanced in rats treated with $2.5 \mathrm{mg} / \mathrm{kg}$ of AMPH each day for 8-12 days and withdrawn for one day. In control animals AMPH failed to stimulate significant $\left[{ }^{3} \mathrm{H}\right]$ serotonin release.

5.3.3.4. Amino acids. It has been suggested that glutamate release is decreased in schizophrenics ${ }^{149}$, and therefore the effects of sensitization on amino acid transmitters is of interest. The repeated intermittent administration of meth-AMPH $(4 \mathrm{mg} / \mathrm{kg}$ daily for 14 days) did reduce $\left[{ }^{3} \mathrm{H}\right]$ kainic acid binding in rat cerebral cortex, when measured 8 days after the last AMPH treatment. This suggests a reduction in glutamate receptors ${ }^{143}$. Unfortunately, it is difficult to assess how relevant studies on presynaptic indices of amino acid transmitter function are to behavioral sensitization, because in two studies animals

\section{TABLE IX}

The effect of amphetamine sensitization on indices of brain norepinephrine activity

Abbreviations: as in previous Tables. NE, norepinephrine; ctx, cortex; hpc, hippocampus, ot., olfactory tubercle; cAMP, cyclic AMP; MHPG, 3 methoxy,4-hydroxy-phenyl-glycol.

\begin{tabular}{|c|c|c|c|c|c|}
\hline Reference & Structure & Injection schedule & $\begin{array}{l}\text { Withdrawal } \\
\text { period }\end{array}$ & Measure & Effect \\
\hline Alloway and Rebec ${ }^{9}$ & striatum & $5 \mathrm{mk} 2 \times / \mathrm{d} \times 6 \mathrm{~d}$ & $1 \mathrm{~d}$ & NE concentrations & Down \\
\hline Alloway and Rebec ${ }^{9}$ & striatum & $1 \mathrm{mk} 2 \times / \mathrm{d} \times 6 \mathrm{~d}$ & $1 \mathrm{~d}$ & NE concentrations & $\mathrm{NC}$ \\
\hline Eichler et al. ${ }^{69}$ & neocortex & $2-4 \mathrm{mk} / \mathrm{d} \times 65 \mathrm{~d}$ & $1 \mathrm{~d}$ & NE concentrations & $\mathrm{NC}$ \\
\hline Eichler et al. ${ }^{69}$ & neocortex & $8-12 \mathrm{mk} / \mathrm{d} \times 65 \mathrm{~d}$ & $1 \mathrm{~d}$ & NE concentrations & Down \\
\hline Herman et al. ${ }^{109}$ & cerebellum & $3 \mathrm{mk} / \mathrm{d} \times 9 \mathrm{mo}$ & $3 d$ & NE concentrations & Down \\
\hline Herman et al. ${ }^{109}$ & ctx, striatum, thalamus & $3 \mathrm{mk} / \mathrm{d} \times 9 \mathrm{mo}$ & $1-3 d$ & NE concentrations & $\mathrm{NC}$ \\
\hline Jackson et al. ${ }^{121}$ & whole brain, minus cerebellum & $5 \mathrm{mk} / \mathrm{d} \times 25 \mathrm{~d}$ & $7 d$ & $\mathrm{NE}$ concentrations & $\mathrm{NC}$ \\
\hline Lynch et al. ${ }^{183}$ & hpc, striatum, brainstem & $0.5 \rightarrow 2 \mathrm{mg} / \mathrm{ml} \times 14 \mathrm{~d}$ & $7 d$ & $\mathrm{NE}$ concentrations & Down \\
\hline Lynch et al. ${ }^{183}$ & ot., amygdala, midbrain & $0.5 \rightarrow 2 \mathrm{mg} / \mathrm{ml} \times 14 \mathrm{~d}$ & $7 \mathrm{~d}$ & NE concentrations & NC \\
\hline Pearl and Seiden ${ }^{205}$ & whole brain & $2.5 \mathrm{mk} / \mathrm{d} \times 60 \mathrm{~d}$ & Id & NE concentrations & Down \\
\hline Riffee and Gerald ${ }^{233}$ & whole brain & $2.5 \mathrm{mk} / \mathrm{d} \times 7 \mathrm{~d}$ & $1-2 d$ & $\mathrm{NE}$ concentrations & $\mathrm{NC}$ \\
\hline Short and Shuster ${ }^{273}$ & whole brain & $10 \mathrm{mk} 2 \times / \mathrm{d} \times 5 \mathrm{~d}$ & $3-25 d^{1}$ & NE concentrations & Down \\
\hline Jackson et al. ${ }^{12 !}$ & whole brain, minus cerebellum & $5 \mathrm{mk} / \mathrm{d} \times 25 \mathrm{~d}$ & $7 \mathrm{~d}$ & NE decline after MPT & $\mathrm{NC}$ \\
\hline Sorensen et al. 278 & cerebellum & $2 \mathrm{mk} / \mathrm{d} \times 21 \mathrm{~d}$ & $10 \mathrm{~d}$ & MHPG concentrations & Up \\
\hline Sorensen et al ${ }^{278}$ & cerebellum & $2 \mathrm{mk} / \mathrm{d} \times 21 \mathrm{~d}$ & $30 \mathrm{~d}$ & MHPG concentrations & $\mathrm{NC}$ \\
\hline Sparber and Tilson 281 & perfuse lateral ventricle & $2.5 \mathrm{mk} / \mathrm{d} \times 8-12 \mathrm{~d}$ & $1 \mathrm{~d}$ & {$\left[{ }^{3} \mathrm{H}\right] \mathrm{NE}$ release } & NC \\
\hline Banerjee et al. ${ }^{24}$ & whole brain, minus cerebellum & $10 \mathrm{mk} / \mathrm{d} \times 6 \mathrm{wk}$ & $4 \mathrm{~d}$ & $\left.{ }^{3} \mathrm{H}\right] \mathrm{DHA}$ binding ${ }^{3}$ & $\mathrm{NC}$ \\
\hline Banerjee et al. ${ }^{24}$ & whole brain, minus cerebellum & $10 \mathrm{mk} / \mathrm{d} \times 6 \mathrm{wk}$ & $1-2 d$ & {$\left[{ }^{3} \mathrm{H}\right] \mathrm{DHA}$ binding ${ }^{3}$} & Up \\
\hline Chanda et al. ${ }^{46}$ & whole brain, minus cerebellum & $10 \mathrm{mk} / \mathrm{d} \times 6 \mathrm{wk}$ & $4 \mathrm{~d}$ & NE stimulated cAMP & NC \\
\hline Chanda et al. 46 & whole brain, minus cerebellum & $10 \mathrm{mk} / \mathrm{d} \times 6 \mathrm{wk}$ & $4 d$ & {$\left[{ }^{3} \mathrm{H}\right]$ DHA binding ${ }^{3}$} & NC \\
\hline Howlett and Nahorski ${ }^{114}$ & striatum, limbic forebrain & $5 \rightarrow 15 \mathrm{mk} 2 \times / \mathrm{d} \times 4-20 \mathrm{~d}^{2}$ & $1 \mathrm{~d}$ & {$\left[{ }^{3} \mathrm{H}\right] \mathrm{DHA}$ binding ${ }^{3}$} & NC \\
\hline
\end{tabular}

${ }^{1} \mathrm{NE}$ concentrations steadily increasing to near normal by $25 \mathrm{d.}{ }^{2}$ Additional AMPH added to drinking water. ${ }^{3} \mathrm{DHA}=$ dihydroalprenol, displaced with NE. 
were not withdrawn from AMPH for even one day ${ }^{148,163}$, and in the other AMPH was provided continuously in the drinking water ${ }^{184}$.

\subsection{The neural basis of behavioral sensitization: con- clusions and a hypothesis}

Despite many attempts to identify an enduring neural change associated with repeated intermittent AMPH administration perusal of Tables I-IX reveals that the neural basis of behavioral sensitization has not been thoroughly characterized. Nevertheless, the available evidence does provide some promising leads. The section of this review on 'neural hypotheses' began with two questions: (1) what is the locus of the neural change(s) underlying behavioral sensitization; and (2) what is the nature of the change(s)? In answer to the first question, there is sufficient evidence to conclude that repeated intermittent exposure to AMPH alters mesotelencephalic DA systems. Of course, other neural systems are probably involved as well, but only DA systems have been studied in any detail. In answer to the second -question, we propose that behavioral sensitization to AMPH is at least partly due to presynaptic changes characterized by enhanced DA release.

Fig. 2 schematically illustrates some of the changes in brain DA neurons that could occur following the repeated intermittent administration of AMPH. Fig. $2 \mathrm{~A}$ illustrates the release of DA induced by AMPH in an animal exposed to AMPH for the first time. Note that DA release can be modulated by autoreceptors on the presynaptic terminal (autoreceptors on the cell body and dendrites are not illustrated), and/or by a presynaptic hyperpolarizing input (indicated by '-'). Fig. 2B illustrates the same terminal after the animal has been repeatedly and intermittently exposed to AMPH, and then after a withdrawal period (weeks to month later) is again challenged with AMPH. It is known that there is an enhanced behavioral response to this challenge injection of AMPH, and the best evidence available to date suggests it is due to enhanced DA release (item no. 1 on Fig. 2B). There is no convincing evidence for changes in postsynaptic DA receptors (indicated by '2' on Fig. 2B), except perhaps a small down-regulation that we propose is secondary to enhanced DA release. The nature of the cellular change underlying enhanced DA release in sensi- tized animals is not known. A number of possibilities are schematically illustrated in Fig. 2B. One possibility is that the autoreceptors regulating DA release or discharge rate are subsensitive ('3'). However, as discussed above, the available evidence for autoreceptor subsensitivity is equivocal, and fails to account for many of the characteristics of behavioral sensitization and the persistence of enhanced DA release. Other possibilities include presynaptic facilitation by hyperpolarization of the DA terminal via a presynaptic input (' 4 '), or a shift in the distribution of DA from a 'storage pool' to a more readily releasable pool (' 5 '). There is no evidence for a change in total DA concentrations, at least during the resting state (note that the number of DA 'molecules' illustrated in Fig. $2 \mathrm{~A}$ and $\mathrm{B}$ is the same), or in DA synthesis rate (' 6 '). Future research on the nature of presynaptic changes in mesotelencephalic DA systems, and on changes in other neurotransmitter systems that influence dopaminergic activity will be required to further elucidate the neural basis of behavioral sensitization. In particular, it will be important in future studies to try and relate changes in specific neural systems (e.g. the mesolimbic, mesocortical or nigrostriatal DA systems) to changes in specific behaviors (e.g. locomotion, the various components of stereotypy, rotational behavior).

One final point to be made here concerns the ambiguity created in the literature when studies involving neurotoxic AMPH treatment regimens are cited as being relevant to the neural basis of behavioral sensitization, and vice versa. This should be avoided. Some of the problem is simply because the same terms are frequently used to refer to different phenomena. For example, the phrase 'repeated AMPH administration' is used to refer to both: (1) treatment paradigms in which very high doses are repeatedly given, which in effect continuously elevates brain concentrations of AMPH and produces neurotoxicity; and (2) paradigms relevant to behavioral sensitization, in which repeated but intermittent injections of non-toxic low doses are used. It is suggested that individual researchers make a greater effort to identify whether the paradigm they use is more relevant to the 'AMPH neurotoxicity syndrome', or the phenomenon of behavioral sensitization; and to be careful about citing evidence relevant to only one phenomenon as being relevant to the other. 
A. NORMAL

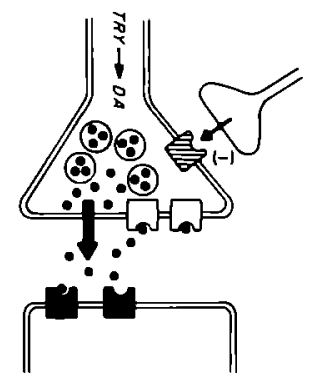

B. SENSITIZED

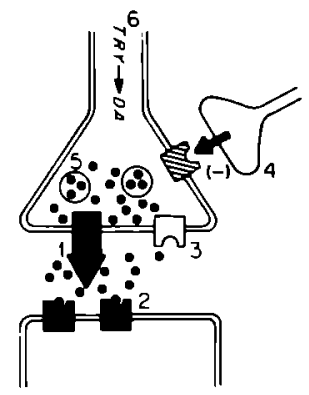

Fig. 2. A schematic illustration of possible changes in dopaminergic neurons following the repeated intermittent administration of amphetamine. A: an illustration of the release of DA from a dopamine terminal the first time it is exposed to amphetamine. The black dots represent DA 'molecules' that are localized either in a 'storage pool' (enclosed circles), or a more 'readily releasable pool' (freely distributed in the cytoplasm). Postsynaptic DA receptors are black, presynaptic autoreceptors are white and a presynaptic receptor receiving a hyperpolarizing input from another cell is striped. B: an illustration of the same terminal after the animal has been sensitized to amphetamine. It is known that there is an enhanced behavioral response to amphetamine in a sensitized animal, and it is suggested that this is due to enhanced DA release (item no. 1) Numbers 2-6 illustrate other possible changes, including changes in postsynaptic receptors (2), presynaptic autoreceptors (3), a hyperpolarizing presynaptic input (4), the intracellular distribution of DA (5), or DA synthesis (6). See the text for a discussion of each of these possibilities.

\section{GENERALIZABILITY OF SENSITIZATION}

\subsection{Stimulants and stress}

Thus far behavioral sensitization has been described as a special kind of behavioral plasticity, where a relatively short-term pharmacological manipulation (exposure to AMPH) produces a very long-lasting change in the response induced by subsequent exposure to the same stimulus. However, it is worth noting at this time that behavioral sensitization is not unique to the psychopharmacology of psychomotor stimulant drugs, but can be produced by nonpharmacologic environmental stimuli as well. For example, there are many studies showing that repeated intermittent stress can sensitize the hypothalamo-pituitary-adrenal (HPA) axis. Daily immobilization or footshock stress produces a dramatic and progressive increase in plasma corticosterone concentrations ${ }^{106,289}$, and in adrenal tyrosine hydroxylase and phenylethanolamine- $\mathrm{N}$-methyl-transferase activity $\left(\mathrm{PNMT}^{171}\right)$. Repeated intermittent stress also en- hances many of the central and behavioral consequences of subsequent stress $s^{4,13,14,17,44,282}$. Of direct relevance to the behavioral sensitization produced by stimulants is evidence that daily injections of cocaine produce a progressive enhancement in plasma norepinephrine (NE) and epinephrine concentrations ${ }^{102}$, and in particular that repeated exposure to stress sensitizes brain DA systems ${ }^{18,103,216}$. It has even been suggested that some of the enduring effects of stimulant drugs on brain and behavior are due to their action as stressors ${ }^{17.19,212}$.

Much of the evidence for an association between AMPH sensitization and sensitization to stress comes from a series of experiments by Antelman and his colleagues, who studied the effect of a variety of stressors on the stereotyped behavior produced by a subsequent injection of AMPH (for review see ref. 17). Exposure to stressors such as tail pinch, food deprivation or footshock all enhance the stereotypy (or polydipsia) produced by an injection of AMPH given weeks later ${ }^{15,17,19,70}$. Studies by other researchers have subsequently shown that immobilization or footshock stress also produce an enduring enhancement in AMPH-induced locomotion ${ }^{108}$ and rotational behavior ${ }^{241}$ (see also ref. 105).

Not only does previous exposure to stress enhance AMPH-induced behavior, but previous exposure to AMPH may influence the effects of subsequent stress. For example, Antelman et al. ${ }^{15}$ reported that rats previously exposed to AMPH are more sensitive to the activational effects of tail pinch. The effects of footshock stress on indices of brain DA activity are also altered by sensitization to AMPH (unpublished studies by the authors). Mild footshock stress is known to enhance DA utilization in a number of brain regions, as indicated by increased DOPAC concentrations, or DOPAC to DA ratios ${ }^{174.227}$ (cf. ref. 291). We have found that $5 \mathrm{~min}$ of mild footshock produces a greater elevation in the ratio of DOPAC to DA in the medial prefrontal cortex and hypothalamus of sensitized female rats than in saline-injected or non-handled control animals, perhaps due to enhanced DA release (unpublished studies). Thus, it appears that AMPH and stress may be to some extent interchangeable in producing sensitization.

Evidence that sensitization to stress may involve enduring changes in mesotelencephalic DA systems is also suggested by recent studies by Kalivas et al. ${ }^{130}$ 
on the effects of intra-VTA injections of the enkephalin analog, DALA. When injected into the VTA, DALA produces hyperactivity, an effect that is thought to be due to the DALA-induced release of DA in the nucleus accumbens ${ }^{131}$. Furthermore, the repeated intermittent administration of DALA produces a progressive sensitization of motor activity, and this is accompanied by sensitization of mesolimbic DA systems ${ }^{129.131}$. Interestingly, previous exposure to mild footshock stress also sensitizes animals to the motor stimulant effects of intra-VTA DALA, and animals sensitized to DALA show an exaggerated dopaminergic response to subsequent stress ${ }^{130}$.

In conclusion, there is sufficient evidence to suggest that the repeated intermittent exposure to either pharmacologic or environmental stimuli that activate brain DA systems can produce enduring changes in DA neurons, and that these changes are characterized by hyperresponsivity to stimuli that subsequently activate brain DA systems.

\subsection{Sex differences, stimulants and stress}

It was mentioned above that there are robust sex differences in the sensitization to AMPH. If sensitization to AMPH and stress are to some extent interchangeable, as just suggested, it follows that there should also be sex differences in the sensitization to stress. Although the evidence is limited, a review of the literature reveals that there are remarkably similar sex differences in both the acute and chronic effects of AMPH and stress.

(a) Acute effects. Female rats show a much greater behavioral response to an acute injection of AMPH than males, as indicated by measures of locomotor activity ${ }^{188}$, stereotyped activity ${ }^{27}$ or rotational behavior $^{31.36,244.245}$. This sex difference in AMPH-induced behavior is not due to sex differences in the metabolism of $A M P H^{101,144,189}$, because it persists when males are given considerably higher systemic doses of AMPH than females ${ }^{36}$, or when doses are titrated so males and females have equivalent brain levels of $\mathrm{AMPH}^{31,43}$. There is a similar sex difference in the response of the HPA axis to acute stress. Female rats show a much greater and more persistent elevation of plasma corticosterone than males in response to either immobilization, footshock or forced running stress $^{141,151}$, or to a direct injection of $\mathrm{ACTH}^{151}$. The release of ACTH to a 3 min 'psychological' stress is also greater in female than in male rats ${ }^{178}$.

These sex differences may be related to the effects of gonadal hormones on brain DA activity and the HPA axis. Gonadal hormones are known to modulate striatal and hypothalamic DA release and receptors in a sexually dimorphic manner ${ }^{28,30,116,304}$, and male and female gonadal hormones differentially effect the HPA axis. For example, Kitay ${ }^{52,150}$ has shown that ovariectomy (OVX) decreases both the pituitary secretion of ACTH and plasma corticosterone $^{57}$, presumably due to a reduction in ACTH synthesis and the sensitivity of the pituitary to corticotropin-releasing factor (CRF). In sharp contrast, castration (CAST) of male rats increases plasma ACTH at rest or after stress, and this is reversed by testosterone replacement ${ }^{53.150}$. Kitay ${ }^{150}$ has suggested that endogenous gonadal hormones in males and females influence HPA activity in an opposing fashion.

(b) Chronic effects. As discussed above, females show much more robust sensitization to repeated intermittent injections of AMPH than males, and this is not affected by $\mathrm{OVX}^{240,244}$. In contrast, CAST males show greater sensitization to AMPH than intact males and are comparable to females. We know of only one study on sex differences in the response of the HPA axis to repeated intermittent stress, but the similarity to the pattern of sex differences seen with AMPH sensitization is striking ${ }^{106}$.

Hennessy et al. ${ }^{106}$ (see for review ref. 107) showed that in gonadally intact female mice the plasma corticosterone response to footshock stress is sensitized by daily footshock sessions. OVX produced a general decline in the circulating levels of corticosterone in all groups, but OVX rats still showed a clear sensitization of the corticosterone response with repeated stress. In contrast, gonadally intact male mice did not sensitize to repeated stress. That is, in intact males the elevation in plasma corticosterone was the same after the 10th shock session as it was after the first. On the other hand, CAST male mice did show sensitization, having significantly higher plasma corticosterone levels after the 10th than after the first shock session $^{106}$.

In summary, the available evidence suggests that: (1) females show more robust sensitization in response to repeated AMPH or stress than do males; (2) removal of the ovaries has no (or little) effect on 
the sensitization produced by repeated AMPH or stress; and (3) removal of the testes enhances the development of sensitization to both repeated AMPH or stress. It is therefore possible that a testicular hormone directly or indirectly retards the development of enduring changes in brain and behavior produced by the repeated intermittent application of either AMPH or stress.

\section{CONCLUSIONS}

In conclusion, we agree with previous suggestions that the hyperdopaminergic state and resultant changes in behavior produced by an acute injection of moderate to high doses of AMPH provides a reasonable model of some changes in brain and behavior associated with some forms of schizophrenia ${ }^{196 .}$ 219.220 .264 . That is, amphetamine psychosis, and possibly paranoid schizophrenia, are associated with, 'high concentrations of DA at the synapse'204 (p. 216). Lower doses of AMPH do not usually produce the perseverative stereotyped behavior so similar to that seen in AMPH psychosis and schizophrenia. However, when low doses of AMPH are repeatedly and intermittently administered they also come to produce high DA concentrations at the synapse, which we propose is due to a progressive enhancement in DA release. This enhancement in DA release is manifested as behavioral sensitization in non-human animals and AMPH psychosis in humans. Furthermore, in individuals sensitized to AMPH other stimuli (e.g. stressors), that do not normally cause a large release of DA, may come to do so, thereby also producing symptoms associated with psychotic disorders.

It will require considerably more research with new techniques to establish whether schizophrenia and AMPH psychosis are accompanied by enhanced DA release. The fact that the neurochemical effects of sensitization have been difficult to identify under steady-state conditions, but are often apparent only following a 'challenge' to the system, may help explain why evidence for presynaptic changes in schizophrenics has been to elusive ${ }^{103,306}$. Not only is it difficult to obtain valid measures of presynaptic activity in human subjects, but matters are further complicated because it may be necessary to 'challenge' subjects just prior to analysis in order to easily detect neurochemical alterations. Perhaps with the development of new non-invasive techniques for imaging neural activity in humans (e.g. PET, NMR) some of these issues will be resolved. Nevertheless, it is interesting to note in this regard that plasma HVA levels are elevated in schizophrenics. There is also a strong positive correlation between the severity of the psychosis and HVA levels ${ }^{61,208}$ (see also ref. 295), and the reduction in psychosis produced by neuroleptic treatment is correlated with a reduction in plasma HVA levels ${ }^{208}$. Enhanced plasma HVA levels could be due to elevated levels of DA release, but unfortunately there are many other possible explanations for these results (e.g. ref. 47).

There is growing evidence to support the suggestion that sensitization is not unique to the psychopharmacology of stimulant drugs ${ }^{17.19 .212}$, but can be produced by any stimulus that greatly increases brain catecholamine activity, including environmental stimuli. For example, we discussed evidence that the repeated administration of $\mathrm{AMPH}$, an enkephalin analog or stress all sensitize brain DA systems. It remains to be determined if the sensitization produced by different agents has the same cellular basis, but thus far the sensitization produced by AMPH and stress seems to be quite interchangeable. Animals that have been previously exposed to AMPH or stress often show an exaggerated response when subsequently challenged with an injection of AMPH, or further stress. In fact, it may be that sensitized animals are hyperresponsive to any stimulus that activates brain catecholamine systems, and that the effects of sensitization are not obvious in the absence of such stimuli. This may help explain why psychosis only tends to recur in former AMPH addicts following reexposure to AMPH or exposure to 'physical or psychological stress' ${ }^{302}$, and why stress is considered a precipitating agent in psychiatric disorders thought to involve brain catecholamine dysfunction ${ }^{13,17,18}$, $39,63,103,210$.

Lastly, it should be noted that there is great individual variation in the susceptability to sensitization, just as there is in the acute effects of stimulants and stress $^{12,42,99,191,221}$.

It was discussed how sex-related hormonal variables may influence the development of sensitization to AMPH or stress, and some researchers have begun to explore genetic influences ${ }^{42,177,274}$. But for the 
most part, factors that account for individual variation in the responsiveness to stimulants and stress have received very little attention. Increased knowledge of these will be important in understanding the etiology of stimulant-induced psychosis and the major endogenous psychoses, especially given the complex interplay between environmental and biological variables in the development of psychoses ${ }^{13,18,99,216}$. Research on how genetic, hormonal and environmental factors influence sensitization to stimulants and stress will be valuable in this regard.

\section{SUMMARY}

Some people who repeatedly use stimulant drugs, such as amphetamine (AMPH), develop an AMPHinduced psychosis that is similar to paranoid schizophrenia. There has been, therefore, considerable interest in characterizing the effects of chronic stimulant drug treatment on brain and behavior in non-human animals, and in developing an animal model of AMPH psychosis. A review of this literature shows that in non-human animals chronic AMPH treatment "can produce at least two different syndromes, and both of these have been proposed as animal models of AMPH psychosis. The first syndrome is called 'AMPH neurotoxicity', and is produced by maintaining elevated brain concentrations of AMPH for prolonged periods of time. AMPH neurotoxicity is characterized by what has been termed 'hallucinatorylike' behavior, which occurs in association with brain damage resulting in the depletion of striatal DA and other brain monoamines. The second syndrome is called 'behavioral sensitization', and is produced by the repeated intermittent administration of lower doses of AMPH. Behavioral sensitization is characterized by a progressive and enduring enhancement in many AMPH-induced behaviors, and is not accompanied by brain damage or monoamine depletion. It is argued that the changes in the brain and behavior associated with the phenomenon of behavioral sensitization provide a better 'model' of AMPH psychosis than those associated with AMPH neurotoxicity.

Much of the review involves a critical analysis of hypotheses regarding the biological basis of behavioral sensitization. Research on this question has fo- cused on mesotelencephalic DA systems, and suggestions that behavioral sensitization is accompanied by: (1) an increase in postsynaptic DA receptors; (2) an increase in DA synthesis; (3) an increase in DA utilization and/or release; and (4) a decrease in DA autoreceptors, are evaluated. It is concluded that there is not convincing evidence for an increase in postsynaptic DA receptors or in DA synthesis in animals sensitized to AMPH. In contrast, there is strong evidence to support the notion that behavioral sensitization is due to enhanced mesotelencephalic DA release, especially upon re-exposure to the drug. The evidence that this enhancement in DA release is due to autoreceptor subsensitivity was found to be equivocal, and therefore other hypotheses should be entertained.

Lastly, evidence is discussed in support of the idea that behavioral sensitization is not unique to the psychopharmacology of stimulant drugs, but may be produced by many environmental stimuli that directly or indirectly activate brain catecholamine systems. For example, there are many studies showing that AMPH and stress are to some extent interchangeable in producing both behavioral sensitization and long-term changes in brain DA systems. It is concluded that sensitized animals may be hyperresponsive to any stimulus that activates brain catecholamine systems, and that the effects of sensitization are not obvious in the absence of such stimuli. This may be related to the fact that psychosis only tends to recur in former AMPH addicts following re-exposure to AMPH or stress, and that stress is considered a precipitating factor in psychiatric disorders thought to involve brain catecholamine dysfunction.

\section{ACKNOWLEDGEMENTS}

Research by the authors described herein was partly supported by grant no. 37277 from the NIMH and Research Career Development Award no. 00844 from the NINCDS to T.E.R. We thank E. Castaneda, M. Washburn, an anonymous reviewer, and especially I.Q. Whishaw for their very helpful comments on an earlier version of the manuscript. Kathe Davids deserves thanks for her patient secretarial services. 


\section{REFERENCES}

1 Abruzzi, W., Drug-induced psychosis, Int. J. Addict., 12 (1977) 183-193.

2 Aceto, M.D., Harris, L.S., Lesher, G.Y., Pearl, J. and Brown, T.G., Pharmacologic studies with 7-benzyl-1ethyl-1,4-dihydro-4-oxo-1,8-naphthyridine-8-carboxylic acid, J. Pharmacol. Exp. Ther., 158 (1967) 286-293.

3 Agid, Y., Javoy, G. and Glowinski, J., Hyperactivity of remaining dopaminergic neurones after partial destruction of the nigro-striatal dopaminergic system in the rat, Nature (London) New Biol., 245 (1973) 150-151.

4 Akil, H., Shiomi, H. and Matthews, J., Induction of the intermediate pituitary by stress: synthesis and release of a nonopioid form of $\beta$-endorphin, Science, 227 (1985) 424-426.

5 Akiyama, K., Sato, M., Kashihara, K. and Otsuki, S., Lasting changes in high affinity ${ }^{3} \mathrm{H}$-spiperone binding to the rat striatum and mesolimbic area after chronic methamphetamine administration: evaluation of dopaminergic and serotonergic receptor components, Biol. Psychiatry, 17 (1982) 1389-1402.

6 Akiyama, K., Sato, M. and Otsuki, S., Increased ${ }^{3} \mathrm{H}$-spiperone binding sites in mesolimbic area related to methamphetamine-induced behavioral hypersensitivity, Biol. Psychiatry, 17 (1982) 223-231.

7 Algeri, S., Brunello, N. and Vantini, G., Different adaptive responses by rat striatal dopamine synthetic and receptor mechanisms after repeated treatment with D-amphetamine, methylphenidate and nomifensine, Pharmacol. Res. Commun., 12 (1980) 675-681.

8 Alloway, K.D. and Rebec, G.V., Apomorphine-induced inhibition of neostriatal activity is enhanced by lesions induced by 6-hydroxydopamine but not by long-term administration of amphetamine, Neuropharmacology, 23 (1984) 1033-1039.

9 Alloway, K.D. and Rebec, G.V., Shift from inhibition to excitation in the neostriatum but not in the nucleus accumbens following long-term amphetamine, Brain Res., 273 (1983) 71-79.

10 Angrist, B.M. and Gershon, S., The phenomenology of experimentally induced amphetamine psychosis: preliminary observations, Biol. Psychiatry, 2 (1970) 95-107.

11 Angrist, B.M. and Gershon, S., Psychiatric sequelae of amphetamine use. In R.I. Shader (Ed.), Psychiatric Complications of Medical Drugs, Raven Press, New York, 1972, pp. 175-199.

12 Angrist, B.M. and Sudilovsky, A., Central nervous system stimulants: historical aspects and clinical effects. In L. L. Iversen, S.D. Iversen and S.H. Snyder (Eds.), Handbook of Psychopharmacology, Vol. 11, Stimulants, Plenum Press, New York, 1978, pp. 99-165.

13 Anisman, H., Vulnerability to depression: contribution of stress. In R.M. Post and J.C. Ballenger (Eds.), Neurobiology of Mood Disorders, Vol. 1, Frontiers of Clinical Neuroscience, Williams and Wilkins, Baltimore, 1984, pp. 407-431.

14 Anisman, H. and Sklar, L.S., Catecholamine depletion upon re-exposure to stress: mediation of the escape deficits produced by inescapable shock, J. Comp. Physiol. Psychol., 93 (1979) 610-625.

15 Antelman, S.M., Eichler, A.J., Black, C.A. and Kocan, D., Interchangeability of stress and amphetamine in sensitization, Science, 207 (1980) 329-331.
16 Antelman, S.M. and Chiodo, L.A., Dopamine autoreceptor subsensitivity: a mechanism common to the treatment of depression and the induction of amphetamine psychosis, Biol. Psychiatry, 16 (1981) 717-727.

17 Antelman, S.M. and Chiodo, L.A., Amphetamine as a stressor. In I. Creese (Ed.), Stimulants: Neurochemical, Behavioral and Clinical Perspectives, Raven Press, New York, 1983, pp. 269-299.

18 Antelman, S.M. and Chiodo, L.A., Stress: its effect on interactions among biogenic amines and role in the induction and treatment of disease. In L.L. Iversen, S.D. Iversen and S.H. Snyder (Eds.), Handbook of Psychopharmacology, Vol. 18, Plenum Press, New York, 1984, pp. 279-341.

19 Antelman, S.M. and Eichler, A.J., Persistent effects of stress on dopamine-related behaviors: clinical implications. In E. Usdin, I.J. Kopin and J. Barchas (Eds.), Catecholamines: Basic and Clinical Frontiers, Pergamon, New York, 1979, pp. 1759-1761.

20 Babbini, M. and Davis, W.M., Time-dose relationships for locomotor activity effects of morphine after acute or repeated treatment, $B r . \quad J$. Pharmacol., 46 (1972) 213-224.

21 Babbini, M., Gaiardi, M. and Bartoletti, M., Persistence of chronic morphine effects upon activity in rats 8 months after ceasing the treatment, Neuropharmacology, 14 (1975) 611-614.

22 Baily, R.C. and Jackson, D.M., A pharmacological study of changes in central nervous system receptor responsiveness after long-term dexamphetamine and apomorphine administration, Psychopharmacology, 56 (1978) 317-326.

23 Bakhit, C., Morgan, M.E., Peat, M.A. and Gibb, J.W., Long-term effects of methamphetamine on the synthesis and metabolism of 5-hydroxytryptamine in various regions of the rat brain, Neuropharmacology, 20 (1981) $1135-1140$.

24 Banerjee, S.P., Sharma, V.K., Kung, L.S. and Chanda, S.K., Amphetamine induces $\beta$-adrenergic receptor supersensitivity, Nature (London), 271 (1978) 380-381

25 Bartoletti, M., Gaiardi, M., Gubellini, G., Bacchi, A. and Babbini, M., Long-term sensitization to the excitatory effects of morphine, Neuropharmacology, 22 (1983) 1193-1196.

26 Baudry, M., Costentin, J., Marcais, H., Martres, M.P., Protais, P. and Schwartz, J.C., Decreased responsiveness to low doses of apomorphine after dopamine agonists and the possible involvement of hyposensitivity of dopamine 'autoreceptors', Neurosci. Lett., 4 (1977) 203-207.

27 Beatty, W.W. and Holzer, G.A., Sex differences in stereotyped behavior in the rat, Pharmacol. Biochem. Behav., 9 (1978) 777-783.

28 Becker, J.B., Beer, M.E. and Robinson, T.E., Striatal dopamine release stimulated by amphetamine or potassium: influence of ovarian hormones and the light-dark cycle, Brain Res., 311 (1984) 157-160.

29 Becker, J.B., Castaneda, E., Robinson, T.E. and Beer, M.E., A simple in vitro technique to measure the release of endogenous dopamine and dihydroxyphenylacetic acid from striatal tissue using high performance liquid chromatography with electrochemical detection, J. Neurosci. Meth., 11 (1984) 19-28.

30 Becker, J.B. and Ramirez, V.D., Sex differences in the amphetamine-stimulated release of catecholamines from rat striatal tissue in vitro, Brain Res., 204 (1981) 361-372. 
31 Becker, J.B., Robinson, T.E. and Lorenz, K.A., Sex differences and estrous cycle variations in amphetamine-elicited rotational behavior, Eur. J. Pharmacol., 80 (1982) 65-72.

32 Bell, D.S., The experimental reproduction of amphetamine psychosis, Arch. Gen. Psychiatry, 29 (1973) 35-40.

33 Berglund, M. and Risberg, J., Regional cerebral blood flow in a case of amphetamine intoxication, Psychopharmacology, 70 (1980) 219-221.

34 Besson, M.-J., Cheramy, A., Gauchy, C. and Musacchio, J., Effects of some psychotropic drugs on tyrosine hydroxylase activity in different structures of the rat brain, Eur. J. Pharmacol, 22 (1973) 181-186.

35 Borison, R.L., Hitri, A., Klawans, H.L. and Diamond, B.I., A new animal model for schizophrenia: behavioral and receptor binding studies. In E. Usdin, I.J. Kopin and J. Barchas (Eds.), Calecholamines: Basic and Clinical Frontiers, Pergamon Press, New York, 1978, pp. 719-721.

36 Brass, C.A. and Glick, S.D., Sex differences in drug-induced rotation in two strains of rats, Brain Res., 223 (1981) 229-234.

37 Brien, J.F., Peachey, J.E., Rogers, B.J. and Kitney, J.C., Amphetamine-induced stereotyped behaviour and brain concentrations of amphetamine and its hydroxylated metabolites in mice, J. Pharm. Pharmacol., 29 (1977) 49-50.

38 Brodie, B.B., Costa, E., Dlabac, A., Neff, N.H. and Smookler, H.H., Application of steady kinetics to the estimation of synthesis rate and turnover time of tissue catecholamines, J. Pharmacol. Exp. Ther., 154 (1966) 493-498.

- 39 Brown, G.W., Birley, J.L.T. and Wing, J.R., Influence of family life on the course of schizophrenic disorders, Brit. J. Psychiatry, 121 (1972) 241-258.

40 Browne, R.G. and Segal, D.S., Metabolic and experiential factors in the behavioral response to repeated amphetamine, Pharmacol. Biochem. Behav., 6 (1977) 545-552.

41 Burt, D.R., Creese, I. and Snyder, S.H., Antischizophrenic drugs: chronic treatment elevates dopamine receptor binding in brain, Science, 196 (1977) 326-328.

42 Cabib, S., Puglisi-Allegra, S. and Oliverio, A., A genetic analysis of stereotypy in the mouse: dopaminergic plasticity following chronic stress, Behav. Neural. Biol., 44 (1985) 239-248.

43 Camp, D.M. and Robinson, T.E., Sex differences in an animal model of amphetamine psychosis, Soc. Neurosci. Abstr., 11 (1985) 550.

44 Cassens, G., Roffman, M., Kuruc, A., Orsulak, P.J. and Schildkraut, J.J., Alterations in brain norepinephrine metabolism induced by environmental stimuli previously paired with inescapable shock, Science, 209 (1980) $1138-1140$

45 Castaneda, E., Becker, J.B., Wilcox, R. and Robinson, T.E., Sensitization to amphetamine is accompanied by enhanced striatal dopamine release, Soc. Neurosci. Abstr., 11 (1985) 499.

46 Chanda, S.K., Sharma, V.K. and Banerjee, S.P., $\beta$-Adrenoceptor sensitivity following psychotropic drug treatment. In E. Usdin, I.J. Kopin and J. Barchas (Eds.), Catecholamines: Basic and Clinical Frontiers, Pergamon, New York, 1978, pp. 586-588.

47 Commissiong, J.W., Monoamine metabolites: their relationship and lack of relationship to monoaminergic neuronal activity, Biochem. Pharmacol, 34 (1985) 1127-1131.
48 Connell, P.H., Amphetamine Psychosis, Chapman and Hill, London, 1958.

49 Conway, P.G. and Uretsky, N.J., Role of striatal dopaminergic receptors in amphetamine-induced behavioral facilitation, J. Pharmacol. Exp. Ther., 221 (1982) 650-655.

50 Costa, E. and Garattini, S. (Eds.), Amphetamines and Related Compounds, Raven Press, New York, 1970

51 Costall, B. and Naylor, R.J., Mesolimbic and extrapyramidal sites for the mediation of stereotyped behavior patterns and hyperactivity by amphetamine and apomorphine in the rat. In E.H. Ellinwood and M.M. Kilbey (Eds.), Cocaine and Other Stimulants, Plenum, New York, 1977, pp. 47-76.

52 Coyne, M.D. and Kitay, J.I., Effect of ovariectomy on pituitary secretion of ACTH, Endocrinology, 85 (1969) 1097-1102.

53 Coyne, M.D. and Kitay, J.I., Effect of orchiectomy on pituitary secretion of ACTH, Endocrinology, 89 (1971) 1024-1028.

54 Creese, I., Burt, D.R, and Snyder, S.H., Dopamine receptor binding enhancement accompanies lesion-induced behavioral sensitivity, Science, 197 (1977) 596-598.

55 deleted

56 Crider, A., Solomon, P.R. and McMahon, M.A., Disruption of selective attention in the rat following chronic Damphetamine administration: relationship to schizophrenic attention disorder, Biol. Psychiatry, 17 (1982) 351-361.

57 Critchlow, V., Liebelt, R.A., Bar-Sela, M., Mountcastle, W. and Lipscomb, H.S., Sex difference in resting pituitary-adrenal function in the rat, Am. J. Physiol., 205 (1963) 807-815

58 Crow, T.J., Schizophrenia. In T.J. Crow (Ed.), Disorders of Neurohumoral Transmission, Academic Press, New York, 1982, pp. 287-340.

59 Daiguji, M. and Meltzer, H.Y., Effect of chronic phencyclidine or D-amphetamine treatment on $\left[{ }^{3} \mathrm{H}\right]$ spiroperidol binding in rat caudate-putamen and nucleus accumbens, Eur. J. Pharmacol., 85 (1982) 339-342.

60 Danielson, T.J., Petrali, E.J. and Wishart, T.B., The effect of acute and chronic injections of D-amphetamine sulfate and substantia nigra lesions on the distribution of amphetamine and para-hydroxyamphetamine in the rat brain, Life Sci., 19 (1976) 1265-1270.

61 Davis, K.L., Davidson, M., Mohs, R.C., Kendler, K.S. Davis, B.M., Johns, C.A., DeNigris, Y. and Horvath, T.B., Plasma homovanillic acid concentration and the severity of schizophrenic illness, Science, 227 (1985) 1601-1602.

62 Demellweek, C. and Goudie, A.J., Behavioural tolerance to amphetamine and other psychostimulants: the case for considering behavioural mechanisms, Psychopharmacology, 80 (1983) 287-307.

63 Dohrenwend, B.P. and Egri, G., Recent stressful life events and episodes of schizophrenia, Schizophr. Bull., 7 (1981) 12-23.

64 Dougherty, G.G. and Ellinwood, E.H., Amphetamine behavioral toxicity: rotational behavior after chronic intrastriatal infusion, Biol. Psychiatry, 16 (1981) 479-488.

65 Dougherty, G.G. and Ellinwood, E.H., Influence of gamma-butyrolactone on behavior due to dopaminergic drugs, Physiol. Behav., 30 (1983) 607-612.

66 Echols, S.D., Reverse tolerance to amphetamine of mice bearing unilateral striatal lesions: effect upon the circling 
response to apomorphine, Life Sci., 24 (1979) 691-696.

67 Echols, S.D., Circling of mice bearing unilateral striatal lesions: development of increased response to D-amphetamine, Life Sci., 21 (1977) 563-568.

68 Ehrich, W.E. and Krumbhaar, E.B., The effects of large doses of benzedrine sulfate on the albino rat: functional and tissue changes, Ann. Int. Med., 10 (1937) 1874-1888.

69 Eichler, A.J., Antelman, S.M. and Black, C.A., Amphetamine stereotypy is not a homogeneous phenomenon: sniffing and licking show distinct profiles of sensitization and tolerance, Psychopharmacology, 68 (1980) 287-290.

70 Eichler, A.J. and Antelman, S.M., Sensitization to amphetamine and stress may involve nucleus accumbens and medial frontal cortex, Brain Res., 176 (1979) 412-416.

71 Eison, M.S., Eison, A.S. and Iversen, S.D., Two routes of continuous amphetamine administration induce different behavioral and neurochemical effects in the rat, Neurosci. Lett., 39 (1983) 313-319.

72 Ellinwood, E.H., Accidental conditioning with chronic methamphetamine intoxication: implications for a theory of drug habituation, Psychopharmacology, 21 (1971) 131-138.

73 Ellinwood, E.H., Amphetamine psychosis. I. Description of the individuals and process, J. Nerv. Ment, Dis., 144 (1967) 273-283.

74 Ellinwood, E.H., Amphetamine psychosis: individuals, settings, and sequences. In E.H. Ellinwood and S. Cohen (Eds.), Current Concepts on Amphetamine Abuse, U.S. Government Printing Office, Washington, DC, 1972, pp. 143-157.

75 Ellinwood, E.H., Amphetamine psychosis. II. Theoretical implications, J. Neuropsychiarry, 4 (1968) 45-54.

76 Ellinwood, E.H., Effects of chronic methamphetamine intoxication in rhesus monkeys, Biol. Psychiatry, 3 (1971) 25-32.

77 Ellinwood, E.M. and Escalante, O., Behavior and histopathological findings during chronic methedrine intoxication, Biol. Psychiatry, 2 (1970) 27-39.

78 Ellinwood, E.H. and Lee, T.H., Effect of continuous systemic infusion of $\mathrm{D}$-amphetamine on the sensitivity of nigral dopamine cells to apomorphine inhibition of firing rates, Brain Res., 273 (1983) 379-383.

79 Ellinwood, E.H., Sudilovsky, A. and Nelson, L.M., Evolving behavior in the clinical and experimental (model) psychosis, Am. J. Psychiairy, 130 (1973) 1088-1092.

80 Ellison, G.D., Animal models of psychopathology: studies in naturalistic colony environments. In J.D. Keehn (Ed.), Psychopathology in Animals, Academic Press, New York, 1979, pp. 81-101.

81 Ellison, G.D. and Eison, M.A., Continuous amphetamine intoxication: an animal model of the acute psychotic episode, Psychol. Med., 13 (1983) 751-762.

82 Ellison, G.D., Eison, M.S., Huberman, H.S. and Daniel, $F$., Long-term changes in dopaminergic innervation of caudate nucleus after continuous amphetamine administration, Science, 201 (1978) 276-278.

83 Ellison, G.D. and Morris, W., Opposed stages of continuous amphetamine administration: parallel alterations in motor stereotypies and in vivo spiroperidol accumulation, Eur. J. Pharmacol., 74 (1981) 207-214.

84 Ellison, G.D., Nielsen, E.B. and Lyon, M., Animal model of psychosis: hallucinatory behaviors in monkeys during the late stage of continuous amphetamine intoxication, J. Psychiat. Res., 16 (1981) 13-22.
85 Ellison, G.D. and Ratan, R., The late stage following continuous amphetamine administration to rats is correlated with altered dopamine but not serotonin metabolism, Life Sci., 31 (1982) 771-777.

86 Farnebo, L.O. and Hamberger, B., Drug-induced changes in release of ${ }^{3} \mathrm{H}$-monoamines from field stimulated rat brain slices, Acla Physiol. Scand., Suppl. 371 (1971) 35-44.

87 Feigenbaum, J.J., Weiner, W.J. and Klawans, H.L., The role of scheduling in amphetamine hypersensitivity and tolerance. In E. Usdin, I.J. Kopin and J. Barchas (Eds.), Catecholamines: Basic and Clinical Frontiers, Vol. 2, Pergamon Press, New York, 1979, pp. 1637-1639.

88 Feinberg, G. and Irwin, S., Effects of chronic methamphetamine administration in the cat, Fed. Proc., 20 (1961) 396.

89 Ferris, R.M., Tang, F.L.M. and Maxwell, R.A., A comparison of the capacities of isomers of amphetamine, deoxypipradrol and methylphenidate to inhibit the uptake of tritiated catecholamines into rat cerebral cortex slices, synaptosomal preparations of rat cerebral cortex, hypothalamus and striatum and into adrenergic nerves of rabbit aorta, J. Pharmacol. Exp. Ther., 181 (1972) 407-416.

90 Fibiger, H.C. and McGeer, E.G., Effect of acute and chronic methamphetamine treatment on tyrosine hydroxylase activity in brain and adrenal medulla, Eur. J. Pharmacol., 16 (1971) 176-180.

91 Finnegan, K.T., Ricaurte, G., Seiden, L.S. and Schuster, C.R., Altered sensitivity to D-methylamphetamine, apomorphine and haloperidol in rhesus monkeys depleted of caudate dopamine by repeated administration of Dmethylamphetamine, Psychopharmacology, 77 (1982) 43-52.

92 Fischer, J.F. and Cho, A.K., Chemical release of dopamine from striatal homogenates: evidence for an exchange-diffusion model, J. Pharmacol. Exp. Ther, 208 (1979) 203-209.

93 Fuller, R.W., Persistent effects of amphetamine, $p$-chloro-amphetamine, and related compounds on central dopamine and serotonin neurons in rodents, Psychopharmacol. Bull., 21 (1985) 528-532.

94 Fuller, R.W. and Hemrick-Luecke, S., Long-lasting depletion of striatal dopamine by a single injection of amphetamine in iprindole-treated rats, Science, 209 (1980) 305-307.

95 Garver, D.S., Schlemmer, R.F., Maas, J.W. and Davis, J.M., A schizophreniform behavioral psychosis mediated by dopamine, Am. J. Psychiatry., 133 (1975) 33-38.

96 Gilman, A.G., Goodman, L.S. and Gilman, A., The Pharmacological Basis of Therapeutics, Macmillan, New York, 1980.

97 Glowinski, J., Properties and functions of intraneuronal monoamine compartments in central aminergic neurons. In L.L. Iversen, S.D. Iversen and S.H. Snyder (Eds.), Handbook of Psychopharmacology. Vol. 3, Plenum Press, New York, 1975, pp. 139-167.

98 Goetz, C.G. and Klawans, H.L., Stimulant-induced chorea: clinical studies and animal models. In I. Creese (Ed.), Stimulants: Neurochemical, Behavioral and Clinical Perspectives, Raven Press, New York, 1983, pp. 227-235.

99 Gold, M.S and Bowers, M.B., Neurobiological vulnerability to low-dose amphetamine psychosis, Am. J. Psychiatry, 135 (1978) 1546-1548.

100 Griffith, J.D., Cavanaugh, J., Held, J. and Oates, J.A., 
Dextroamphetamine evaluation of psychomimetic properties in man, Arch. Gen. Psychiatry, 26 (1972) 97-100.

101 Gropetti, A. and Costa, E., Factors affecting the rate of disappearance of amphetamine in rats, Int. J. Neuropharmacol. , 8 (1969) 209-215.

102 Gunne, L.M. and Jonsson, J., Effects of cocaine administration on brain, adrenal and urinary adrenaline and noradrenaline in rats, Psychopharmacology, 6 (1964) $125-129$.

103 Haracz, J., A neural plasticity hypothesis of schizophrenia, Neurosci. Biobehav. Rev., 8 (1984) 55-71.

104 Hefti, F., Melamed, E. and Wurtman, R.J., Partial lesions of the dopaminergic nigrostriatal system in rat brain: biochemical characterization, Brain Res., 195 (1980) 123-137.

105 Hellman, P.A., Crider, A. and Solomon, P.R., Interaction of tail-pressure stress and $D$-amphetamine in disruption of the rat's ability to ignore an irrelevant stimulus, $B e$ hav. Neurosci., 97 (1983) 1017-1021.

106 Hennessy, J.W., Levin, R. and Levine, S., Influence of experiential factors and gonadal hormones on pituitary. adrenal response of the mouse to novelty and electric shock, J. Comp. Physiol. Psychol., 91 (1977) 770-777.

107 Hennessy, J.W. and Levine, S., Stress, arousal and the pituitary-adrenal system: a psychoendocrine hypothesis. In J.M. Sprague and A.N. Epstein (Eds.), Progress in Psychobiology and Physiological Psychology, Vol. 8, 1979, pp. 133-178.

108 Herman, J.P., Stinus, L. and Le Moal, M., Repeated stress increases locomotor response to amphetamine, Psychopharmacology, 84 (1984) 431-435.

109 Herman, Z.S., Trzeciak, H., Chrusciel, T.L., KmieciakKolada, K., Drybanski, A. and Sokola, A., The influence of prolonged amphetamine treatment and amphetamine withdrawal on brain biogenic amine content and behavior in the rat, Psychopharmacology, 21 (1971) 74-81.

110 Hirabayashi, M. and Alam, M.R., Enhancing effect of methamphetamine on ambulatory activity produced by re. peated administration in mice, Pharmacol. Biochem. Behav., 15 (1981) 925-932.

111 Hitzemann, R., Wu, J., Hom, D. and Loh, H., Brain locations controlling the behavioral effects of chronic amphetamine intoxication, Psychopharmacology, 72 (1980) 93-101.

112 Hitzemann, R.J., Tseng, L.F., Hitzemann, B.A., Sampath-Khanna, S. and Loh, H.H., Effects of withdrawal from chronic amphetamine intoxication on exploratory and stereotyped behaviors in the rat, Psychopharmacology, 54 (1977) 295-302.

113 Hotchkiss, A.J. and Gibb, J.W., Long-term effects of multiple doses of methamphetamine on tryptophan hy. droxylase and tyrosine hydroxylase activity in rat brain, J. Pharmacol. Exp. Ther., 214 (1980) 257-262.

114 Howlett, D.R. and Nahorski, S.R., Effect of acute and chronic amphetamine administration on $\beta$-adrenoceptors and dopamine receptors in rat corpus striatum and limbic forebrain, Br. J. Pharmacol., 64 (1978) 411P

115 Howlett, D.R. and Nahorski, S.R., Acute and chronic amphetamine treatments modulate striatal dopamine receptor binding sites, Brain Res., 161 (1979) 173-178.

116 Hruska, R.E., Ludmer, L.M. and Silbergeld, E.K., Characterization of the striatal dopamine receptor supersensitivity produced by estrogen treatment of male rats, Neuropharmacology, 19 (1980) 923-926.
117 Huberman, H.S., Eison, M.S., Bryan, K.S. and Ellison, G., A slow-release silicone pellet for chronic amphetamine administration, Eur. J. Pharmacol, 45 (1977) 237-242.

118 Hulme, E.C., Hill, R., North, M. and Kibby, M.R., Effects of chronic administration of drugs which modify neurotransmitter re-uptake, storage and turnover on levels of tyrosine and tryptophan hydroxylase in rat brain, Biochem. Pharmacol., 23 (1974) 1393-1404.

119 Iversen, S.D., Brain dopamine systems and behavior. In L.L. Iversen, S.D. Iversen and S.H. Snyder (Eds.), Handbook of Psychopharmacology, Vol. 8, Plenum, New York, 1977, pp. 333-383.

120 Iversen, S.D and Iversen, L.L., Behavioral Pharmacology, Oxford University Press, New York, 1981.

121 Jackson, D.M., Bailey, R.C., Christie, M.J., Crisp, E.A. and Skerritt, J.H., Long-term D-amphetamine in rats: lack of a change in postsynaptic dopamine receptor sensitivity, Psychopharmacology, 73 (1981) 276-280.

122 Jacobs, B.L., An animal behavior model for studying central serotonergic synapses, Life Sci., 19 (1976) 777-786.

123 Jacobs, B.L., Trulson, M.E. and Stern, W.C., Behavioral effects of LSD in the cat: proposal of an animal behavior model for studying the actions of hallucinogenic drugs, Brain Res., 132 (1977) 301-314.

124 Janowsky, D.S. and Risch, C., Amphetamine psychosis and psychotic symptoms, Psychopharmacology, 65 (1979) 73-77.

125 Jenner, P., Pycock, C. and Marsden, C.D., The effect of chronic administration and withdrawal of amphetamine on cerebral dopamine receptor sensitivity, Psychopharmacology, 58 (1978) 131-136.

126 Jonsson, L.E., Anggard, E. and Gunne, L.M., Blockade of intravenous amphetamine euphoria in man, Clin. Pharmacol. Ther., 12 (1971) 889-896.

127 Jori, A. and Bernardi, D., Further studies on the increase of striatal homovanillic acid induced by amphetamine and fenfluramine, Eur. J. Pharmacol., 19 (1972) 276-280.

128 Joyce, E.M. and Iversen, S.D., The effect of morphine applied locally to mesencephalic dopamine cell bodies on spontaneous motor activity in the rat, Neurosci. Lett., 14 (1979) 207-212.

129 Kalivas, P.W., Sensitization to repeated enkephalin administration into the ventral tegmental area of the rat. II. Involvement of the mesolimbic dopamine system, J. Pharmacol. Exp. Ther., 235 (1985) 544-550.

130 Kalivas, P.W., Richardson-Carlson, R. and Van Orden, $G$., Cross-sensitization between footshock stress and enkephalin-induced motor activity, Biol. Psychiatry, in press.

131 Kalivas, P.W., Taylor, S. and Miller, J.S., Sensitization to repeated enkephalin administration into the ventral tegmental area of the rat. I. Behavioral characterization, J. Pharmacol. Exp. Ther., 235 (1985) 537-543.

132 Kamal, L.A., Arbilla, S. and Langer, S.Z., Presynaptic modulation of the release of dopamine from the rabbit caudate nucleus: differences between electrical stimulation, amphetamine and tyramine, J. Pharmacol. Exp. Ther., 216 (1981) 592-598.

133 Kamata, K. and Rebec, G.V., Dopaminergic and neostriatal neurons: dose-dependent changes in sensitivity to amphetamine following long-term treatment, Neuropharmacology, 22 (1983) 1377-1382.

134 Kamata, K. and Rebec, G.V., Nigral dopaminergic neu- 
rons: differential sensitivity to apomorphine following long-term treatment with low and high doses of amphetamine, Brain Res., 321 (1984) 147-150.

135 Kamata, K. and Rebec, G.V., Long-term amphetamine treatment attenuates or reverses the depression of neuronal activity produced by dopamine agonists in the ventral tegmental area, Life Sci., 34 (1984) 2419-2427.

136 Kamata, K. and Rebec, G.V., Iontophoretic evidence for subsensitivity of postsynaptic dopamine receptors following long-term amphetamine administration, Eur. J. Pharmacol., 106 (1985) 393-397.

137 Kamata, K. and Rebec, G.V., Nigral reticulata neurons: potentiation of responsiveness to amphetamine with longterm treatment, Brain Res., 332 (1985) 188-193.

138 Kandel, E.R. and Schwartz, J.H., Molecular biology of learning: modulation of transmitter release, Science, 218 (1982) 433-443

139 Kaneno, S. and Shimazono, Y., Decreased in vivo $\left[{ }^{3} \mathrm{H}\right]$ spiroperidol binding in rat brain after repeated methamphetamine administration, Eur. J. Pharmacol., 72 (1981) 101-105.

140 Kanner, B.I., Bioenergetics of neurotransmitter transport, Biochem. Biophys. Acta, 726 (1983) 293-316.

141 Kant, G.J., Lenox, R.H., Bunnell, B.N., Mougey, E.H., Pennington, L.L. and Meyerhoff, J.L., Comparison of stress response in male and female rats: pituitary cyclic AMP and plasma prolactin, growth hormone and corticosterone, Psychoneuroendocrinology, 8 (1983) 421-428.

142 Karoum, F., Speciale, S.G., Chuang, L.-W. and Wyatt, R.J., Selective effects of phenylethylamine on central catecholamines: a comparative study with amphetamine, J. Pharmacol. Exp. Ther., 223 (1982) 432-439.

143 Kashiwabara, K., Sato, M. and Otsuki, S., Reduction of ${ }^{3} \mathrm{H}$-kainic acid binding in rat cerebral cortex by chronic methamphetamine administration, Biol. Psychiatry, 19 (1984) 1173-1182.

144 Kato, R., Sex-related differences in drug metabolism, Drug Metabol. Rev., 3 (1974) 1-32.

145 Kilbey, M.M. and Ellinwood, E.H., Chronic administration of stimulant drugs: response modification. In E.H. Ellinwood and M.M. Kilbey (Eds.), Cocaine and Other Stimulants, Plenum, New York, 1977b, pp. 409-429.

146 Kilbey, M.M. and Ellinwood, E.H., Reverse tolerance to stimulant-induced abnormal behavior, Life Sci., 20 (1977) 1063-1076.

147 Kilbey, M.M. and Sannerud, C.A., Models of tolerance: do they predict sensitization to the effects of psychomotor stimulants. In L.S. Seiden and R.L. Balster (Eds.), Behavioral Pharmacology: The Current Status, Alan R. Liss, New York, 1985, pp. 295-321.

$148 \mathrm{Kim}$, J.S., Kornhuber, H.H., Brand, U. and Menge, H.G., Effects of chronic amphetamine treatment on the glutamate concentration in cerebrospinal fluid and brain: implications for a theory of schizophrenia, Neurosci. Lett., 24 (1981) 93-96.

149 Kim, J.S., Kornhuber, H.H., Schmid-Burgk, W. and Holzmuller, B., Low cerebrospinal fluid glutamate in schizophrenic patients and a new hypothesis of schizophrenia, Neurosci. Lett., 20 (1980) 379-382.

150 Kitay, J.I., Pituitary-adrenal function in the rat after gonadectomy and gonadal hormone replacement, Endocrinology, 73 (1963) 253-260.

151 Kitay, J.I., Sex differences in adrenal cortical secretion in the rat, Endocrinology, 68 (1961) 818-824.
152 Klawans, H.L. and Margolin, D.I., Amphetamine-induced dopaminergic hypersensitivity in guinea pigs, Arch. Gen. Psychiatry, 32 (1975) 725-732.

153 Klawans, H.L., Margolin, D.I., Dava, N. and Crosset, P., Supersensitivity to D-amphetamine and apomorphine-induced stereotyped behavior induced by chronic D-amphetamine administration, J. Neurol. Sci., 25 (1975) 283-289.

154 Klawans, H.L., Hitri, A., Carvey, P.M., Nausieda, P.A. and Weiner, W.J., Effect of chronic dopaminergic agonist on striatal membrane dopamine binding, Adv. Neurol., 24 (1979) 217-224.

155 Kogan, F.J., Nichols, W.K. and Gibb, J.W., Influence of methamphetamine on nigral and striatal tyrosine hydroxylase activity and on striatal dopamine levels, Eur. J. Pharmacol., 36 (1976) 363-371.

156 Kokkinidis, L., Effects of chronic intermittent and continuous amphetamine administration on acoustic startle, Pharmacol. Biochem. Behav., 20 (1984) 367-372.

157 Kokkinidis, L. and Anisman, H., Amphetamine models of paranoid schizophrenia: an overview and elaboration of animal experimentation, Psychol. Bull., 88 (1980) $551-579$.

158 Kokkinidis, L. and Anisman, H., Amphetamine psychosis and schizophrenia: a dual model, Neurosci. Biobehav. Rev., 5 (1981) 449-461.

159 Kokkinidis, L. and MacNeill, E.P., Potentiation of D-amphetamine and L-DOPA-induced acoustic startle activity after long-term exposure to amphetamine, Psychopharmacology, 78 (1982) 331-355.

$160 \mathrm{Kolb}, \mathrm{B}$. and Whishaw, I.Q., Performance of schizophrenic patients on tests sensitive to left or right frontal, temporal, or parietal function in neurological patients, J. Nerv. Ment. Dis., 171 (1983) 435-443.

161 Kolta, M.B., Shreve, P., De Souza, V. and Uretsky, N.J., Time course of the development of the enhanced behavioral and biochemical responses to amphetamine after pretreatment with amphetamine, Neuropharmacology, 24 (1985) 823-829.

162 Korf, J., Grasdijk, L. and Westerink, B.H.C., Effects of electrical stimulation of the nigrostriatal pathway of the rat on dopamine metabolism, J. Neurochem., 26 (1976) 579-584.

163 Korpi, E.R. and Wyatt, R.J., Effects of chronic D-amphetamine and phenylethylamine on the concentrations of neurotransmitter amino acids in the rat brain, Int. J. Neurosci., 18 (1983) 239-246.

164 Kosman, M.E. and Unna, K.R., Effects of chronic administration of the amphetamines and other stimulants on behavior, Clin. Pharmacol. Ther., 9 (1968) 240-254.

165 Kramer, J.C., Fischman, V.S. and Littlefield, D.C., Amphetamine abuse, J. Am. Med. Assoc., 201 (1967) 305-309.

166 Kuczenski, R., Biochemical actions of amphetamine and other stimulants. In I. Creese (Ed.), Stimulants: Neurochemical, Behavioral and Clinical Perspectives, Raven Press, New York, 1983, pp. 31-61.

167 Kuczenski, R. and Leith, N.J., Chronic amphetamine: is dopamine a link in or mediator of the development of tolerance and reverse tolerance?, Pharmacol. Biochem. Behav., 15 (1981) 405-413.

168 Kuczenski, R., Leith, N.J. and Applegate, C.D., Striatal dopamine metabolism in response to apomorphine: the effects of repeated amphetamine pretreatment, Brain Res., 258 (1983) 333-337. 
169 Kuczenski, R., Segal, D.S., Weinberger, S.B. and Browne, R.G., Evidence that a behavioral augmentation following repeated amphetamine administration does not involve peripheral mechanisms, Pharmacol. Biochem. Behav., 17 (1982) 547-553.

170 Kuhn, C.M. and Schanberg, S.M., Distribution and metabolism of amphetamine in tolerant animals. In E.H. Ellinwood and M.M. Kilbey (Eds.), Cocaine and Other Stimulants, Plenum, New York, 1977, pp. 161-177.

171 Kvetnansky, R., Gewirtz, G.P., Weise, V.K. and Kopin, I.J., Effect of hypophysectomy on immobilization-induced elevation of tyrosine hydroxylase and phenylethanolamine-N-methyl transferase in the rat adrenal, Endocrinology, 87 (1970) 1323-1329.

172 Langer, S.Z. and Arbilla, S., Presynaptic regulation of neurotransmitter release: physiological and pharmacological implications. In R. Caputto and C. Ajmone Marsan (Eds.), Neural Transmission, Learning and Memory, Raven Press, New York, 1983, pp. 11-20.

173 Langer, S.Z. and Arbilla, S., The amphetamine paradox in dopaminergic neurotransmission, Trends Pharmacol. Sci., 5 (1984) 387-390.

174 Lavielle, S., Tassin, J.-P., Thierry, A.-M., Blanc, G., Herve, D., Barthelemy, C. and Glowinski, J., Blockade by benzodiazepines of the selective high increase in dopamine turnover induced by stress in mesocortical dopaminergic neurons of the rat, Brain Res., 168 (1978) $585-594$

175 Leff, S.E. and Creese, I., Dopaminergic D-3 binding sites are not presynaptic autoreceptors, Narure (London), 306 (1983) 586-589.

176 Leith, N.J. and Kuczenski, R., Chronic amphetamine: tolerance and reverse tolerance reflect different behavioral actions of the drug, Pharmacol. Biochem. Behav., 15 (1981) 399-404.

177 Leith, N.J. and Kuczenski, R., Two dissociable components of behavioral sensitization following repeated amphetamine administration, Psychopharmacology, 76 (1982) 310-315.

178 Le Mevel, J.C., Abitbol, S., Beraud, G. and Maniey, J., Temporal changes in plasma adrenocorticotropin concentration after repeated neurotropic stress in male and female rats, Endocrinology, 105 (1979) 812-817.

179 Levine, M.S., Hull, C.D., Garcia-Rill, E., Erinoff, L. Buchwald, N.A. and Heller, A., Long-term decreases in spontaneous firing of caudate neurons induced by amphetamine in cats, Brain Res., 194 (1980) 263-268.

180 Lewander, T., Experimental and clinical studies on am. phetamine dependence. In H.M. Van Praag (Ed.), Biochemical and Pharmacological Aspects of Dependence and Reports on Marijuana Research, De Erven F. Bohn, Haarlem, The Netherlands, 1972, pp. 69-84.

181 Lorez, H., Fluorescence histochemistry indicates damage of striatal dopamine nerve terminals in rats after multiple doses of methamphetamine, Life Sci., 28 (1981) 911-916.

182 Lynch, J.J., Stein, E.A. and Fertziger, A.P., An analysis of 70 years of morphine classical conditioning: implica. tions for clinical treatment of narcotic addiction, J. Nerv. Ment. Dis., 163 (1976) 47-58.

183 Lynch, M., Kenny, M. and Leonard, B.E., The effect of chronic administration of $\mathrm{D}$-amphetamine on regional changes in catecholamines in the rat brain, $J$. Neurosci. Res., 3 (1977) 295-300

184 Lynch, M.A. and Leonard, B.E., Changes in brain gam- ma-aminobutyric acid concentrations following acute and chronic amphetamine administration and during post amphetamine depression, Biochem. Pharmacol., 27 (1978) 1853-1855.

185 Magos, L., Persistence of the effect of amphetamine on stereotyped activity in rats, Eur. J. Pharmacol., 6 (1969) 200-201.

186 Martres, M.P., Costentin, J., Baudry, M., Marcais, H., Protais, P. and Schwartz, J.C., Long-term changes in the sensitivity of pre- and post-synaptic dopamine receptors in mouse striatum evidenced by behavioral and biochemical studies, Brain Res., 136 (1977) 319-337.

187 Melamed, E., Hefti, F. and Wurtman, R.J., Tyrosine administration increases striatal dopamine release in rats with partial nigrostriatal lesions, Proc. Natl. Acad. Sci. U.S.A., 77 (1980) 4305-4309.

188 Meyer, E., Age- and sex-related differences in amphetamine-induced locomotor activity, Fed. Proc., 36 (1977) 1033.

189 Meyer̈, J.E.M. and Lytle, L.D., Sex related differences in the physiological disposition of amphetamine and its metabolites in the rat, Proc. West. Pharmacol. Soc., 21 (1978) 313-316.

190 Mishra, R.K., Gardner, E.L., Katzman, R. and Makman, M.H., Enhancement of dopamine-stimulated adenylate cyclase activity in rat caudate after lesions in substantia nigra: evidence for denervation supersensitivity, Proc. Natl. Acad. Sci. U.S.A., 71 (1974) 3883-3887

191 Mittleman, G., Castaneda, E., Robinson, T.E.. and Valenstein, E.S., The propensity for non-regulatory ingestive behavior is related to differences in dopamine systems: behavioral and biochemical evidence, Behav. Neurosci., 100 (1986) 213-220.

192 Moore, K.E., Amphetamines: biochemical and behavioral actions in animals. In L.L. Iversen, S.D. Iversen and S.H. Snyder (Eds.), Handbook of Psychopharmacology, Plenum Press, New York, 1978, pp. 41-98.

193 Moore, K.E. and Kelly, P.H., Biochemical pharmacology of mesolimbic and mesocortical dopamine neurons. In M.A. Lipton, A. DiMascio and K.F. Killam (Eds.), Psychopharmacology: A Generation of Progress, Raven Press, New York, 1978, pp. 221-234.

194 Morgan, M.E. and Gibb, J.W., Short-term and long-term effects of methamphetamine on biogenic amine metabolism in extrastriatal dopaminergic nuclei, Neuropharmacology, 19 (1980) 989-995.

195 Muller, P. and Seeman, P., Presynaptic subsensitivity as a possible basis for sensitization by long-term dopamine mimetics, Eur. J. Pharmacol., 55 (1979) 149-157.

196 Munkvad, I., Randrup, A. and Fog, R., Amphetamines and psychosis. In D. DeWied and P.A. VanKeep (Eds.), Hormones and Behavior, University Park Press, Baltimore, 1980, pp. 221-229.

197 Nelson, L.R. and Ellison, G., Enhanced stereotypies after repeated injections but not continuous amphetamines, Neuropharmacology, 17 (1978) 1081-1084.

198 Nielsen, E.B., Rapid decline of stereotyped behavior in rats during constant one week administration of amphetamine via implanted ALZET osmotic minipumps, Pharmacol. Biochem. Behav., 15 (1981) 161-165.

199 Nielsen, E.B., Eison, M.S., Lyon, M. and Iversen, S.D., Hallucinatory behaviors in primates produced by aroundthe-clock amphetamine treatment for several days via implanted capsules. In K.A. Miczek (Eds.), Ethopharmaco- 
logy. Primate Models of Neuropsychiatric Disorders, Alan R. Liss, New York, 1983, pp. 79-100.

200 Nielsen, E.B., Lee, T.H. and Ellison, G., Following several days of continuous administration $\mathrm{D}$-amphetamine acquires hallucinogen-like properties, Psychopharmacology, 68 (1980) 197-200.

201 Nilsson, A., Risberg, J., Johanson, M. and Gustafson, L., Regional changes of cerebral blood flow during haloperidol therapy in patients with paranoid symptoms, Acta Neurol. Scand., 5 (1977) 478-479.

202 Nishikawa, T., Mataga, N., Takashima, M. and Toru, M., Behavioral sensitization and relative hyperresponsiveness of striatal and limbic dopaminergic neurons after repeated methamphetamine treatment, Eur. J. Pharmacol., 88 (1983) 195-203.

203 Nwanze, E. and Jonsson, G., Amphetamine neurotoxicity on dopamine nerve terminals in the caudate nucleus of mice, Neurosci. Lett., 26 (1981) 163-168.

204 Owen, F., Baker, H.F., Ridley, R.M., Cross, A.J. and Crow, T.J., Effect of chronic amphetamine administration on central dopaminergic mechanisms in the vervet, Psychopharmacology, 74 (1981) 213-216.

205 Pearl, R.G. and Seiden, L.S., The existance of tolerance to and cross-tolerance between $\mathrm{D}$-amphetamine and methylphenidate for their effects on milk consumption and on differential reinforcement-of-low-rate performance in the rat, J. Pharmacol. Exp. Ther., 198 (1976) 635-647.

206 Pearl, R.G. and Seiden, L.S., D-Amphetamine-induced increase in catecholamine synthesis in the corpus striatum of the rat: persistence of the effect after tolerance, J. Neural. Transm., 44 (1979) 21-38.

207 Peat, M.A., Warren, P.F. and Gibb, J.W., Effects of a single dose of methamphetamine and iprindole on the serotonergic and dopaminergic system of the rat brain, J. Pharmacol. Exp. Ther., 225 (1983) 126-131.

208 Pickar, D., Labarca, R., Linnoila, M., Roy, A., Hommer, D., Everett, D. and Paul, S.M., Neuroleptic-induced decrease in plasma homovanillic acid and antipsychotic activity in schizophrenic patients, Science, 225 (1984) 954-957.

209 Pickens, R. and Dougherty, J.A., Conditioning of the activity effects of drugs. In T.I. Thompson and R. Pickens (Eds.), Stimulus Properties of Drugs, Appleton-CenturyCrofts, New York, 1971, pp. 39-50.

210 Post, R.M., Central stimulants: clinical and experimental evidence on tolerance and sensitization. In Y. Israel, F.B. Glaser, H. Kalant, R.E. Pophano, W. Schmidt and R.G. Smart (Eds.), Research Advances in Alcohol and Drug Problems, Vol. 6, Plenum Press, New York, 1981, pp. $1-65$.

211 Post, R.M., Intermittent versus continuous stimulation: effect of time interval on the development of sensitization or tolerance, Life Sci., 26 (1980) 1275-1282.

212 Post, R.M., Cocaine psychosis: a continuum model, $\mathrm{Am}$. J. Psychiatry, 132 (1975) 225-231.

213 Post, R.M. and Contel, N.R., Human and animal studies of cocaine: implications for development of behavioral pathology. In I. Creese (Ed.), Stimulants: Neurochemical, Behavioral and Clinical Perspectives, Raven Press, New York, 1983, pp. 169-203.

214 Post, R.M., Contel, N.R. and Gold, P., Impaired behavioral sensitization to cocaine in vasopressin deficient rats, Life Sci., 31 (1982) 2745-2750.
215 Post, R.M., Lockfeld, A., Squillace, K.M. and Contel, N.R., Drug-environment interaction: context dependency of cocaine-induced behavioral sensitization, Life Sci., 28 (1981) 755-760.

216 Post, R.M., Rubinow, D.R. and Ballenger, J.C., Condjtioning, sensitization and kindling: implications for the course of affective illness. In R.M. Post and J.C. Ballenger (Eds.), Neurobiology of Mood Disorders. Frontiers of Clinical Neuroscience, Williams and Wilkins, Baltimore, 1984, pp. 432-466.

217 Predy, P.A. and Kokkinidis, L., Sensitization to the effects of repeated amphetamine administration on intracranial self-stimulation: evidence for changes in reward, $B e$ hav. Brain Res., 13 (1984) 251-259.

218 Preston, K.L., Wagner, G.C., Schuster, C.R. and Seiden, L.S., Long-term effects of repeated methylamphetamine administration on monoamine neurons in the rhesus monkey brain, Brain Res., 338 (1985) 243-248.

219 Randrup, A. and Munkvad, I., Stereotyped activities produced by amphetamine in several animal species and man, Psychopharmacology, 11 (1967) 300-310.

220 Randrup, A. and Munkvad, I., Biochemical, anatomical and psychological investigations of stereotyped behavior induced by amphetamines. In E. Costa and S. Garattini (Eds.), Amphetamines and Related Compounds, Raven Press, New York, 1970, pp. 695-713.

221 Ranje, C. and Ungerstedt, U., Chronic amphetamine treatment: vast individual differences in performing a learned response, Eur. J. Pharmacol., 29 (1974) 307-311.

222 Rebec, G.V., Auto- and postsynaptic dopamine receptors in the central nervous system. In J. Marwaha and W.J. Anderson (Eds.), Neuroreceptors in Health and Disease. Monographs in the Neural Sciences, Vol. 10, Karger, Basel, 1984, pp. 207-223.

223 Rebec, G.V. and Bashore, T.R., Comments on 'amphetamine models of paranoid schizophrenia': a precautionary note, Psychol. Bull., 92 (1982) 403-409.

224 Rebec, G.V. and Segal, D.S., Apparent tolerance to some aspects of amphetamine stereotypy with long-term treatment, Pharmacol. Biochem. Behav., 13 (1980) 793-797.

225 Rebec, G.V. and Segal, D.S., Enhanced responsiveness to intraventricular infusion of amphetamine following its repeated systemic administration, Psychopharmacology, 62 (1979) 101-102.

226 Rech, R.H., Tilson, H.A. and Marquis, W.J., Adaptive changes in behavior after repeated administration of various psychoactive drugs, Adv. Biochem. Psychopharmacol., 13 (1975) 263-286.

227 Reinhard, J.F., Bannon, M.J. and Roth, R.H., Acceleration by stress of dopamine synthesis and metabolism in prefrontal cortex: antagonism by diazepam, NaunynSchmiedeberg's Arch. Pharmacol., 318 (1982) 374-377.

228 Ricaurte, G.A., Schuster, C.R. and Seiden, L.S., Longterm effects of repeated methylamphetamine administration on dopamine and serotonin neurons in the rat brain: a regional study, Brain Res., 193 (1980) 153-163.

229 Ricaurte, G.A., Seiden, L.S. and Schuster, C.R., Further evidence that amphetamines produce long-lasting dopamine neurochemical deficits by destroying dopamine nerve fibers, Brain Res., 303 (1984) 359-364.

230 Ricaurte, G.A., Guillery, R.W., Seiden, L.S. and Schuster, C.R., Nerve terminal degeneration after a single injection of D-amphetamine in iprindole treated rats: relation to selective long-lasting dopamine depletion, Brain 
Res., 291 (1984) 378-382.

231 Ridley, R.M., Baker, H.F., Owen, F., Cross, A.J. and Crow, T.J., Behavioural and biochemical effects of chronic amphetamine treatment in the vervet monkey, Psychopharmacology, 78 (1982) 245-251

232 Ridley, R.M., Baker, H.F. and Scraggs, P.R., The timecourse of the behavioral effects of amphetamine and their reversal by haloperidol in a primate species, Biol. Psychiatry, 14 (1979) 753-765.

233 Riffee, W.H. and Gerald, M.C., The effects of chronic administration and withdrawal of (+)amphetamine on seizure threshold and endogenous catecholamine concentrations and their rates of biosynthesis in mice, Psychopharmacology, 51 (1977) 175-179.

234 Riffee, W.H. and Wilcox, R., Effects of multiple pretreatment with apomorphine and amphetamine on amphetamine-induced locomotor activity and its inhibition by apomorphine, Psychopharmacology, 85 (1985) 97-101.

235 Riffee, W.H., Wilcox, R.E., Vaughn, D.M. and Smith, R.V., Dopamine receptor sensitivity after chronic dopamine agonists, Psychopharmacology, 77 (1982) 146-149.

236 Robertson, A. and Mogenson, G.J., Facilitation of selfstimulation of the prefrontal cortex in rats following chronic administration of spiroperidol or amphetamine, Psychopharmacology, 65 (1979) 149-154.

237 Robertson, H.A., Chronic phencyclidine, like amphetamine, produces a decrease in $\left[{ }^{3} \mathrm{H}\right]$ spiroperidol binding in rat striatum, Eur. J. Pharmacol., 78 (1982) 363-365.

238 Robertson, H.A., Effect of chronic D-amphetamine or $\beta$ phenylethylamine on dopamine binding in rat striatum and limbic system, Soc. Neurosci. Abstr., 5 (1979) 570

239 Robertson, H.A., Chronic D-amphetamine and phencyclidine: effects on dopamine agonist and antagonist binding sites in the extrapyramidal and mesolimbic systems, Brain Res., 267 (1983) 179-182

240 Robinson, T.E., Behavioral sensitization: characterization of enduring changes in rotational behavior produced by intermittent injections of amphetamine in male and female rats, Psychopharmacology, 84 (1984) 466-475.

241 Robinson, T.E., Angus, A.L. and Becker, J.B., Sensitization to stress: the enduring effects' of prior stress on amphetamine-induced rotational behavior, Life Sci., 37 (1985) 1039-1042.

242 Robinson, T.E. and Becker, J.B., Behavioral sensitization is accompanied by an enhancement in amphetaminestimulated dopamine release from striatal tissue in vitro, Eur. J. Pharmacol., 85 (1982) 253-254.

243 Robinson, T.E., Becker, J.B., Moore, C.J., Castaneda, E. and Mittleman, G., Enduring enhancement in frontal cortex dopamine utilization in an animal model of amphetamine psychosis, Brain Res., 343 (1985) 374-377.

244 Robinson, T.E., Becker, J.B. and Presty, S.K., Longterm facilitation of amphetamine-induced rotational behavior and striatal dopamine release produced by a single exposure to amphetamine: sex differences, Brain Res., 253 (1982) 231-241.

245 Robinson, T.E., Becker, J.B. and Ramirez, V.D., Sex differences in amphetamine-elicited rotational behavior and the lateralization of striatal dopamine in rats, Brain Res. Bull., 5 (1980) 539-545.

246 Roth, R.H., Murrin, C.L. and Walters, J.R., Central dopaminergic neurons: effects of alterations in impulse flow on the accumulation of dihydroxyphenylacetic acid, Eur. J. Pharmacol., 36 (1976) 163-171.
247 Rowland, N., Antelman, S.M. and Kocan, D., Elevated water intake in rats treated chronically with amphetamine: drinking in excess of need, Appetite, 2 (1981) $51-66$.

248 Sato, M., Chen, C.-C., Akiyama, K. and Otsuki, S., Acute exacerbation of paranoid psychotic state after longterm abstinence in patients with previous methamphetamine psychosis, Biol. Psychiatry., 18 (1983) 429-440.

249 Scheel-Kruger, J.C., Comparative studies of various amphetamine analogues demonstrating different interactions with the metabolism of the catecholamines in the brain, Eur. J. Pharmacol., 14 (1971) 47-59.

250 Schiff, S.R., Conditioned dopaminergic activity, Biol. Psychiatry, 17 (1982) 135-154.

251 Schiorring, E., Amphetamine induced selective stimulation of certain behaviour items with concurrent inhibition of others in an open-field test with rats, Behavior, 39 (1971) 1-17.

252 Schiorring, E., An open field study of stereotyped locomotor activity in amphetamine treated rats, Psychopharmacology, 66 (1979) 281-287.

253 Schiorring, E., Psychopathology induced by 'speed drugs', Pharmacol. Biochem. Behav., 14 (1981) 109-122.

254 Schmidt, C.J. and Gibb, J.W., Role of the dopamine uptake carrier in the neurochemical response to methamphetamine: effects of amfonelic acid, Eur. J. Pharmacol., 109 (1985) 73-80.

255 Schmidt, C.J., Gehlert, D.R., Peat, M.A., Sonsalla, P.K., Hanson, G.R., Wamsley, J.K. and Gibb, J.W., Studies on the mechanism of tolerance for methamphetamine, Brain Res., 343 (1985) 305-313.

256 Schmidt, C.J., Ritter, J.K., Sonsalla, P.K., Hanson, G.R. and Gibb, D.W., Role of dopamine in the neurotoxic effects of methamphetamine, J. Pharmacol. Exp. Ther., 233 (1985) 539-544.

257 Schmidt, C.J., Sonsalla, P.K., Hanson, G. R., Peat, M.A. and Gibb, J.W., Methamphetamine-induced depression of monoamine synthesis in the rat: development of tolerance, $J$. Neurochem., 44 (1985) 852-855.

258 Schuster, C.R. and Johanson, C.E., Efficacy, dependence potential and neurotoxicity of anorectic drugs. In L.S. Seiden and R.L. Balster (Eds.), Behavioral Pharmacology: The Current Status, Alan R. Liss, New York, 1985, pp. 263-279.

259 Schwartz, J.C., Costentin, J., Martres, M.P., Protais, P. and Baudry, M., Modulation of receptor mechanisms in the CNS: hyper- and hyposensitivity to catecholamines, Neuropharmacology, 17 (1978) 665-685.

260 Schwarz, R.D., Uretsky, N.J. and Biachine, J.R., The relationship between the stimulation of dopamine synthesis and release produced by amphetamine and high potassium in striatal slices, J. Neurochem., 35 (1980) 1120-1127.

261 Schweitzer, B.I. and Bacopoulos, N.G., Reversible decrease in dopaminergic ${ }^{3} \mathrm{H}$-agonist binding after 6hydroxydopamine and irreversible decrease after kainic acid, Life Sci., 32 (1983) 531-540.

262 Searle, L.V. and Brown, C.W., The effect of subcutaneous injections of benzedrine sulfate on the activity of white rats, J. Exp. Psychol., 22 (1938) 480-490.

263 Segal, D.S., Behavioral and neurochemical correlates of repeated D-amphetamine administration, Adv. Biochem. Psychopharmacol., 13 (1975) 247-262.

264 Segal, D.S., Geyer, M.A. and Schuckit, M.A., Stimulantinduced psychosis: an evaluation of animal models. In 
M.B.H. Youdim, W. Lovenberg, D.F. Sharman and J.R. Lagnado (Eds.), Essays in Neurochemistry and Neuropharmacology, Vol. 5, John Wiley and Sons, London, 1981 , pp. 95-129.

265 Segal, D.S. and Janowsky, D.S., Psychostimulant-induced behavioral effects: possible models of schizophrenia. In M.A. Lipton, A. DiMascio and K.F. Killam (Eds.), Psychopharmacology: A Generation of Progress, Raven Press, New York, 1978, pp. 1113-1123.

266 Segal, D.S., Kelly, P., Koob, G. and Roberts, D.C.S., Non-striatal dopamine mechanisms in the response to repeated D-amphetamine administration. In E. Usdin, I.J. Kopin and J. Barchas (Eds.), Catecholamines: Basic and Clinical Frontiers, Vol. 2, Pergamon Press, New York, 1979, pp. 1672-1674.

267 Segal, D.S. and Mandell, A.J., Long-term administration of amphetamine: progressive augmentation of motor activity and stereotypy, Pharmacol. Biochem. Behav., 2 (1974) 249-255.

268 Segal, D.S. and Schuckit, M.A., Animal models of stimulant-induced psychosis. In I. Creese (Ed.), Stimulants: Neurochemical, Behavioral and Clinical Perspectives, Raven Press, New York, 1983, pp. 131-167.

269 Segal, D.S., Weinberger, S.B., Cahill, J. and McCunney, S.J., Multiple daily amphetamine administration: behavioral and neurochemical alterations, Science, 207 (1980) 904-907.

270 Seiden, L.S., Fischman, M.W. and Schuster, C.R., Longterm methamphetamine induced changes in brain catecholamines in tolerant rhesus monkeys, Drug Alcohol Depend., 1 (1975/76) 215-219.

271 Seiden, L.S. and Vosmer, G., Formation of 6-hydroxydopamine in caudate nucleus of the rat brain after a single large dose of methylamphetamine, Pharmacol. Biochem. Behav., 21 (1984) 29-31.

272 Sever, P.S., Caldwell, J. and Williams, R.T., Tolerance to amphetamine in two species (rat and guinea pig) that metabolize it differently, Psychol. Med., 6 (1976) 35-42.

273 Short, P.H. and Shuster, L., Changes in brain norepinephrine associated with sensitization to D-amphetamine, Psychopharmacology, 48 (1976) 59-67.

274 Shuster, L., Yu, G. and Bates, A., Sensitization to cocaine stimulation in mice, Psychopharmacology, 52 (1977) $185-190$.

275 Snyder, S.H., Amphetamine psychosis: a 'model' schizophrenia mediated by catecholamines, Am. J. Psychiatry, 130 (1973) 61-67.

276 Snyder, S.H., Banerjee, S.P., Yamamura, H.I. and Greenberg, D., Drugs, neurotransmitters and schizophrenia, Science, 184 (1974) 1243-1253.

277 Solomon, P.R., Crider, A., Winkelman, J.W., Turi, A., Kamer, R.M. and Kaplan, L.J., Disrupted latent inhibition in the rat with chronic amphetamine or haloperidolinduced supersensitivity: relationship to schizophrenic attention disorder, Biol. Psychiatry, 16 (1981) 519-537.

278 Sorensen, S.M., Hattox, S., Johnson, S.W., Bickford, P., Murphy, R. and Freedman, R., Norepinephrine-dependent and independent mechanisms of persistent effects of amphetamine in rat cerebellum, Life Sci., 36 (1985) 2383-2389.

279 Sorenson, S.M., Johnson, S.W. and Freedman, R., Persistent effects of amphetamine on cerebellar Purkinje neurons following chronic administration, Brain Res., 247 (1982) 365-371.
280 Sparber, S.B., Nagashawa, S. and Burkulund, K.E.A., A mobilizable pool of $D$-amphetamine in adipose tissue after daily administration to rats, Res. Commun. Chem. Pathol. Pharmacol., 18 (1977) 423-431.

281 Sparber, S.B. and Tilson, H.A., The releasability of central norepinephrine and serotonin by peripherally administered D-amphetamine before and after tolerance, Life Sci., 11 (1972) 1059-1067.

282 Stanford, C., Fillenz, M. and Ryan, E., The effect of repeated mild stress on cerebral cortical adrenoceptors and noradrenaline synthesis in the rat, Neurosci. Lett., 45 (1984) 163-168.

283 Staunton, D.A., Young, S.J. and Groves, P.M., The effect of long-term amphetamine administration on the activity of dopaminergic neurons of the substantia nigra, Brain Res., 188 (1980) 107-117.

284 Steranka, L.R., Stereospecific long-term effects of amphetamine on striatal dopamine neurons in rats, Eur. $J$. Pharmacol., 76 (1981) 443-446.

285 Steranka, L.R., Long-term effects of a priming dose and short-term infusion of amphetamine on striatal dopamine neurons in rats, Eur. J. Pharmacol., 96 (1983) 159-164.

286 Steranka, L.R., Effects of antipsychotic drugs on the longterm effects of amphetamine on nigro-striatal dopamine neurons in iprindole-treated rats, Arch. Pharmacol., 325 (1984) 198-204.

287 Steranka, L.R. and Sanders-Bush, E., Long-term effects of continuous exposure to amphetamine on brain dopamine concentration and synaptosomal uptake in mice, Eur. J. Pharmacol., 65 (1980) 439-443.

288 Stricker, E.M. and Zigmond, M.J., Recovery of function after damage to central catecholamine-containing neurons: a neurochemical model for the lateral hypothalamic syndrome. In J.M. Sprague and A. Epstein (Eds.), Progress in Psychobiology and Physiological Psychology, Vol. 6, Academic Press, New York, 1976, pp. 121-187.

289 Tache, Y., Du Ruisseau, P., Tache, J., Selye, H. and Collu, R., Shift in adenohypophyseal activity during chronic intermittent immobilization of rats, Neuroendocrinology, 22 (1976) 325-336

290 Taylor, D. and Ho, B.T., Neurochemical effects of cocaine following acute and repeated injection, $J$. Neurosci. Res., 3 (1977) 95-101.

291 Thierry, A.M., Tassin, J.P., Blanc, G. and Glowinski, J., Selective activation of the mesocortical DA system by stress, Nature (London), 263 (1976) 242-244.

292 Thompson, T.I. and Pickens, R., Stimulus Properties of Drugs, Appleton-Century-Crofts, New York, 1971.

293 Tilson, H.A. and Rech, R.H., Conditioned drug effects and absence of tolerance to D-amphetamine induced motor activity, Pharmacol. Biochem. Behav., 1 (1973) 149-153.

294 Tormey, J. and Lasagna, L., Relation of thyroid function to acute and chronic effects of amphetamine in the rat, J. Pharmacol. Exp. Ther., 128 (1960) 201-209.

295 Toru, M., Mataga, N., Takashima, M. and Nishikawa, T., Enhancement of haloperidol-induced increase in rat striatal or mesolimbic 3,4-dihydroxyphenylacetic acid and homovanillic acid by pretreatment with chronic methamphetamine, Psychopharmacology, 74 (1981) 316-320.

296 Toru, M., Nishikawa, T., Mataga, N. and Takashima, M., Dopamine metabolism increases in post-mortem schizophrenic basal ganglia, J. Neural Transm., 54 (1982) 181-191. 
297 Trulson, M.E. and Crisp, T., Behavioral effects of serotonergic and dopaminergic drugs in cats following chronic amphetamine administration, Eur. J. Pharmacol., 99 (1984) 313-324.

298 Trulson, M.E. and Jacobs, B.L., Long-term amphetamine treatment decreases brain serotonin metabolism: implications for theories of schizophrenia, Science, 205 (1979) 1295-1297.

299 Trulson, M.E. and Trulson, V.M., Reduction in brain serotonin synthesis rate following chronic methamphetamine administration in rats, Eur. J. Pharmacol., 83 (1982) $97-100$

300 Ungerstedt, U., Central dopamine mechanisms and unconditioned behavior. In A.S. Horn, J. Korf and B.H.C. Westerink (Eds.), Neurobiology of Dopamine, Academic Press, London, 1979, pp. 577-596.

301 Utena, H., On relapse-liability: schizophrenia, amphetamine psychosis and animal model. In $\mathrm{H}$. Mitsuda and $\mathrm{T}$. Fukuda (Eds.), Biological Mechanisms of Schizophrenia and Schizophrenia-Like Psychoses, Igaku Shoin, Tokyo, 1974, pp. 285-287.

302 Utena, H., Behavioral aberrations in methamphetamineintoxicated animals and chemical correlates in the brain. In T. Tokizane and J.P. Schade (Eds.), Progress in Brain Research, Vol. 21B, Correlative Neurosciences: Clinical Studies, Elsevier, Amsterdam, 1966, pp. 192-207.

303 Utena, H., Machiyama, Y., Hsu, S.C., Katagiri, M. and Hirata, A., A monkey model for schizophrenia produced by methamphetamine. In $S$. Kondo, $M$. Kawai and $A$. Ehara (Eds.), Contempory Primalology, Karger, Basel, 1975, pp. 502-507.

304 Vaccari, A., Sexual differentation of monoamine neurotransmitters. In H. Parvez and S. Parvez (Eds.), Biogenic Amines in Development, Elsevier/North Holland, Amsterdam, 1980, pp. 327-352.

305 Van Kammen, D.P., Docherty, J.P. and Bunney, W.E., Jr. , Prediction of early relapse after pimozide discontinuation by response to $\mathrm{D}$-amphetamine during pimozide treatment, Biol. Psychiatry, 17 (1982) 233-242.

306 Van Kammen, D.P., The dopamine hypothesis of schizophrenia revisited, Psychoneuroendocrinology, 4 (1979) $37-46$.

307 Vezina, P. and Stewart, J., Conditioning and place-specific sensitization of increases in activity induced by morphine in the VTA, Pharmacol. Biochem. Behav., 20 (1984) 925-934.

308 Wagner, G.C., Ricaurte, G.A., Johanson, C.E., Schuster, C.R. and Seiden, L.S., Amphetamine induces depletion of dopamine and loss of dopamine uptake sites in cau- date, Neurology, 30 (1980) 547-550.

309 Wagner, G.C., Ricaurte, G.A., Seiden, L.S., Schuster, C.R., Miller, R.J. and Westley, J., Long-lasting depletion of striatal dopamine and loss of dopamine uptake sites following repeated administration of methamphetamine, Brain Res., 181 (1980) 151-160.

310 Wahnschaffe, U. and Esslen, J., Structural evidence for the neurotoxicity of methylamphetamine in the frontal cortex of gerbils (meriones unguiculatus): a light and electron-microscopical study, Brain Res., 337 (1985) 299-310.

311 Wallach, M.B. and Gershon, S., Sensitization to amphetamines, Psychopharmacol. Bull., 7 (1971) 30-31.

312 Weiner, W.J., Goetz, C.G., Nausieda, P.A and Klawans, H.L., Amphetamine-induced hypersensitivity in guinea pigs, Neurology, 29 (1979) 1054-1057.

313 Weissman, A.B., Koe, B.K. and Tenen, S.S., Antiamphetamine effects following inhibition of tyrosine hydroxylase, J. Pharmacol., 151 (1966) 339-352.

314 Westfall, T.C., Besson, M.J., Gioguieff, M.F. and Glowinski, J., The role of presynaptic receptors in the release and synthesis of ${ }^{5} \mathrm{H}$-dopamine by slices in rat striatum, Naunyn-Schmiedeberg's Arch. Pharmacol., 292 (1976) 279-287.

315 Westfall, T.C. and Tittermary, V., Inhibition of the electrically induced release of $\left[{ }^{3} \mathrm{H}\right]$ dopamine by serotonin from superfused rat striatal slices, Neurosci. Lett., 28 (1982) 205-209.

316 Weston, P.F. and Overstreet, D.J., Does tolerance develop to low doses of D- and L-amphetamine on locomotor activity in rats? Pharmacol. Biochem. Behav., 5 (1976) 645-649.

317 White, F.J. and Wang, R.Y., Electrophysiological evidence for A10 dopamine autoreceptor subsensitivity following chronic D-amphetamine treatment, Brain Res., 309 (1984) 283-292.

318 Wightman, R.M., Bright, C. and Caviness, J.N., Direct measurement of the effect of potassium, calcium, veratridine and amphetamine on the rate of release of dopamine from superfused brain tissue, Life Sci., 28 (1981) $1279-1286$

319 Wilcox, R.E., Riffee, W.H., Chen, P.C., Hammett, S. and Smith, R.V., Behavioral facilitation following chronic administration of N-n-propylnorapomorphine, Psychopharmacology, 72 (1980) 113-115.

320 Young, D. and Scoville, W.B., Paranoid psychosis in narcolepsy and the possible danger of benzedrine treatment, Med. Clin. North Am., 22 (1938) 637-646.

321 Zieve, L., Effect of benzedrine on activity, Psychol. Rec., 1 (1937) 393-396. 